Frutos de duas espécies de palmeiras como recurso alimentar para vertebrados no Cerrado Pé-de-Gigante (Santa Rita do Passa Quatro, SP)

Mariana Morais Vidal

São Paulo 
Mariana Morais Vidal

\section{Frutos de duas espécies de palmeiras como recurso alimentar para vertebrados no Cerrado Pé-de-Gigante (Santa Rita do Passa Quatro, SP)}

Dissertação apresentada ao Instituto de Biociências da Universidade de São Paulo, para a obtenção de Título de Mestre em Ciências, na área de Ecologia.

Orientadora: Profa. Dra. Vânia Regina Pivello 
Ficha catalográfica

Vidal, Mariana Morais

Frutos de duas espécies de palmeiras como recurso alimentar para vertebrados no Cerrado Pé-de-Gigante (Santa Rita do Passa Quatro, SP).

Número de páginas: 83

Dissertação (Mestrado) - Instituto de Biociências da Universidade de São Paulo. Departamento de Ecologia. 2007.

1. Attalea geraensis; 2. Syagrus petraea; 3. fenologia reprodutiva; 4. composição nutricional dos frutos; 5. cerrado.

Universidade de São Paulo. Instituto de Biociências. Departamento de Ecologia.

\section{Comissão Julgadora:}

$\operatorname{Prof}(a) \cdot \operatorname{Dr}(a)$.

$\operatorname{Prof}(a) \cdot \operatorname{Dr}(a)$.

Profa. Dra. Vânia Regina Pivello

Orientadora 


\section{Agradecimentos}

À Vânia Pivello pela orientação, dedicação e amizade.

À FAPESP, pela bolsa concedida, e à Neotropical Grassland Conservancy pelo apoio financeiro ao laboratório.

Ao diretor do Parque Estadual de Vassununga, Héverton Ribeiro, e a toda a equipe do PEV, que proporcionaram e apoiaram o desenvolvimento de todo o trabalho.

Ao Prof. Dr. Antonio Salatino e a todos do Laboratório de Fitoquímica do Instituto de Biociências da USP, em especial a Mayumi, Anary e Mourisa, que me auxiliaram com as análises de composição nutricional.

Ao Dr. Edison Chu, Dra. Rita Ribeiro e a todos da Seção de Fisiologia e Bioquímica de Plantas do Instituto de Botânica de São Paulo, fundamentais para a conclusão das análises químicas dos frutos.

Ao Laboratório de Biologia Celular de Plantas do Instituto de Biociências da USP, especialmente a Dra. Claudete Santa Catarina, Dr. Vanildo Silveira e Tiago Balbuena, que me ajudaram com idéias e também com a liofilização dos frutos.

Ao Laboratório de Clima e Biosfera do Instituto de Astronomia, Geofísica e Ciências Atmosféricas da USP pelos dados de precipitação e temperatura na área de estudo.

Ao Prof. Dr. Márcio Martins, pelo empréstimo de diversas câmeras automáticas.

Ao Dr. Julio Voltolini, pelas contribuições feitas no início do trabalho.

Ao Dr. Amauri Marcato pelo auxílio com a identificação das palmeiras.

A todos os pesquisadores que contribuíram para a identificação da fauna: Alexandre Reis Percequillo, Ana Paula Carmignotto, Cristiano Nogueira, Márcio Martins, Maria Tereza Thomé, Nilton Carlos Cáceres, Norberto Hulle.

Ao Prof. Dr. Marco Batalha, pelo auxílio com a fenologia e disponibilização de dados.

Aos meus amigos, que me ajudaram bastante, nas viagens a campo, discussões, idéias e no dia-a-dia - Daniela Petenon, Leandro Tambosi, Alexandre Igari, Talita Zuppo, Elizabeth Gorgone, Giordano Ciocheti, Maria Carolina Lyra Jorge, Daniela Castro, Klécia Gili, Raquel Junqueira, Flávia Jesus, Maria Carolina Checchia, Sylene Del Carlo, Luciano Lopes, e todos os amigos do Lepac e da Ecologia. Aos meus amigos Guilherme Rueda, Rita Figueira, Juliana Tieme, Juliana Narita, Monalisa Nascimento, Renata Souza e Camila Cambuí.

À minha família pelo apoio, carinho e paciência. Em especial aos meus pais, Dorival e Maria, e à minha irmã, Adriana, que sempre me ajudaram... E também aos meus tios, Daniel e Cida, que me apoiaram bastante!

Ao Lê, uma pessoa especial, que está sempre ao meu lado, me incentivando e me ajudando muito. 


\section{ÍNDICE}

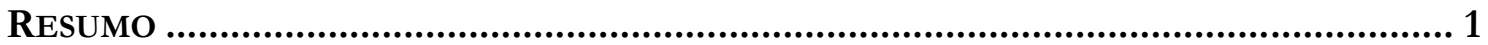

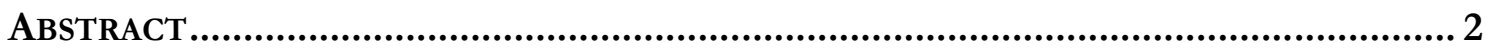

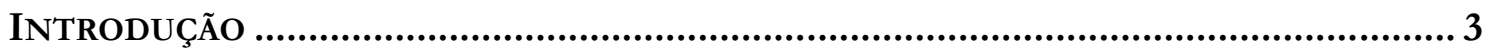

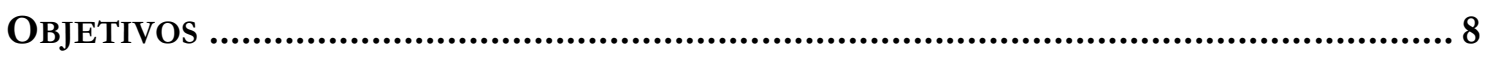

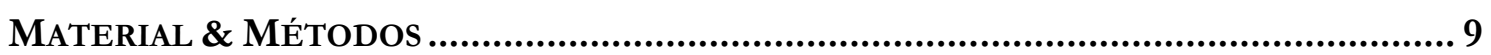

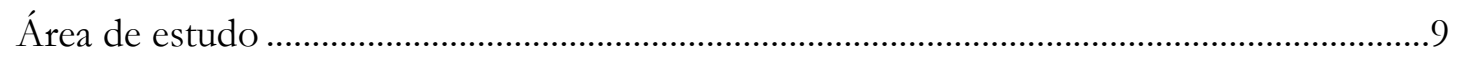

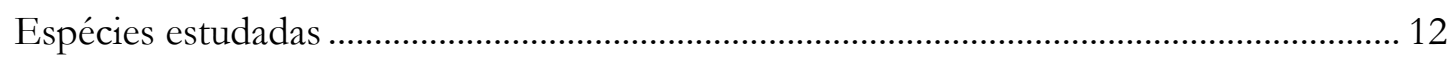

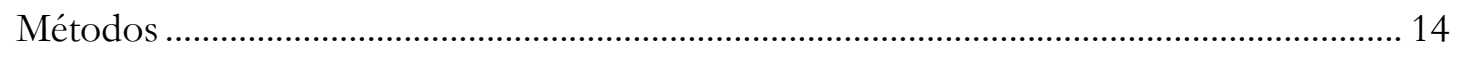

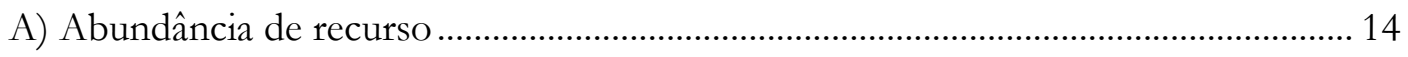

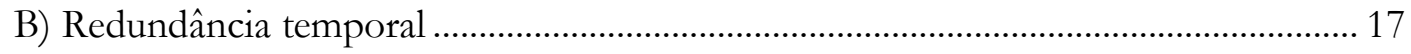

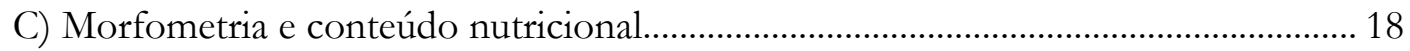

D) Vertebrados consumidores dos frutos de Attalea geraensis e Syagrus petraea ............... 23

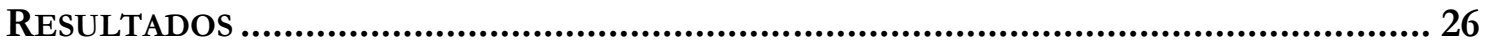

A) Abundância de recurso......................................................................................................... 26

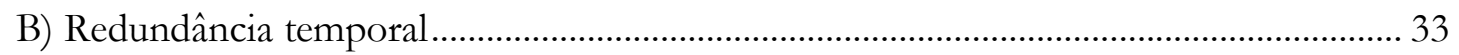

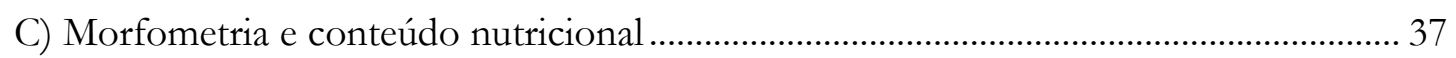

D) Vertebrados consumidores dos frutos de Attalea geraensis e Syagrus petraea ................... 41

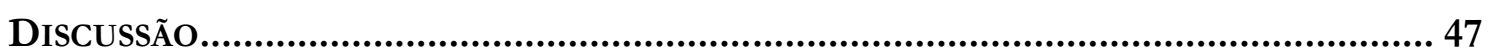

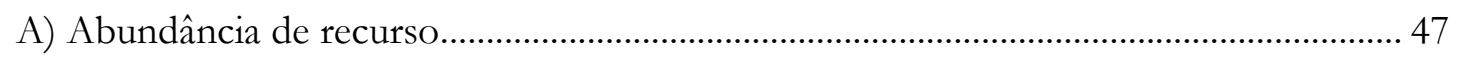

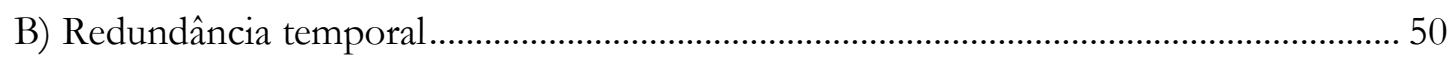

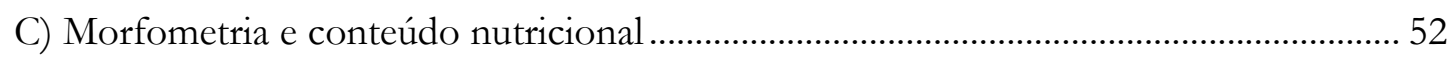

D) Vertebrados consumidores dos frutos de Syagrus petraea ................................................. 54

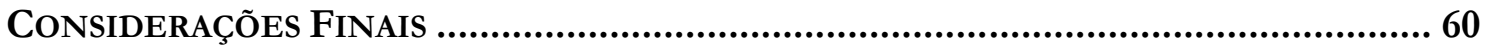

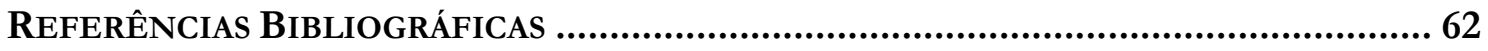

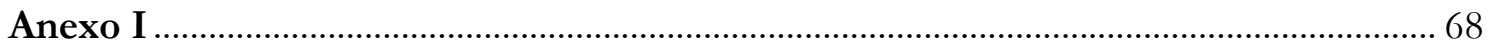

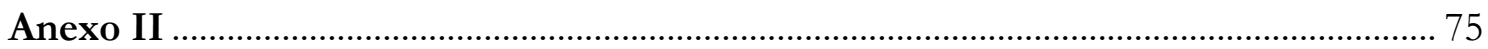

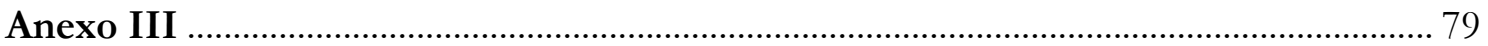




\section{FRUTOS DE DUAS ESPÉCIES DE PALMEIRAS COMO RECURSO ALIMENTAR PARA VERTEBRADOS no Cerrado PÉ-de-Gigante (Santa Rita do Passa Quatro, SP)}

\section{RESUMO}

No cerrado, as palmeiras não são muito diversas, no entanto, são abundantes e representam recursos valiosos para a vida silvestre. Foram avaliadas características dos frutos de Syagrus petraea e Attalea geraensis (Arecaceae) como recurso alimentar para vertebrados em cerrado denso no Cerrado Pé-de-Gigante (Santa Rita do Passa Quatro, SP), que incluem sua disponibilidade no tempo e seu conteúdo nutricional. Entre janeiro de 2005 e novembro de 2006, foi realizado um acompanhamento fenológico e feita uma estimativa da abundância de indivíduos adultos das duas espécies de palmeiras estudadas. $\mathrm{O}$ teor nutricional dos frutos foi caracterizado quantitativamente, com dosagens de lipídios, açúcares solúveis totais e proteínas solúveis. Além disso, foi feita, por meio de câmeras fotográficas automáticas, a identificação dos vertebrados que possivelmente utilizam os frutos destas palmeiras como recurso alimentar. Foi encontrada uma densidade média de 0,006 indivíduo de A. geraensis por $\mathrm{m}^{2}$ e 0,024 indivíduo de $S$. petraea por $\mathrm{m}^{2}$. A. geraensis produziu um único fruto durante todo o período de estudo, ao passo que os frutos de $S$. petraea estiveram disponíveis durante a maior parte do tempo, apesar da sazonalidade bastante acentuada. Os frutos de $S$. petraea constituem um recurso nutritivo, principalmente o endosperma, que é mais rico que a "polpa", contendo principalmente lipídios. Os consumidores dos frutos de S. petraea identificados foram Cyanocorax chrysops (Aves: Corvidae), Didelphis albiventris (Marsupialia: Didelphidae), Micoureus paraguayanus (Marsupialia: Didelphidae) e Cerradomys subflavus (Rodentia: Muridae). 


\begin{abstract}
The Arecaceae family (palms) is not very much diverse in cerrado physiognomies, although such species are abundant and represent valuable resources to wildlife. Traits of Syagrus petraea and Attalea geraensis (Arecaceae) fruits, such as temporal availability and its nutrient content, were evaluated as food resources for vertebrates in "cerrado denso" physiognomy, in the Cerrado Pé-de-Gigante (Santa Rita do Passa Quatro, SP). A phenological study of both palm species was carried out between January/2005 and November/2006; moreover, estimates of the abundance of adult individuals were studied. The nutrient content of the fruits was quantitatively analysed, being evaluated the amounts of lipids, soluble sugars and soluble proteins. Furthermore, vertebrates that possibly use the palms' fruits as food resources were identified through the camera trapping method. The mean density of $A$. geraensis was 0.006 individual per $\mathrm{m}^{2}$ and the mean density of $S$. petraea was 0,024 individual per $\mathrm{m}^{2}$. A. geraensis yielded only one fruit during all the study period, on the other hand $S$. petraea fruited throughout the entire period of study despite the seasonality in the fruiting phenophase. S. petraea fruits are a nutrient-rich resource, especially the endosperm which contains more lipids than the pulp. The identified animals that feed on S. petraea fruits were Cyanocorax chrysops (Aves: Corvidae), Didelphis albiventris (Marsupialia: Didelphidae), Micoureus paraguayanus (Marsupialia: Didelphidae) and Cerradomys subflavus (Rodentia: Muridae).
\end{abstract}




\section{INTRODUÇÃO}

\section{O Cerrado}

O Cerrado é o segundo maior bioma do Brasil em área, representando cerca de $23 \%$ do território brasileiro e abrange como área contínua os estados de Goiás, Tocantins e o Distrito Federal, parte dos estados da Bahia, Ceará, Maranhão, Mato Grosso, Mato Grosso do Sul, Minas Gerais, Piaú, Rondônia e São Paulo. Também ocorre em áreas disjuntas ao norte nos estados do Amapá, Amazonas, Pará e Roraima, e ao sul, em pequenas manchas no Paraná (Ribeiro \& Walter 1998).

O bioma Cerrado é climaticamente definido pela presença de invernos secos e verões chuvosos, com chuvas concentradas entre outubro e março, e a temperatura média do mês mais frio é superior a $18^{\circ} \mathrm{C}$ (Ribeiro \& Walter 1998).

Os cerrados brasileiros estão incluídos entre os 25 principais hotspots de diversidade do mundo, áreas com grande endemismo e menos de 30\% de vegetação natural remanescente (Myers et al. 2000). A biodiversidade total do bioma Cerrado está estimada em 160.000 espécies de plantas, animais e fungos (Oliveira \& Marquis 2002). O endemismo das plantas superiores do Cerrado foi recentemente estimado em 4.400 espécies, representando $1,5 \%$ de todas as espécies de plantas vasculares do mundo. Vertebrados endêmicos variam de 3\% (aves) a 30\% (anfíbios) das espécies registradas (Myers 2000). Os cerrados também são importantes por servirem de corredores para espécies que habitam biomas vizinhos, como as Florestas Amazônica e Atlântica (Oliveira \& Marquis 2002).

O Cerrado é atualmente um dos biomas sul-americanos mais ameaçados, devido à rápida expansão da agricultura. Cerca de 35\% de sua cobertura natural foi convertida em pastos e plantações (Oliveira \& Marquis 2002).

No estado de São Paulo, onde as pressões para o desmatamento e a ocupação das terras têm sido intensas há mais de um século, os raros fragmentos de cerrado que ainda restam são alvos constantes do desejo de agricultores, devido também à proximidade dos centros consumidores. Por serem os únicos restantes, esses fragmentos de cerrado desempenham papel vital na preservação da biodiversidade (Pivello \& Korman 2005).

Os cerrados marginais, como os do estado de São Paulo, têm características peculiares que os diferem dos cerrados nucleares, tanto em termos de variabilidade ambiental como genética, uma vez que mesclam componentes dos domínios morfoclimáticos vizinhos. Dessa forma, é grande a importância destes ecossistemas marginais na manutenção da variabilidade biológica e ambiental (Pivello \& Korman 2005). 


\section{A Vegetação do Cerrado}

Ribeiro \& Walter (1998) descreveram onze tipos fitofisionômicos para a vegetação do Cerrado, discriminados pela estrutura da vegetação, pelas formas de crescimento dominantes e por variações sazonais na vegetação. Os autores consideraram também a composição florística e fatores edáficos para a diferenciação destes tipos fitofisionômicos.

Segundo os autores, as formações florestais do Cerrado englobam os tipos de vegetação com predominância de espécies arbóreas e formação de dossel e correspondem à Mata Ciliar, Mata de Galeria, Mata Seca e Cerradão. As formações campestres (Campo Sujo, Campo Rupestre e Campo Limpo) são áreas com predomínio de espécies herbáceas e presença de algumas espécies arbustivas, sem a presença de árvores. Por fim, as formações savânicas constituem áreas com árvores e arbustos espalhados sobre um estrato herbáceo desenvolvido, sem a formação de dossel contínuo, e são o Parque de Cerrado, Palmeiral, Vereda e Cerrado sensu stricto.

O Cerrado sensu stricto caracteriza-se pela presença de árvores baixas, inclinadas, tortuosas, com ramificações irregulares e retorcidas. Na época chuvosa, os estratos subarbustivo e herbáceo tornam-se exuberantes devido ao seu rápido crescimento. Vários fatores parecem condicionar a densidade arbórea do Cerrado sensu stricto, como o pH, a fertilidade, as condições hídricas e a profundidade do solo, a freqüência de queimadas e ações antrópicas. Dada a complexidade destes fatores condicionantes, originam-se subdivisões fisionômicas distintas do Cerrado sensu stricto, sendo uma delas o Cerrado Denso, em que foi desenvolvido o presente trabalho.

O Cerrado Denso é predominantemente arbóreo; essas árvores oferecem cobertura de $50 \%$ a $70 \%$ e têm altura média de cinco a oito metros, representando a forma mais densa e alta do Cerrado sensu stricto. Os estratos arbustivo e herbáceo são mais ralos, provavelmente devido ao sombreamento resultante da maior densidade de árvores.

\section{Palmeiras (Arecaceae)}

Embora abundantes, as palmeiras no Cerrado não são muito diversas, mas sua importância ecológica, econômica e cultural ultrapassa grandemente a sua baixa diversidade taxonômica. Elas representam recursos valiosos para a vida silvestre, animais domesticados e muitas populações rurais. Várias espécies da fauna silvestre, tais como roedores de pequeno e médio porte, psitacídeos, a ema (Rhea americana), lobinho (Cerdocyon thous), loboguará (Chrysocyon brachyurus), raposa-do-campo (Lycalopex vetulus), porco-do-mato (Tayassu 
spp.) e anta (Tapirus terrestris), alimentam-se de folhas, polpa de frutos e sementes de palmeiras no cerrado (Filgueiras 2002, Lima et al. 2003).

As palmeiras que ocorrem no cerrado são quase todas acaulescentes, com caules subterrâneos profundos, os quais crescem, pelo menos no início do desenvolvimento, com geotropismo positivo (Uhl \& Dransfield 1987). Os principais gêneros que ocorrem no cerrado são: Acrocomia, Allagoptera, Astrocaryum, Attalea, Butia e Syagrus (Henderson et al. 1995).

As palmeiras constituem uma das maiores famílias de monocotiledôneas, mas, diferentemente da maioria de outras famílias, elas têm caules lenhosos; não há palmeiras herbáceas (Henderson 2002). A morfologia é muito diversa entre as espécies, havendo palmeiras arbóreas e arbustivas, variando em tamanho desde $25 \mathrm{~cm}$ a $60 \mathrm{~m}$. As folhas, raízes, inflorescências, frutos e sementes também são muito variáveis (Johnson et al. 1996). Algumas formas de vida não evoluíram na família, de modo que não se conhecem palmeiras parasitas, nem aquáticas submersas ou decíduas, e talvez não haja palmeiras verdadeiramente epífitas, apesar de plântulas ou mesmo indivíduos adultos de algumas espécies serem encontrados em porções de solo em copas de árvores (Uhl \& Dransfield 1987).

A maioria das espécies de palmeiras são tropicais ou subtropicais, e poucas ocorrem fora dessas regiões (Henderson 2002, Johnson 1988). Nos trópicos, elas ocorrem em todos os habitats: floresta pluvial, floresta semidecídua, pântano de água doce e salina, várzea de rio, savana, deserto e montanha. Este fator faz da conservação das palmeiras um assunto com dimensões geográficas muito amplas (Johnson et al. 1996).

Arecaceae é uma família de grande diversidade, tão antiga quanto qualquer outro grupo de angiospermas, e tem sido profundamente associada com a cultura humana (Johnson 1988). É a terceira família vegetal mais útil ao homem, depois das gramíneas e leguminosas (Johnson et al. 1996). Algumas de suas utilizações pelo homem são para a alimentação, na forma de frutos comestíveis, palmito, óleos comestíveis provenientes das sementes, bebidas e doces. Outros usos envolvem o aproveitamento das fibras foliares para artesanato, tecelagem, confecção de cordas, escovas e outros produtos. Os troncos lenhosos, pecíolos e folhas podem constituir materiais de construção, muitas vezes utilizados para coberturas. Além disso, a medicina popular também utiliza frutos, óleos, ceras e raízes de palmeiras (Borgtoft-Pedersen 1994, Johnson 1988, Lima et al. 2003, McSweeney 1995). 
A principal ameaça à diversidade das palmeiras é o desmatamento nos trópicos, já que a maior diversidade de espécies desta família ocorre no sub-bosque das florestas tropicais. A super-exploração das palmeiras de importância econômica também é uma ameaça, já que a crescente população humana e demandas comerciais têm levado a uma alarmante depleção destes recursos naturais em muitas regiões (Johnson et al. 1996, Uhl \& Dransfield 1987).

Dada a sua importância econômica e o papel que desempenham nos sistemas naturais, as palmeiras constituem excelentes objetos para investigações ecológicas (Putz 1986). A conservação destas plantas tem muitas aplicações práticas e depende do conhecimento sobre a família. As recomendações conservacionistas devem encontrar um balanço entre a sua preservação e a sua utilização pelas populações humanas (Johnson 1988, Johnson et al. 1996).

\section{Frutos}

Os frutos das palmeiras podem ser classificados como uma baga ou drupa fibrosa, ou seja, possuem uma ou mais sementes, têm mesocarpo carnoso ou fibroso e um endocarpo que pode ser fino (baga) ou espesso e esclerótico (drupa). A textura do mesocarpo está primariamente relacionada ao modo de dispersão, visto que o mesocarpo carnoso é uma fonte de alimento para animais dispersores, enquanto um mesocarpo mais fibroso é encontrado especialmente nos frutos que flutuam e são dispersos pela água (Tomlinson 1990).

A maioria das palmeiras parece ser dispersa por animais, freqüentemente através de seus sistemas digestivos. Os frutos de praticamente todas as espécies das subfamílias Coryphoideae, Ceroxyloideae e Arecoideae têm mesocarpos carnosos e epicarpos coloridos, que são atrativos para vertebrados (Uhl \& Dransfield 1987).

A polpa de frutos carnosos, com os tecidos macios, comestíveis e nutritivos ao redor das sementes, é um recurso alimentar primário para muitos animais frugívoros, notavelmente mamíferos e aves, mas também répteis. Alguns destes animais regurgitam, defecam, descartam ou derrubam sementes intactas para longe das plantas parentais. Eles são os dispersores de sementes, que estabelecem uma ligação dinâmica entre a planta em frutificação e o banco de sementes e plântulas em comunidades naturais. Portanto, a frugivoria é um processo central nas populações vegetais onde a regeneração natural é fortemente dependente da disseminação de sementes por animais (Jordano 2000). 
Quase todos os frutos ou sementes de palmeiras são comestíveis e nutritivos, constituindo um item importante da dieta de muitos animais (Henderson 2002, Uhl \& Dransfield 1987).

Para a maioria dos frugívoros, frutos carnosos são recursos alimentares nãoexclusivos, que são suplementados com presas animais, partes vegetativas de plantas, sementes, etc. Pouquíssimos vertebrados contam totalmente com frutos como alimento, mas muitas espécies são frugívoras "parciais", que consomem outras presas com variadas quantidades de frutos (Jordano 2000).

Apesar dos frutos das palmeiras, na maioria dos casos, serem consumidos por frugívoros generalistas, tem sido amplamente aceito que eles constituem um importante recurso para a fauna em florestas tropicais, pois as palmeiras produzem grandes quantidades de frutos durante períodos de escassez, os quais são consumidos por uma grande variedade de animais (Galetti \& Aleixo 1998, Kiew \& Davison 1991, Terborgh 1986), como macacos, tucanos, psitacídeos, porcos-do-mato, roedores de pequeno e médio porte e centenas de outros mamíferos, aves, peixes, e insetos. Para muitos destes animais, as palmeiras são os componentes principais de sua dieta (Henderson et al. 1995, Lima et al. 2003).

Algumas das características dos frutos como itens alimentares, a partir da perspectiva dos animais forrageadores, são intrínsecas a cada fruto, como o formato e o valor nutritivo; outras estão relacionadas com padrões temporais e espaciais de disponibilidade do recurso. Tais características são determinantes do avistamento dos frutos pelos frugívoros, seu modo de manipulação e processamento (Jordano 2000).

A disponibilidade temporal dos frutos pode ser analisada com um estudo fenológico. A fenologia é definida como o estudo da periodicidade sazonal de eventos biológicos cíclicos. Para as plantas, esta periodicidade pode ser crítica para a sobrevivência e reprodução (Rathcke \& Lacey 1985). O acompanhamento fenológico é fundamental para a avaliação de quando e em que quantidades os frutos estão disponíveis aos frugívoros, em uma determinada área (Galetti et al. 2003). Um outro aspecto da disponibilidade dos frutos no tempo é a redundância temporal, definida em termos do grau com que a disponibilidade de um determinado recurso vegetal está sincronizada com a disponibilidade de recursos alimentares alternativos usados por um determinado grupo de consumidores (Peres 2000). 


\section{OBJETIVOS}

\section{OBJETIVO GERAL}

Tendo em vista as características dos frutos como itens alimentares, o presente trabalho teve como objetivo a caracterização dos frutos de duas espécies de palmeiras muito comuns nos cerrados paulistas: Attalea geraensis Barb. Rodr. e Syagrus petraea (Mart.) Becc quanto à disponibilidade temporal, tamanho, abundância e conteúdo nutricional, além de identificar os vertebrados que possivelmente utilizam tais frutos como recurso alimentar em uma área de cerrado denso, na Gleba Cerrado Pé-de-Gigante (Santa Rita do Passa Quatro, SP).

\section{OBJETIVOS ESPECÍFICOS}

A caracterização dos frutos foi feita com base em quatro objetivos mais específicos, que procuraram responder as seguintes perguntas, que abordam algumas das características dos frutos como itens alimentares:

A. Qual a quantidade de frutos de $A$. geraensis e $S$. petraea disponíveis em cerrado denso na Gleba Cerrado Pé-de-Gigante e como esta disponibilidade varia temporalmente?

B. Na comunidade como um todo, há redundância temporal quanto à disponibilidade de frutos dessas duas espécies de palmeiras?

C. Quais espécies de vertebrados consomem os frutos dessas duas espécies de palmeiras, na área de estudo?

D. Qual o tamanho e o conteúdo nutricional dos frutos maduros dessas duas espécies de palmeiras, em relação às porcentagens de água, lipídios, açúcares solúveis e proteínas solúveis? 


\section{MATERIAL \& MÉTODOS}

\section{ÁreA DE ESTUdo}

O presente trabalho foi desenvolvido na Gleba Cerrado Pé-de-Gigante. O Cerrado Pé-de-Gigante é uma das seis glebas que constituem o Parque Estadual de Vassununga (PEV), criado em 1970 e gerenciado atualmente pelo Instituto Florestal (Pivello et al. 1999).

O Cerrado Pé-de-Gigante está localizado no município de Santa Rita do Passa Quatro (Figura 1), vizinho a oeste dos municípios de Descalvado e Luiz Antônio, na região administrativa de Ribeirão Preto, nordeste do estado de São Paulo, nas coordenadas

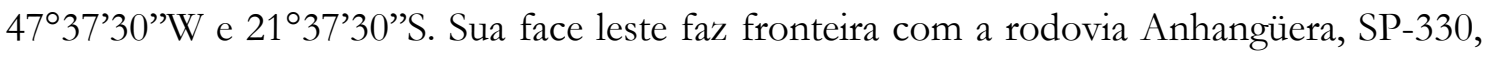
entre os quilômetros 254,5 e 258,5 (Pivello et al. 1999). A área possui 1.225 ha e cotas altimétricas entre 590 e 740 m (Mesquita-Júnior 1998).

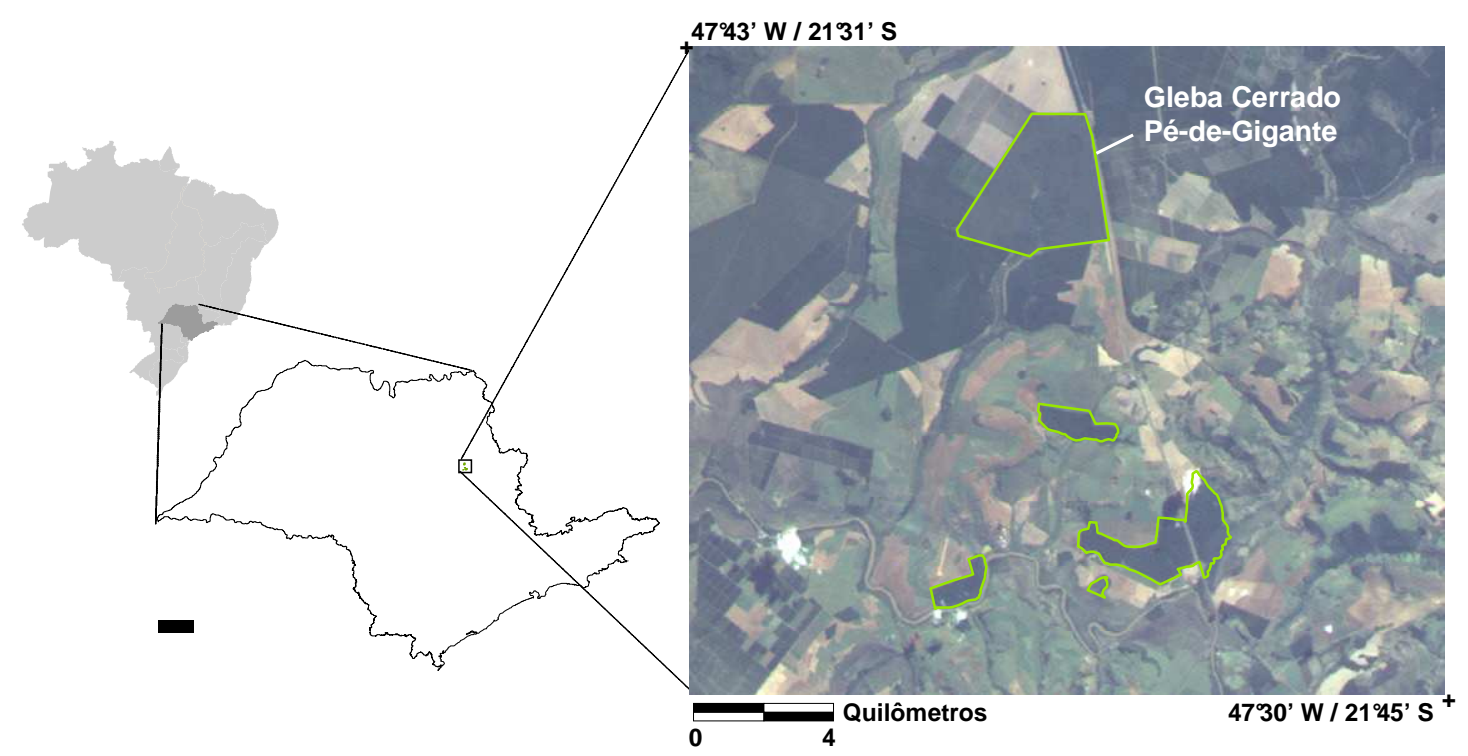

Figura 1. Localização do Parque Estadual de Vassununga, destacando a Gleba Cerrado Pé-deGigante, Santa Rita do Passa Quatro, SP. Imagem do satélite CBERS-2, composição colorida RGB bandas 3, 2 e 1 (Figura: Leandro R. Tambosi).

O tipo climático na região é classificado como Cwa, segundo Köppen (1948). As temperaturas médias mensais variam entre $17,6^{\circ} \mathrm{C}$, no mês mais frio (julho), a $23,5^{\circ} \mathrm{C}$, no mês mais quente (fevereiro), e a precipitação média anual é de $1.478 \mathrm{~mm}$, sendo concentrada no verão (Figura 2). Pode-se dizer que o período mais seco está entre junho e agosto, e o mais úmido, entre setembro e maio (Batalha \& Mantovani 2000). 

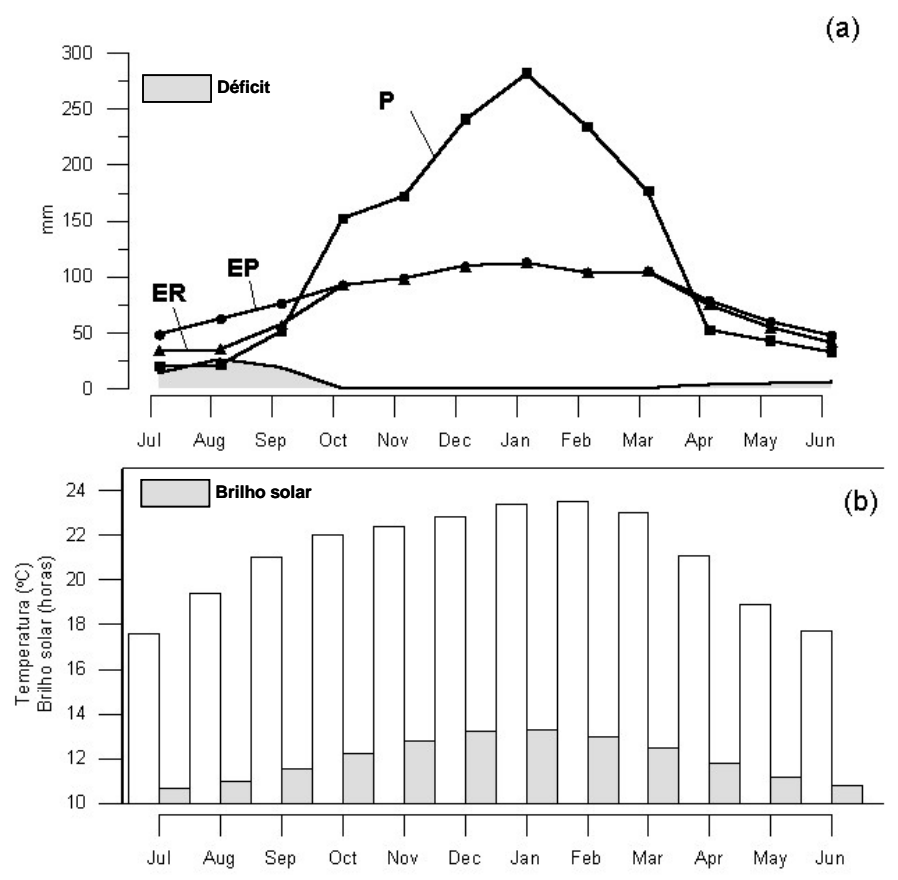

Figura 2. Médias mensais das variáveis climáticas observadas e calculadas na estação climatológica

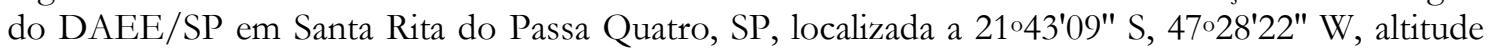
715 m, no período 1941-1970: (a) precipitação (P), evaporação potencial (EP), evaporação real (ER) e déficit hídrico, em $\mathrm{mm}$ de água; (b) temperatura do ar $\left(\mathrm{em}^{\circ} \mathrm{C}\right)$ e número de horas de brilho solar (modificado de Pires Neto et al. 2005).

$\mathrm{Na}$ região do município de Santa Rita do Passa Quatro, a fragmentação da vegetação se deu principalmente devido a sucessivos ciclos agro-econômicos (café, cana-de açúcar e silvicultura) que substituíram a vegetação original por monoculturas, determinados pelas políticas públicas adotadas na época. Além das pressões e impactos causados pelas monoculturas, a região sofre historicamente outras pressões antropogênicas, como queimadas, coleta seletiva de espécies e invasão por plantas exóticas, sendo a principal conseqüência dessas pressões, a diminuição de diversidade biológica na região (Korman \& Pivello 2005, Shida 2005). Atualmente, as atividades agrícolas predominam, com o plantio de cana-de-açúcar e, principalmente, de eucalipto, mas houve, entre as décadas de 30 e 70, atividade pecuária, inclusive com a presença de gado no interior do Cerrado Pé-de-Gigante (Freitas 1999).

Dentro do Cerrado Pé-de-Gigante, encontram-se variações fisionômicas de cerrado - do campo sujo ao cerradão - além de campo úmido, floresta semidecídua e floresta ripária, influenciadas pelo tipo de solo local (Ruggiero et al 2002). A fitofisionomia predominante na gleba (em área) é o cerrado sensu stricto, que corresponde a quase $80 \%$ da área da Reserva (Tabela 1). Devido a esta predominância na área de estudo e ao fato de que 
as demais fisionomias, com exceção do campo cerrado, praticamente não apresentam as palmeiras aqui estudadas, o presente trabalho foi desenvolvido em uma área de cerrado sensu stricto, mais precisamente de cerrado denso [sensu Ribeiro \& Walter (1998)], no Cerrado Pé-de-Gigante.

Tabela 1. Porcentagem da área do Cerrado Pé-de-Gigante correspondente a cada fitofisionomia (modificado de Mesquita-Júnior. 1998).

\begin{tabular}{lc}
\hline \multicolumn{1}{c}{ Fisionomia } & Área (\%) \\
\hline Campo sujo & 0,2 \\
Campo cerrado & 7,9 \\
Cerrado sensu stricto & 79,0 \\
Cerradão & 11,1 \\
Floresta estacional semidecídua & 1,2 \\
Campo úmido & 0,6 \\
\hline
\end{tabular}

Apesar da expansão agrícola na região (hoje predominando culturas de cítricos, eucalipto e cana-de-açúcar), ainda são encontrados na gleba Cerrado Pé-de-Gigante e imediações, vestígios de animais de médio porte, como capivara (Hydrochoerus hydrochaeris), veado (Mazama sp.), cateto (Tayassu tajacu) e diversas espécies raras ou em vias de extinção, como lobo-guará (Chrysocyon brachyurus), onça parda (Puma concolor), irara (Eira barbara) e tamanduá-bandeira (Myrmecophaga tridactyla) (Lyra Jorge \& Pivello 2005), indicando que ainda há boa capacidade de suporte para a fauna nativa. Isto provavelmente se deve à existência de corredores naturais (matas ciliares) ou artificiais (reflorestamentos) e de "stepping stones" (pequenos capões de mata), propiciando a interligação das maiores áreas vegetadas (Pivello et al. 1998). 


\section{ESPÉCIES ESTUDADAS}

Attalea geraensis e Syagrus petraea são duas espécies acaulescentes, monóicas, pertencentes à subfamília Arecoideae, tribo Cocoeae (Henderson et al. 1995, Uhl \& Dransfield 1987).

Attalea geraensis Barb. Rodr. (Figura 3)

Conhecida popularmente como indaiá, esta palmeira possui caule simples, subterrâneo. Suas folhas emergem do solo em número de três a seis, com cerca de 1,4 m de comprimento, recurvadas, regularmente distribuídas, rígidas, sustentadas por pecíolo de 20 $\mathrm{cm}$ em média, com bainha fibrosa e solta nas margens. A espécie possui inflorescências estaminadas e pistiladas no mesmo indivíduo, envoltas por duas brácteas lenhosas. Os frutos têm polpa suculenta com duas a quatro sementes. O endosperma é comestível para vários animais e é produtor de óleo vegetal. $\mathrm{O}$ mesocarpo, de fácil acesso, é adocicado e apreciado por grande número de roedores. A espécie multiplica-se por sementes disseminadas pela fauna (Lorenzi et al. 1996, Medeiros-Costa \& Panizza 1983).
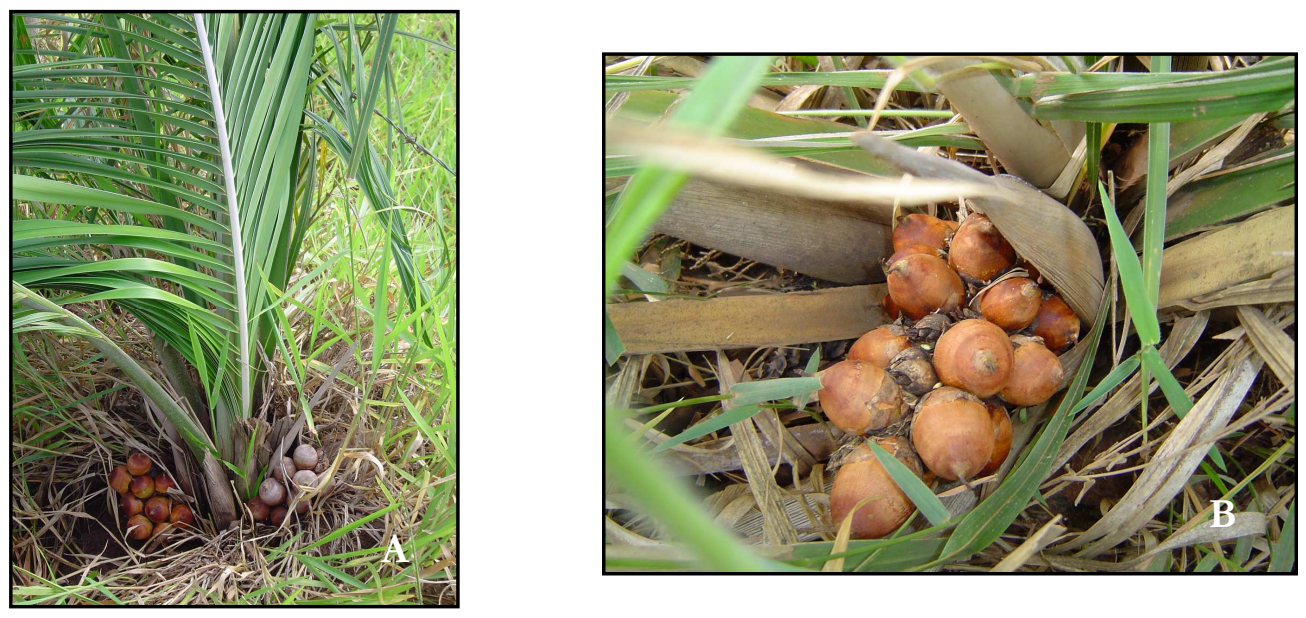

Figura 3. Indivíduo de Attalea geraensis Barb. Rodr. (Arecaceae). A. Indivíduo de A. geraensis com infrutescências, em fisionomia campestre no Cerrado Pé-de-Gigante. B. Detalhe dos frutos (Fotos: Leandro R. Tambosi).

Syagrus petraea (Mart.) Becc. (Figura 4)

Esta espécie apresenta caules simples ou múltiplos, muito curtos (até $60 \mathrm{~cm}$ acima do solo) ou subterrâneos, atingindo o conjunto pouco mais de $1 \mathrm{~m}$ de altura. As folhas são pinadas, em número de cinco a oito, de 30 a $120 \mathrm{~cm}$ de comprimento. As pinas são em 
número de 10 a 50 de cada lado da raque, regularmente dispostas num único plano, ou agrupadas formando planos levemente diferentes. A inflorescência geralmente é espiciforme e posicionada rente ao solo. Os frutos são elipsóides, de 2 a $3 \mathrm{~cm}$ de comprimento, de cor verde e com tomento marrom quando maduros. Possuem mesocarpo mucilaginoso, comestível e são severamente predados pela fauna (Lorenzi et al. 1996, Medeiros-Costa \& Panizza 1983).
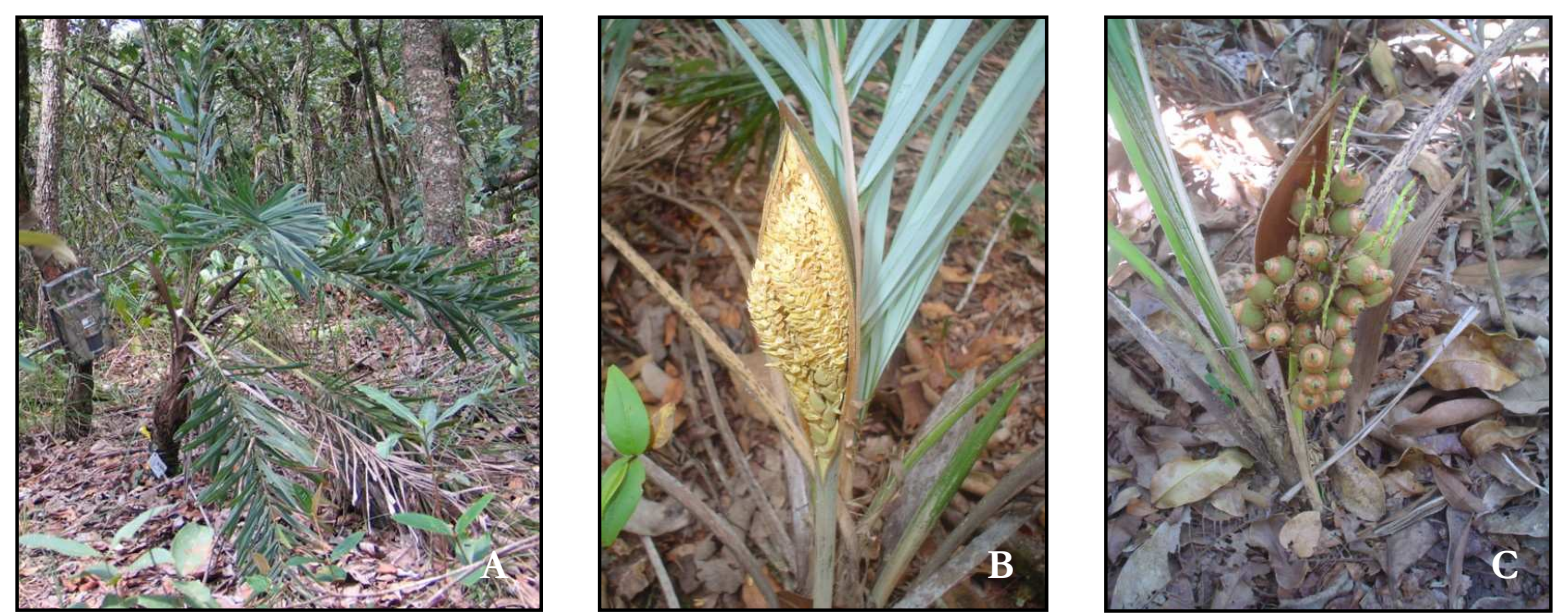

Figura 4. Indivíduos de Syagrus petraea (Mart.) Becc. (Arecaceae) em cerrado sensu stricto, no Cerrado Pé-de-Gigante. A. Indivíduo de $S$. petraea monitorado por uma câmera fotográfica automática (Foto: Klécia G. Massi). B. Detalhe de uma inflorescência. C. Detalhe de uma infrutescência com frutos maduros (Fotos: Mariana M. Vidal). 


\section{MÉTODOS}

\section{A) ABUNDÂNCIA DE RECURSO}

Para avaliar a abundância de recurso disponível à fauna local, foram quantificadas a abundância de indivíduos adultos de Attalea geraensis e Syagrus petraea e o número médio de frutos encontrados por indivíduo reprodutivo em uma área de cerrado denso no Cerrado Pé-de-Gigante.

A estimativa da abundância de Attalea geraensis e Syagrus petraea na área de estudo foi feita com a instalação de dezoito parcelas de $10 \times 10 \mathrm{~m}$, dispostas sistematicamente ao longo de uma trilha, na fisionomia de interesse, sendo nove parcelas instaladas de um lado da trilha e as demais, do lado oposto. A distância entre as parcelas de cada lado da trilha foi de cerca de $100 \mathrm{~m}$ e a distância entre as duas linhas de parcelas aproximou-se de $30 \mathrm{~m}$ (Figura 5). Em cada parcela, foi registrado o número de indivíduos de cada uma das espécies estudadas. As parcelas foram colocadas ao longo de uma trilha num trecho visualmente semelhante ao restante da porção que constitui a fisionomia estudada, e a disposição das parcelas ao longo desta trilha facilitou o acesso a elas, evitando que novas trilhas fossem abertas.

Como Syagrus petraea possui caules subterrâneos múltiplos, a definição de indivíduo para esta espécie não é óbvia. Neste estudo, foi usada uma distância máxima de $30 \mathrm{~cm}$ entre cada conjunto de folhas emergentes do solo como critério para a definição de um indivíduo.

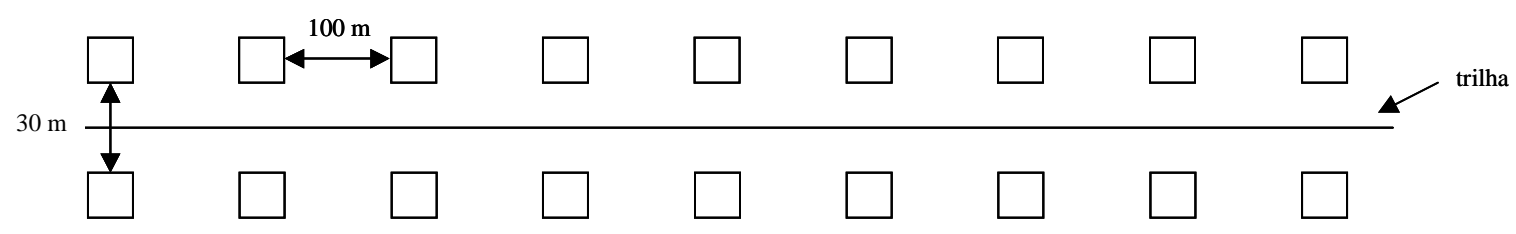

Figura 5. Esquema da disposição aproximada das parcelas instaladas em campo. Cada quadrado representa uma parcela e o traço central horizontal representa a trilha. A escala do desenho não é real e tem caráter meramente ilustrativo.

Quanto à produção de frutos por indivíduo adulto, foi feito um acompanhamento fenológico, inicialmente contando com dez indivíduos de $A$. geraensis e dez indivíduos de $S$. petraea, e, posteriormente, incorporando-se mais sete indivíduos de cada espécie. Os indivíduos foram escolhidos segundo sua aparência saudável e, sempre que possível, pela presença de estruturas reprodutivas, fossem elas atuais ou apenas vestígios de eventos reprodutivos passados. Dessa maneira, buscou-se assegurar que as plantas designadas para 
a fenologia estivessem em idade adulta. As avaliações foram feitas com um intervalo médio de 25 dias, entre janeiro de 2005 e novembro de 2006, totalizando 27 tomadas de dados: 27/jan/2005; 19/fev/2005; 14/mar/2005; 05/abr/2005; 02/mai/2005; 24/mai/2005; 14/jun/2005; 12/jul/2005; 04/ago/2005; 01/set/2005; 16/set/2005; 06/out/2005; 19/out/2005; 24/nov/2005; 21/dez/2005; 19/jan/2006; 10/fev/2006; 23/fev/2006, 20/mar/2006, 24/abr/2006, 23/mai/2006, 19/jun/2006, 18/jul/2006, 21/ago/2006, $21 /$ set/2006, 20/out/2006 e 21/nov/2006. A partir de 04/ago/2005, foram incorporados os outros sete indivíduos de $A$. geraensis e sete indivíduos de $S$. petraea ao acompanhamento fenológico. A descrição do comportamento fenológico das palmeiras durante o período de estudo foi feita sempre com dez indivíduos de cada espécie, por abranger um período maior de tempo. O acompanhamento com 17 indivíduos por espécie foi considerado somente na avaliação da redundância temporal dos recursos, conforme descrito na página 17, por envolver mais indivíduos durante um intervalo de tempo suficiente para as comparações propostas.

As fenofases avaliadas foram a floração e a frutificação, considerando-se também a presença de inflorescências ainda fechadas. Esta avaliação dos padrões fenológicos foi feita por meio de métodos diretos qualitativos, em que se aplica uma escala nominal, que consiste no registro da presença e ausência da fenofase; e, no caso da frutificação, foi adotado também um método direto quantitativo, sendo a produção de frutos mensurada por contagem total (d’Eça-Neves \& Morellato 2004).

A constatação da presença ou ausência de determinada fenofase no indivíduo é um método conhecido como "índice de atividade" e indica a porcentagem de indivíduos da população que está manifestando o evento fenológico em questão (Bencke \& Morellato 2002). Este método também estima a sincronia entre os indivíduos de uma população (Morellato et al. 1990), considerando que quanto maior o número de indivíduos manifestando a fenofase ao mesmo tempo, maior é a sincronia desta população. A contagem total dos frutos que foi feita consiste em uma medida de intensidade da fenofase de frutificação em cada indivíduo.

A associação do período de atividade aos níveis de intensidade de uma fenofase, além de facilitar a análise e a interpretação do comportamento fenológico da espécie, pode representar um importante papel nas pesquisas sobre interações animal-planta, pois combina informações sobre sincronia e quantidade (Bencke \& Morellato 2002).

Como poderá ser verificado na seção de "Resultados" do presente trabalho, Attalea geraensis apresentou pouca atividade quanto às fenofases aqui estudadas, sendo que somente 
um indivíduo floresceu e frutificou. Deste modo, apenas Syagrus petraea foi estatisticamente analisada.

Para os dez indivíduos de $S$. petraea acompanhados desde o início de 2005, foram feitas análises estatísticas circulares, usando as fenofases de inflorescências fechadas, floração e frutificação. Com a finalidade de se obter intervalos mais regulares entre as coletas, foram excluídos das análises circulares os dados coletados em 02/mai/2005, 01/set/2005, 06/out/2005 e 10/fev/2006.

Para calcular os parâmetros da estatística circular, os meses foram convertidos a ângulos desde $0^{\circ}$ (= janeiro) a $330^{\circ}$ (= dezembro), em intervalos de $30^{\circ}$. A freqüência de ocorrência dos indivíduos em cada variável fenológica dentro de cada ângulo foi calculada e os seguintes parâmetros estimados: o ângulo médio (a), a dispersão angular (medida por meio do cálculo do desvio padrão circular) e o vetor $\boldsymbol{r}$, uma medida de concentração ao redor do ângulo médio. Como os dados foram registrados como tempos, e não como ângulos, a data média correspondente ao ângulo médio para cada fenofase foi determinada convertendo-se as direções angulares médias a datas médias correspondentes (Zar 1996). Para testar a ocorrência de sazonalidade nas fenofases avaliadas, foi aplicado o teste de Rayleigh.

O ângulo médio (a) ou data média é o tempo do ano ao redor do qual as datas de uma determinada fenofase ocorreram para a maioria dos indivíduos. O teste de Rayleigh (z) determina a significância do ângulo médio (Zar 1996). As hipóteses testadas foram: $\mathrm{H}_{0}$ : as datas são distribuídas uniformemente (ou aleatoriamente) ao redor do círculo ou ano; há uniformidade circular ou não há direção média e, conseqüentemente, não há sazonalidade. $\mathrm{H}_{\mathrm{A}}$ : as datas não são uniformemente distribuídas ao longo do ano; há um ângulo médio, ou direção média, significativo e, conseqüentemente, há alguma sazonalidade. Se $\mathrm{H}_{\mathrm{A}}$ for aceita, a intensidade de concentração ao redor do ângulo médio, denotada por $\boldsymbol{r}$, pode ser considerada uma medida do "grau" de sazonalidade (Morellato et al. 2000). O vetor $\boldsymbol{r}$ não tem unidade e pode variar de 0 (quando a atividade fenológica está distribuída uniformemente ao longo do ano) a 1 (quando a atividade fenológica está concentrada em torno de uma única data ou período do ano). $\mathrm{Se}_{0}$ não for rejeitada, então $\boldsymbol{r}=0$ e, não havendo distribuição bimodal, a conclusão é de que os dados não exibiram sazonalidade significativa.

Como os dados do presente trabalho estão agrupados em intervalos de $30^{\circ}$, e medidas de dispersão angular podem ficar enviesadas por dados agrupados, foi utilizado aqui um fator de correção $(\boldsymbol{c})$ para o cálculo do vetor $\boldsymbol{r}$. O $\boldsymbol{r}$ corrigido $(\boldsymbol{r})$ é utilizado para a 
quantidade $\boldsymbol{r}$ e para as estatísticas calculadas em função de $\boldsymbol{r}$, o ângulo médio não requer nenhuma correção para agrupamento (Zar 1996).

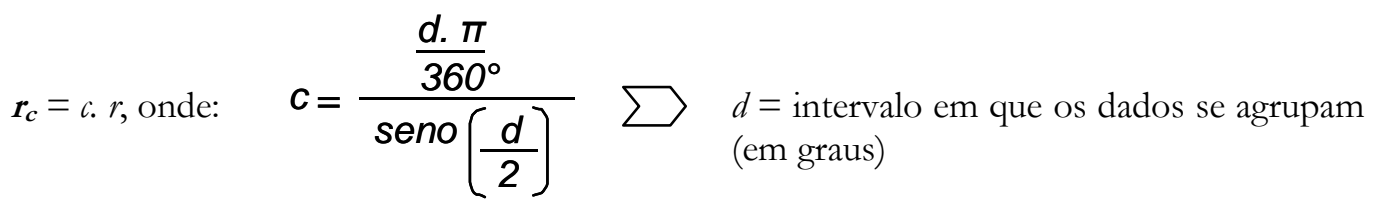

\section{B) REDUNDÂNCIA TEMPORAL}

A redundância temporal dos recursos estudados é uma informação que depende de acompanhamentos em nível de comunidade e de longa duração. Como o presente trabalho analisou apenas duas espécies, recorreu-se a informações da literatura.

O que se fez foi comparar o período de disponibilidade de frutos de $S$. petraea e $A$. geraensis - dados primários levantados neste trabalho - com a fenologia de frutificação das demais espécies presentes na comunidade, por meio de dados secundários, obtidos na literatura, de modo a verificar se a disponibilidade dos recursos estudados (frutos das palmeiras) está sincronizada com a disponibilidade de recursos alimentares alternativos para a fauna, o que caracterizaria uma redundância temporal. Optou-se por utilizar os dados obtidos com o acompanhamento fenológico dos 17 indivíduos, ao invés de se considerar apenas os dez acompanhados desde janeiro de 2005, já que o maior número de plantas aumenta a confiabilidade dos dados e um ano de acompanhamento já fornece dados suficentes para as comparações propostas.

A principal referência considerada aqui foi Batalha (1997), que estudou a fenologia reprodutiva de espécies lenhosas e herbáceas em várias fisionomias do Cerrado Pé-deGigante, entre setembro de 1995 e fevereiro de 1997, por meio do registro da presença ou ausência das fenofases estudadas. Tal trabalho foi essencial para a avaliação da questão da redundância temporal, visto que foi realizado na mesma área de estudo do presente trabalho e incluiu um grande número de espécies, tanto lenhosas quanto herbáceas. De todas as espécies registradas no trabalho citado acima, foram selecionadas somente as angiospermas com ocorrência em cerrado sensu stricto [segundo classificação adotada por Batalha (1997)] (anexo I). A partir desta seleção, foi possível comparar o período de frutificação de $A$. geraensis e $S$. petraea com o pico de frutificação das demais espécies presentes em cerrado sensu stricto no período estudado (setembro de 1995 a fevereiro de 1997). Depois disso, uma segunda seleção foi feita com a finalidade de comparar o período de disponibilidade dos frutos das duas palmeiras com a disponibilidade de recursos semelhantes - frutos carnosos -, restringindo a análise a angiospermas de ocorrência em 
cerrado sensu stricto, com síndrome de dispersão zoocórica, e unidades de dispersão carnosas.

Define-se unidade de dispersão como sendo a(s) semente(s) e qualquer parte adicional de um fruto ou infrutescência quando este conjunto forma uma unidade estrutural e funcional que é ingerida e/ou dispersa (Gottsberger \& Silberbauer-Gottsberger

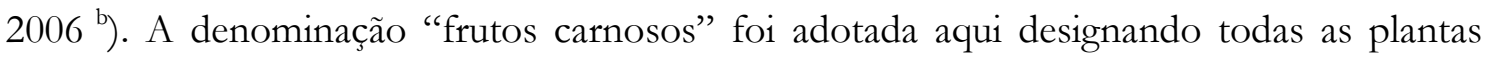
cuja unidade de dispersão possui uma sarcotesta carnosa ou suculenta, arilo ou elaiossomo, no caso das sementes, ou, no caso dos frutos, quando há camadas carnosas no pericarpo (Gottsberger \& Silberbauer-Gottsberger $2006^{\text {b) }}$. A classificação em frutos secos ou carnosos foi feita com base em literatura e consulta a especialistas (M.A. Batalha 2007 comunicação pessoal, Gottsberger \& Silberbauer-Gottsberger $2006^{\text {b }}$, Lorenzi et al. 1996, Melo et al. 1998).

Para caracterizar melhor o comportamento fenológico das espécies selecionadas, foi também analisado o trabalho de Batalha et al. (1997), desenvolvido no Cerrado de Emas (Pirassununga, SP), a cerca de $40 \mathrm{~km}$ do local deste presente trabalho, sujeito ao mesmo tipo climático (Cwa, segundo Köppen 1948). Dentre as espécies registradas por Batalha et al. (1997), foram selecionadas somente aquelas citadas para a fisionomia de cerrado sensu stricto do Cerrado Pé-de-Gigante (ver anexo II). Depois disso, também foi feita uma segunda seleção, incluindo somente as plantas zoocóricas com frutos carnosos.

\section{C) MORFometria E CONTEÚdo Nutricional}

\section{Coleta e processamento dos frutos}

Somente os frutos de Syagrus petraea foram caracterizados quanto a parâmetros morfométricos e conteúdo nutricional, já que apenas um fruto de Attalea geraensis foi encontrado. A coleta dos frutos foi feita em duas excursões a campo (19/01/2006 e 24/05/2006), sendo que mais de 80\% do material foi obtido na primeira viagem. Após a busca e marcação de indivíduos de Syagrus petraea com frutos maduros na fisionomia estudada, excetuando-se os indivíduos designados ao acompanhamento fenológico, os frutos foram coletados e congelados em campo, em gelo seco. Todo o material coletado foi mantido em freezer a $-20^{\circ} \mathrm{C}$ até que as medidas morfométricas e pesagens fossem feitas. 
Os frutos coletados seguiram alguns critérios de inclusão, de modo a se tentar padronizar o que chamamos aqui de "frutos maduros". Deste modo, foram coletados somente frutos de tamanho semelhante, de consistência rígida e de coloração verde, com extremidades mais alaranjadas (Figura 6), buscando limitar a coleta a frutos em estágios semelhantes de maturação.

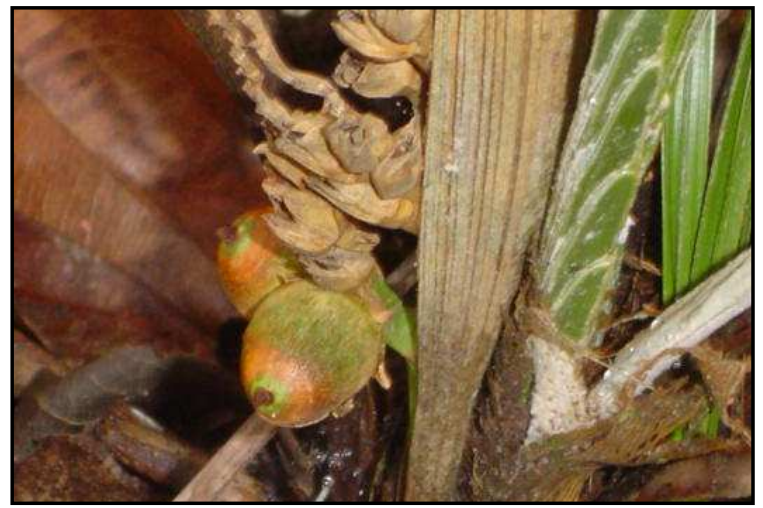

Figura 6. Frutos maduros de Syagrus petraea (Foto: Mariana M. Vidal).

No total, foram coletados 54 frutos maduros de $S$. petraea, provenientes de 16 indivíduos diferentes. Em laboratório, foram medidos o comprimento e o maior diâmetro de cada fruto, com o uso de paquímetro. Além disso, todos os frutos congelados foram pesados em balança analítica de precisão, o que forneceu os dados de massa fresca de cada fruto. Os 54 frutos foram então liofilizados e, em seguida, o material seco foi pesado na mesma balança analítica utilizada para a determinação da massa fresca dos frutos.

Para a análise do conteúdo nutricional, foram selecionados dez indivíduos entre os 16 inicialmente amostrados. Esta seleção foi feita com base na maior homogeneidade em termos de massa fresca, massa seca, porcentagem de água e características morfológicas de cada fruto. Os indivíduos com frutos mais discrepantes dentre os disponíveis não foram analisados quanto ao conteúdo nutricional. Com isso, 31 frutos, correspondentes aos dez indivíduos, constituíram o material destinado às análises nutricionais, as quais foram feitas em nível de indivíduo.

Há duas partes comestíveis nos frutos das palmeiras: o mesocarpo e o endosperma (Henderson 2002) e, por isso, as análises nutricionais foram feitas separadamente para estas duas frações. Os 31 frutos foram manualmente despolpados, separando-se o endosperma e a "polpa", que corresponde ao mesocarpo e epicarpo do fruto. As "polpas" e endospermas provenientes de um mesmo indivíduo foram agrupados, compondo uma única amostra de "polpa" e uma única amostra de endosperma para cada indivíduo. 
A despolpa só foi realizada após a secagem dos frutos porque o processo implicava em muita perda de material quando feito com os frutos congelados, ou parcialmente congelados. Assim, não foi possível obter as massas fresca e seca da "polpa" e do endosperma separadamente, mas somente do fruto inteiro.

Todo o material destinado à análise de conteúdo nutricional foi pulverizado em almofariz (Figura 7) com auxílio de nitrogênio líquido e mantido em freezer a $-20^{\circ} \mathrm{C}$ até que as análises fossem feitas.

A
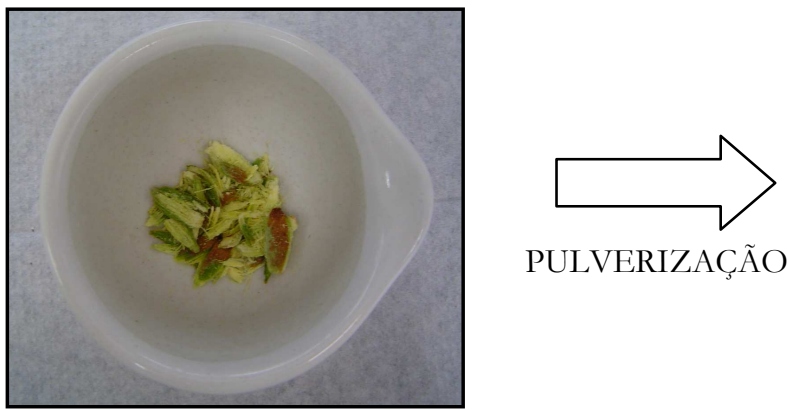

PULVERIZAÇÃO

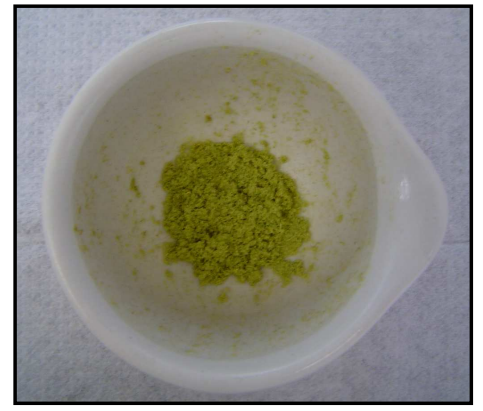

B
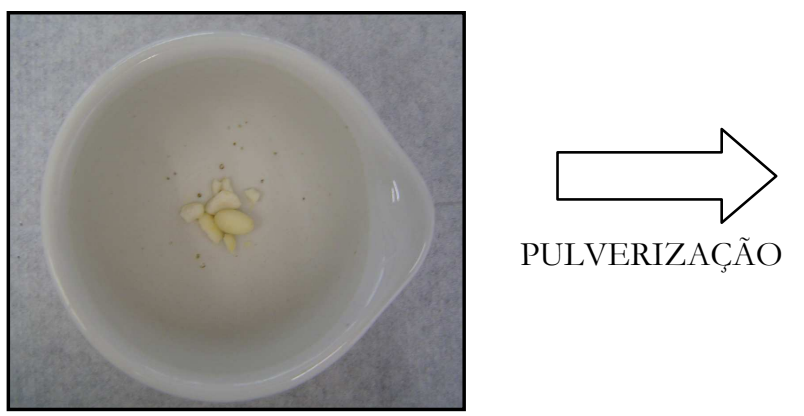

PULVERIZAÇÃO

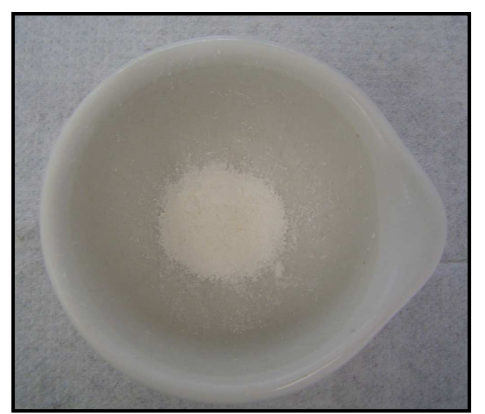

Figura 7. Material íntegro e após a pulverização em almofariz. A. "Polpa". B. Endosperma (Fotos: Mariana M. Vidal).

\section{Extrações de lipídios, carboidratos e proteínas solúveis}

As dez amostras de "polpa" e dez amostras de endosperma pulverizadas foram caracterizadas quanto às porcentagens (em relação à massa seca) de lipídios, carboidratos solúveis e proteínas solúveis. Foram utilizados protocolos de extração e dosagens do Laboratório de Fitoquímica do Departamento de Botânica do Instituto de Biociências da USP (para a extração e dosagem dos lipídios) e da Seção de Fisiologia e Bioquímica de Plantas do Instituto de Botânica de São Paulo (extração e dosagem de carboidratos e proteínas).

Todo o material foi desengordurado, de modo que as extrações seguintes (carboidratos e proteínas solúveis) foram feitas a partir de material sem lipídios. A extração dos óleos foi feita empregando-se extratores Soxhlet, sendo que as amostras foram tratadas com n-hexano durante seis horas. Os extratos foram secos em rotaevaporador sob pressão 
reduzida e as amostras foram transferidas para frascos previamente pesados e armazenadas em dessecadores até atingirem massa constante para obtenção do rendimento lipídico.

Uma fração (cerca de 0,1 g) do material desengordurado ("polpa” e endosperma) de cada indivíduo foi pesada em balança analítica, armazenada em microtubos de polipropileno $(1,5 \mathrm{ml})$ à $-20^{\circ} \mathrm{C}$ e, então, destinada às extrações de carboidratos e proteínas solúveis.

Para a extração dos carboidratos solúveis, foram feitas quatro extrações com etanol. Cada extração constituiu na adição de $1 \mathrm{ml}$ de etanol 80\% às amostras (ou resíduos), que foram agitadas em vortex e mantidas a temperatura ambiente por cinco minutos, quando uma nova agitação foi feita. As amostras ficaram em processo de extração por mais cinco minutos, passaram uma terceira vez pelo vortex e foram centrifugadas em microcentrífuga para microtubos a $13.238 \mathrm{~g}$ por dez minutos a temperatura ambiente. Os sobrenadantes com os açúcares solúveis foram transferidos para frascos previamente identificados, constituindo os extratos etanólicos da "polpa" e do endosperma de cada indivíduo. Este processo foi feito quatro vezes, de maneira a assegurar que todos os açúcares solúveis fossem extraídos.

Os extratos etanólicos passaram por uma filtragem com pré-filtro de fibra de vidro, para a retirada de possíveis partículas em suspensão e tiveram seus volumes ajustados em proveta com etanol $80 \%$.

Os resíduos das extrações dos carboidratos solúveis foram submetidos às extrações das proteínas solúveis. Foi adicionado $1 \mathrm{ml}$ de tampão fosfato $210 \mathrm{mM}$ a cada amostra, as quais foram agitadas em vortex e ficaram em extração por cinco minutos em banho de gelo. Nova agitação foi feita e as amostras ficaram em extração por mais cinco minutos também em banho de gelo. Uma última agitação em vortex foi feita antes da centrifugação das amostras, sendo esta centrifugação executada em microcentrífuga para microtubos a $13.238 \mathrm{~g}$ por dez minutos a temperatura ambiente. Este procedimento foi feito três vezes, garantindo a extração de todas as proteínas solúveis do material. Os sobrenadantes contendo as proteínas solúveis foram transferidos para frascos identificados, constituindo os extratos aquosos da "polpa" e do endosperma de cada indivíduo.

Assim como foi feito com os extratos etanólicos, os extratos aquosos também foram submetidos a uma filtragem com pré-filtro de fibra de vidro para a retirada de partículas em suspensão. Foi executado então o ajuste do volume final com auxílio de uma proveta, com o mesmo tampão fosfato. 
Todos os extratos (etanólicos e aquosos) foram mantidos em freezer a $-20^{\circ} \mathrm{C}$ até que as dosagens de carboidratos e proteínas fossem feitas.

\section{Dosagens de carboidratos e proteínas solúveis}

A dosagem de carboidratos solúveis totais foi realizada por meio do método do fenol-sulfúrico modificado (Dubois et al. 1956), um método colorimétrico que consiste na reação entre fenol e ácido sulfúrico e carboidratos, formando produtos coloridos característicos. Após a reação, a leitura das absorbâncias das amostras em espectrofotômetro fornece a massa de carboidratos presentes no material, quando se fazem as comparações com uma curva padrão, elaborada com massas conhecidas de glicose.

Foi preparada uma solução padrão de glicose a $100 \mu \mathrm{g} / 100 \mu \mathrm{l}$ de água, da qual foram retiradas alíquotas de modo a se obter uma curva padrão com os seguintes valores de massa de glicose: $5 \mu \mathrm{g}, 10 \mu \mathrm{g}, 25 \mu \mathrm{g}, 40 \mu \mathrm{g}, 55 \mu \mathrm{g}$ e $70 \mu \mathrm{g}$. O volume de cada alíquota foi completado com água destilada até o valor de $500 \mu$ l. As alíquotas receberam $500 \mu \mathrm{l}$ de fenol a 5\% e 2,5 ml de ácido sulfúrico P.A. Baker (95-97\%), agitadas, esfriadas até atingir a temperatura ambiente e então foram levadas a um espectrofotômetro Shimadzu UV-1201 para o registro das absorbâncias a $490 \mathrm{~nm}$ em cubetas de $10 \mathrm{~mm}$. Com os valores de absorbância e as massas conhecidas de açúcar nas diferentes alíquotas, foi elaborada a curva padrão, que gerou uma equação de regressão, a qual descreve a reta ajustada entre os pontos observados. Com esta equação, foi possível estimar a massa de açúcares presentes nos extratos etanólicos da "polpa" e do endosperma de cada indivíduo.

Para a maior parte das amostras, foram pipetados $20 \mu \mathrm{l}$ de cada extrato de "polpa" e $5 \mu \mathrm{l}$ de cada extrato de endosperma para a dosagem de carboidratos. No entanto, algumas amostras de polpa possuíam muito açúcar e uma nova dosagem foi feita com apenas $5 \mu \mathrm{l}$ do extrato. A estes volumes de $20 \mu \mathrm{l}$ e $5 \mu \mathrm{l}$ foram adicionados, respectivamente, $480 \mu \mathrm{l}$ e $495 \mu \mathrm{l}$ de água destilada para atingir o volume final de $500 \mu \mathrm{l}$, ao qual somaram-se os volumes de reagentes $(0,5 \mathrm{ml}$ de fenol e 2,5 $\mathrm{ml}$ de ácido sulfúrico). Em seguida, foi feita a leitura das absorbâncias no espectrofotômetro e posterior cálculo da massa de carboidratos presentes no material, com base na equação da reta gerada pela curva padrão. A partir destes valores, foi possível estimar a porcentagem de carboidratos presentes na massa seca de "polpa" e de endosperma de cada indivíduo analisado.

A dosagem de proteínas solúveis foi feita com o ensaio de proteínas Bio-Rad, baseado no método de Bradford (Bradford 1976). O método envolve a adição de um 
corante à solução protéica e subseqüente medida a $595 \mathrm{~nm}$ em espectrofotômetro. A comparação com uma curva padrão fornece uma medida relativa da massa de proteínas encontrada na amostra. O corante utilizado no ensaio foi o Coomassie ${ }^{\circledR}$ Brilliant Blue G250 (Bio-Rad) em solução, cuja absorbância máxima muda de 465 nm para 595 nm quando ocorre a ligação com proteínas.

A solução padrão foi preparada com albumina bovina e tampão fosfato, na concentração de $100 \mu \mathrm{g} / \mathrm{ml}$, e foram retiradas alíquotas correspondentes a 1,2 $\mu \mathrm{g}, 2,0 \mu \mathrm{g}$, 3,0 $\mu \mathrm{g}, 4,0 \mu \mathrm{g}, 5,0 \mu \mathrm{g}, 6,0 \mu \mathrm{g}, 7,0 \mu \mathrm{g}, 8,0 \mu \mathrm{g}, 9,0 \mu \mathrm{g}$ e 10,0 $\mu \mathrm{g}$ de proteína. O volume de cada alíquota foi completado com água destilada até o valor de $200 \mu$ l. As alíquotas receberam $800 \mu \mathrm{l}$ de reagente em solução aquosa (1 parte de reagente concentrado com 4 partes de água tipo 1) e então foram levadas ao espectrofotômetro para a leitura das absorbâncias a $595 \mathrm{~nm}$. Com os valores de absorbância e as massas conhecidas de proteína nas diferentes alíquotas, foi elaborada a curva padrão, a partir da qual se estimou o conteúdo de proteínas nos extratos aquosos de "polpa" e endosperma.

As amostras relativas à "polpa" dos frutos foram de $100 \mu \mathrm{l}$ de extrato aquoso, ao passo que as amostras dos extratos de endosperma foram de $7 \mu$, com exceção de um indivíduo, cuja composição protéica do endosperma foi analisada com um volume um pouco maior $(10 \mu \mathrm{l})$ para que seu valor de absorbância correspondesse a um valor mais intermediário da curva padrão e não tão baixo como foi obtido com $7 \mu$ l. Os volumes foram completados com água destilada até completarem $200 \mu$ e então receberam $800 \mu \mathrm{l}$ de reagente. Após a reação, foram registradas as absorbâncias a $595 \mathrm{~nm} \mathrm{em}$ espectrofotômetro, dados que permitiram a estimativa do conteúdo de proteínas no material.

Após as dosagens, foram feitos os cálculos para a obtenção do conteúdo de lipídios, carboidratos solúveis e proteínas solúveis na "polpa" e endosperma de frutos maduros de cada indivíduo de Syagrus petraea, expresso em $\mathrm{mg} / \mathrm{g}$ de massa seca. Para determinar a significância das diferenças entre "polpa" e endosperma quanto aos conteúdos de lipídios, açúcares, proteínas e resíduos foi aplicado o teste de Wilcoxon para amostras pareadas (Zar 1996).

D) Vertebrados consumidores dos frutos de AtTalea geraEnsis e Syagrus PETRAEA

A fim de identificar as espécies de vertebrados terrestres que possivelmente consomem os frutos de $A$. geraensis e $S$. petraea, foram feitas buscas por indivíduos em 
frutificação na fisionomia de cerrado denso ao longo de todo o período de estudo. $O$ número de indivíduos de $S$. petraea encontrados com frutos variou de acordo com a época do ano, ao passo que, conforme citado anteriormente, somente um indivíduo de A.geraensis foi encontrado com um único fruto durante todo o período de estudo.

Para identificar possíveis consumidores dos frutos de $S$. petraea, foram feitos, no início do trabalho, canteiros de pegadas ao redor de cada palmeira em frutificação, além de colocadas armadilhas fotográficas focadas nas infrutescências (Figura 8).

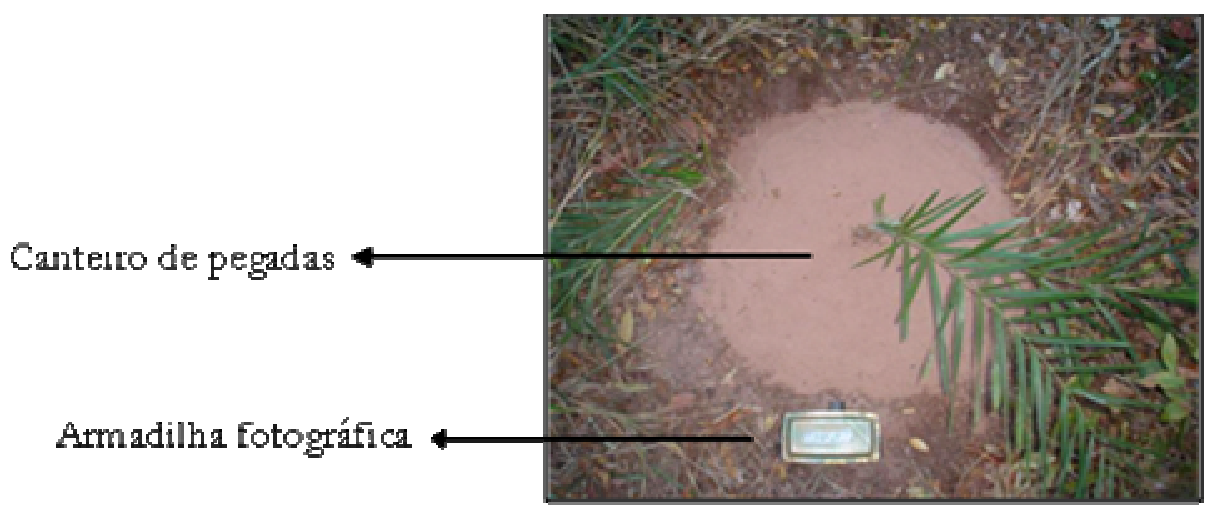

Figura 8. Disposição do canteiro de pegadas e da armadilha fotográfica em relação a um indivíduo de Syagrus petraea em frutificação (Foto: Mariana M. Vidal).

O uso de câmeras fotográficas automáticas para estudos de fauna tem recebido maior atenção nos últimos anos, sendo empregado também para estudos de frugivoria (Galetti et al. 2003). O método consiste em direcionar aos frutos de interesse, um sensor de calor e movimento ligado a uma câmera fotográfica, constituindo a armadilha fotográfica.

Os canteiros de pegadas consistiam de círculos, com o tamanho variando em função das dimensões da palmeira central, mantendo a proporção de área livre para a impressão das pegadas (cerca de $0,5 \mathrm{~m}^{2}$ ). Nestes círculos, o solo foi destituído de matéria vegetal, solto e alisado, e recebeu uma camada de areia com posterior umidificação da superfície para facilitar o registro das pegadas. Os canteiros de pegadas eram preparados em um dia e verificados no dia seguinte, no entanto, eles foram removidos no decorrer do trabalho. Justifica-se tal remoção pelo insucesso do método para os objetivos aqui propostos, ou seja, pela ausência de registros de pegadas e pelo fato dos canteiros prejudicarem o bom funcionamento das armadilhas fotográficas, na medida em que deixavam o solo nu, causando o encobrimento das câmeras por areia na ocasião de fortes chuvas. Deste modo, a identificação dos consumidores foi feita somente com o uso das armadilhas fotográficas. 
No caso de Attalea geraensis, o único fruto produzido (em abril de 2006) foi monitorado apenas com a armadilha fotográfica, não tendo sido feito nenhum canteiro de pegadas, já que a ineficiência deste método para os objetivos propostos já tinha sido constatada.

As câmeras fotográficas automáticas monitoraram, durante todo o período de estudo, um número total de 45 indivíduos com frutos - 44 indivíduos de Syagrus petraea e apenas um indivíduo de Attalea geraensis - e foram verificadas num intervalo médio de 26 dias entre 14/junho/2005 e 21/novembro/2006, totalizando 21 verificações. Nestas verificações, as trocas de filmes e pilhas das câmeras fotográficas foram feitas com um intervalo variável, de acordo com a ocorrência de remoção dos frutos e com o número de fotografias registradas.

Os indivíduos com as armadilhas fotográficas não foram incluídos no acompanhamento fenológico, já que foram escolhidos por estarem na fenofase de frutificação, o que poderia alterar os resultados da fenologia. O que se fez foi registrar a presença das fenofases (inflorescências fechadas, flores e frutos) nestes indivíduos e o número de frutos em cada um deles, para que se pudessem detectar possíveis eventos de remoção. Os eventos de remoção foram definidos como o desaparecimento dos frutos dos indivíduos monitorados.

Os animais fotografados imediatamente antes do desaparecimento de parte, ou de todos os frutos da infrutescência, ou antes da retirada da "polpa" dos frutos, foram designados como "consumidores". Grande parte dos animais registrados pelas câmeras automáticas foram designados apenas como "visitantes", por não terem removido os frutos, nem consumido sua "polpa" ou semente.

A identificação dos animais registrados foi feita através do envio das fotografias a especialistas do Museu de Zoologia da Universidade de São Paulo, Instituto de Biociências da Universidade de São Paulo, Departamento de Sistemática e Ecologia da Universidade Federal da Paraíba e Centro de Ciências Naturais e Exatas da Universidade Federal de Santa Maria. Todos os especialistas consultados chamaram a atenção para a dificuldade em identificar animais por fotografias, principalmente pequenos mamíferos. Muitas vezes, os registros fotográficos não são capazes de detectar detalhes importantes para uma identificação precisa. Deste modo, as identificações da fauna neste trabalho não são precisas e isto constitui uma limitação do método. 


\section{RESULTADOS}

\section{A) ABundânCIA de RECURSo}

\section{Abundância de indivíduos adultos de Attalea geraensis e Syagrus petraea}

A densidade média de Attalea geraensis na fitofisionomia estudada foi de 0,006 indivíduo por $\mathrm{m}^{2}$ e, no caso de Syagrus petraea, a densidade média encontrada foi de 0,024 indivíduo por $\mathrm{m}^{2}$. O padrão de distribuição de ambas as espécies parece ser agregado, já que os indivíduos de A. geraensis concentraram-se em $34 \%$ das parcelas e os de S. petraea, em $45 \%$ das parcelas.

\section{$\underline{\text { Fenologia reprodutiva }}$}

\section{Attalea geraensis}

A atividade de floração e frutificação de Attalea geraensis foi muito baixa durante todo o período de estudo.

O pico de atividade de floração de Attalea geraensis, ou seja, o momento em que o número máximo de indivíduos da amostra apresentou a fenofase de floração, ocorreu no início de abril de 2005, quando 10\% deles floresceram (Figura 9), o que correspondeu a apenas um indivíduo. Em janeiro de 2005, dois indivíduos de A. geraensis (20\%) apresentavam cachos fechados, sendo que as inflorescências de somente um deles se abriram, entre março e abril de 2005. As inflorescências do outro indivíduo apodreceram ainda fechadas. Em fevereiro de 2006, o mesmo indivíduo que havia florescido em abril de 2005 apresentou uma inflorescência ainda fechada, que se abriu entre uma coleta de dados e outra (23/03/06 e 24/04/2006). Assim, não foi possível o registro da fenofase de floração para este indivíduo, mas sabe-se que o padrão de floração por volta do mês de abril, encontrado em 2005, se repetiu em 2006. Desta inflorescência, somente um fruto foi produzido, o qual permaneceu na planta até o final do acompanhamento fenológico, em novembro de 2006 (Figura 9). 


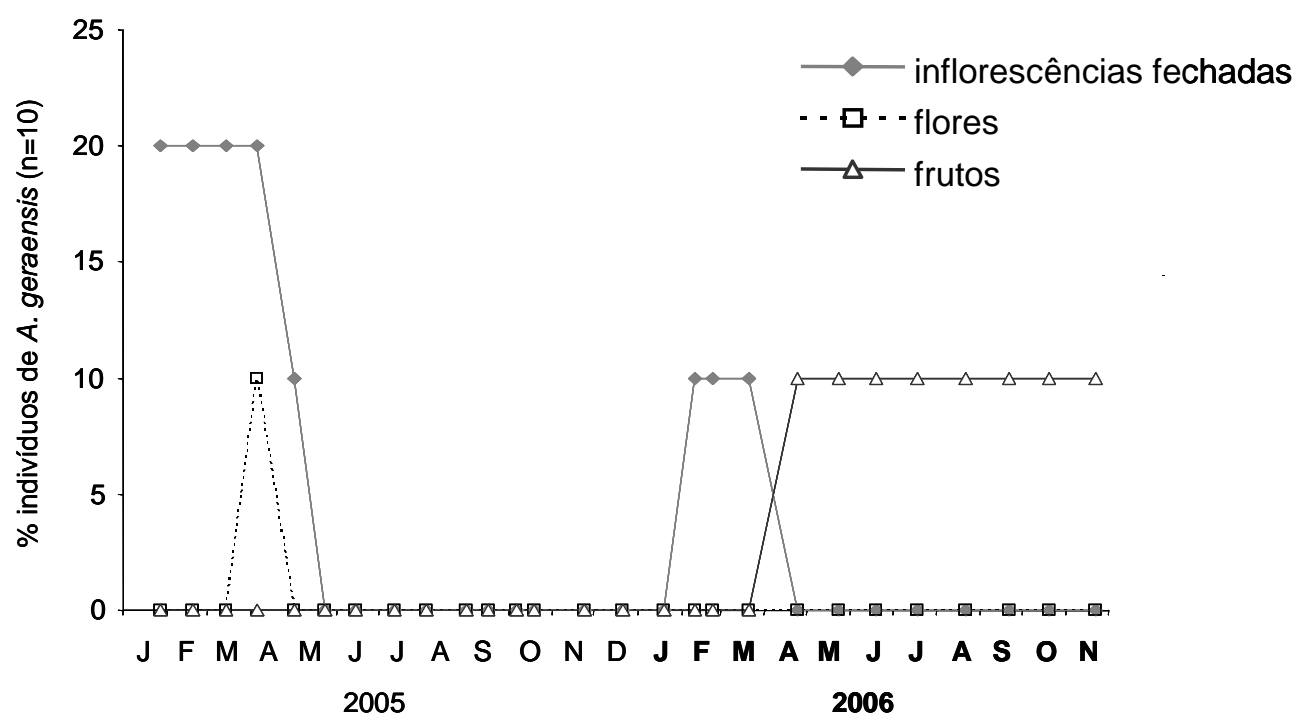

Figura 9: Porcentagem do número de indivíduos de Attalea geraensis $(\mathrm{n}=10)$ apresentando cada fenofase observada entre janeiro de 2005 e novembro de 2006.

Syagrus petraea

Entre os dez indivíduos de $S$. petraea acompanhados, a produção de inflorescências foi contínua durante todo o período de estudo (Figura 10), havendo no mínimo dois indivíduos portando inflorescências fechadas em cada tomada de dados. É possível identificar dois picos de produção de inflorescências: entre julho e setembro de 2005, quando $90 \%$ dos indivíduos apresentavam inflorescências fechadas e um segundo pico em abril de 2006, com $80 \%$ dos indivíduos nesta fenofase.

A abertura das inflorescências foi irregular, principalmente no primeiro ano de acompanhamento, quando se observaram pequenos pulsos de floração em fevereiro (um indivíduo com flores) e junho (dois indivíduos com flores). As demais inflorescências produzidas começaram a se abrir no início de setembro de 2005, e o pico de atividade de floração de $S$. petraea ocorreu em novembro, ocasião em que 40\% dos indivíduos acompanhados floresceram. Em 2006, houve um pequeno pulso de floração em fevereiro, e esta fenofase foi mais contínua no decorrer do ano, sendo que $20 \%$ dos indivíduos apresentavam flores entre abril e agosto, número que subiu para 30\% em setembro e outubro (Figura 10).

A porcentagem de indivíduos na fenofase de frutificação foi relativamente alta em janeiro de 2005, quando 40\% dos indivíduos frutificaram. Com o passar do tempo, esta porcentagem foi declinando até que nenhum indivíduo frutificou entre março e abril de 2005. Entre maio e agosto de 2005, um único indivíduo (10\%) esteve com frutos, número que foi aumentando até que se atingiu o pico de atividade de frutificação em janeiro e 
fevereiro de 2006 (Figura 10), quando 60\% dos indivíduos estavam frutificando. A partir de então, a porcentagem de plantas com frutos foi diminuindo e em abril de 2006 nenhum indivíduo tinha frutos. Entre maio e agosto de 2006, um único indivíduo esteve com frutos, mas este número foi aumentando até que 30\% dos indivíduos frutificaram em outubro de 2006.

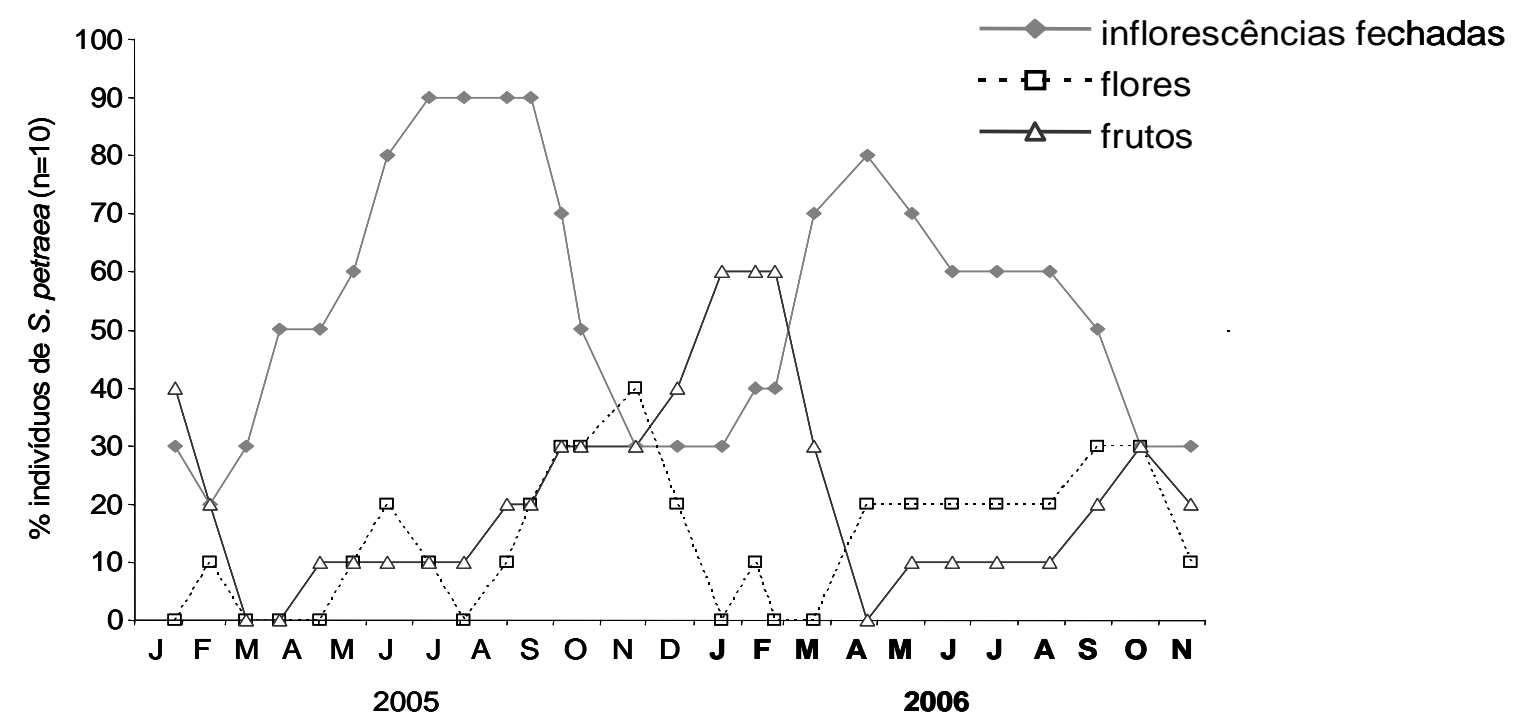

Figura 10: Porcentagem do número de indivíduos de Syagrus petraea $(\mathrm{n}=10)$ apresentando cada fenofase avaliada entre janeiro de 2005 e novembro de 2006.

O teste de Rayleigh, realizado com os dados coletados em 23 coletas mensais, mostra que houve sazonalidade nas três fenofases avaliadas (Tabela 2). O grau de sazonalidade, denotado por $\boldsymbol{r}_{c}$, foi menor para a fenofase de inflorescências fechadas $\left(\boldsymbol{r}_{\boldsymbol{c}}=\right.$ $0,27)$ e mais elevado para as fenofases de floração e frutificação, ambas com $\boldsymbol{r}_{\boldsymbol{c}}=0,37$.

A data média, ou seja, o tempo do ano ao redor do qual as datas de uma determinada fenofase ocorreram para a maioria dos indivíduos, ocorreu no período seco (18/julho) para a fenofase de inflorescências fechadas. As datas médias das fenofases de floração e frutificação ocorreram, respectivamente, no início (24/setembro) e meio da estação chuvosa (06/janeiro) (Figura 11). 
Tabela 2. Resultado de análise estatística circular testando para a ocorrência de sazonalidade no comportamento fenológico de Syagrus petraea (Arecaceae) em fisionomia de cerrado denso no Cerrado Pé-de-Gigante (Santa Rita do Passa Quatro, SP). O teste de Rayleigh foi aplicado para significância do ângulo médio (a) ou data média (dada entre parênteses).

\begin{tabular}{lccc}
\hline & \multicolumn{3}{c}{ Variáveis fenológicas } \\
\cline { 2 - 4 } & $\begin{array}{c}\text { Inflorescências } \\
\text { fechadas }\end{array}$ & Floração & Frutificação \\
\hline Observações $(n)$ & 123 & 33 & 48 \\
Ângulo médio $(a)$ & $180^{\circ}$ & $248^{\circ}$ & $350^{\circ}$ \\
& $(18 /$ julho $)$ & $(24 /$ setembro $)$ & $(06 /$ janeiro $)$ \\
Desvio padrão circular & $92,58^{\circ}$ & $81,34^{\circ}$ & $80,72^{\circ}$ \\
Comprimento do vetor médio $\left(r_{c}\right)$ & 0,27 & 0,37 & 0,37 \\
Teste de Rayleigh para uniformidade $(p)$ & 0,0001 & 0,0113 & 0,0012 \\
\hline
\end{tabular}
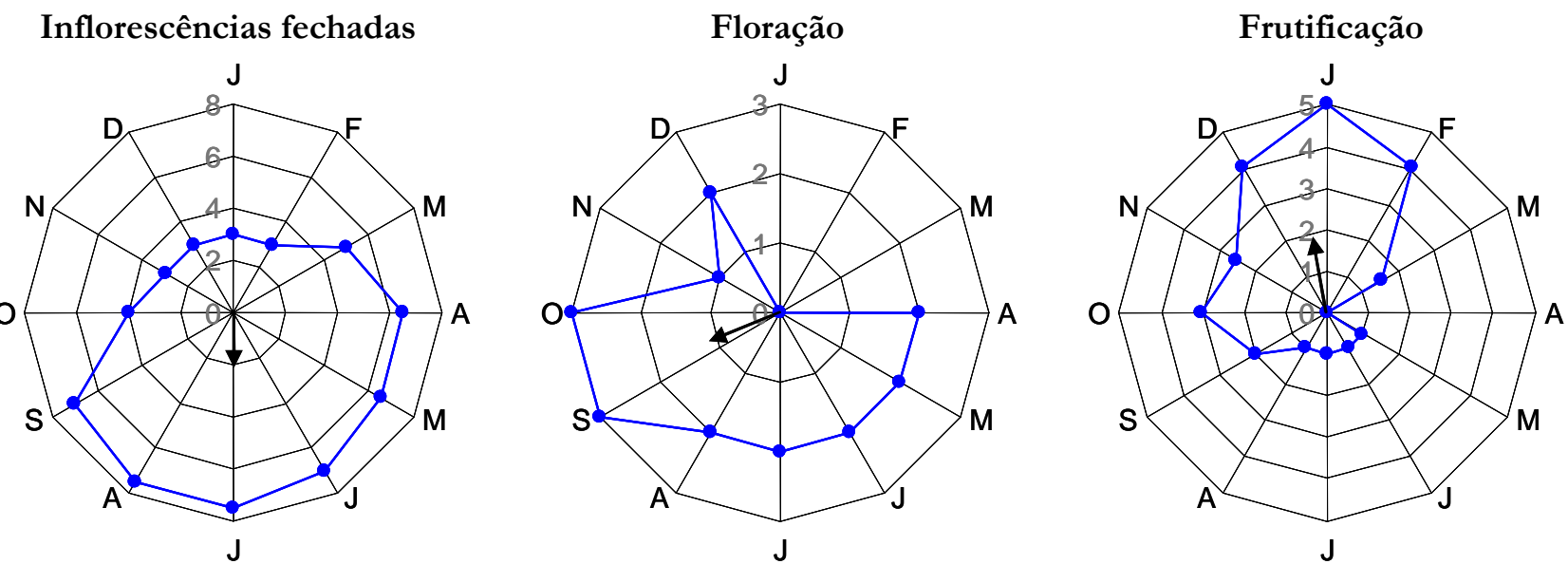

Figura 11. Número médio de indivíduos $(\mathrm{n}=10)$ apresentando as fenofases avaliadas em cada mês do ano (dados obtidos entre janeiro de 2005 e novembro de 2006). A seta central indica o ângulo médio e o comprimento do vetor $\mathrm{r}$. Partindo do alto dos diagramas, em sentido horário: $\mathrm{J}=$ janeiro; $\mathrm{F}=$ fevereiro; $\mathrm{M}=$ março; $\mathrm{A}=$ abril; $\mathrm{M}=$ maio; $\mathrm{J}=$ junho; $\mathrm{J}=$ julho; $\mathrm{A}=\operatorname{agosto} ; \mathrm{S}=$ setembro; $\mathrm{O}$ = outubro; $\mathrm{N}=$ novembro; $\mathrm{D}=$ dezembro.

O comportamento fenológico dos dez indivíduos foi um pouco distinto entre os anos analisados (Figura 12). Nota-se que há certo atraso na fenofase de inflorescências fechadas em 2005, em relação a 2006, o que acarretou em picos de atividade de floração e frutificação ocorrendo também mais tarde no primeiro ano de acompanhamento.

Segundo os dados de precipitação obtidos para a região de estudo entre 1941 e 1970, é possível identificar claramente uma época mais seca entre abril e setembro, e um período mais chuvoso entre outubro e março (Pires Neto et al. 2005). Esta estação seca bem definida pode ser observada para o ano de 2006, mas o ano de 2005 foi atípico, apresentando índices pluviométricos consideravelmente abaixo do normal para os meses de fevereiro, novembro e dezembro, ao passo que os meses de maio e setembro foram mais chuvosos em 2005 do que os dados normais para o período. As temperaturas médias 
mensais não variaram muito entre os dois anos (Figura 13). A precipitação anual em 2005 (1.084 mm) e em 2006 (1.094 mm) estiveram um pouco abaixo dos dados normais para Santa Rita do Passa Quatro (1.478 mm).

\section{Inflorescências fechadas}

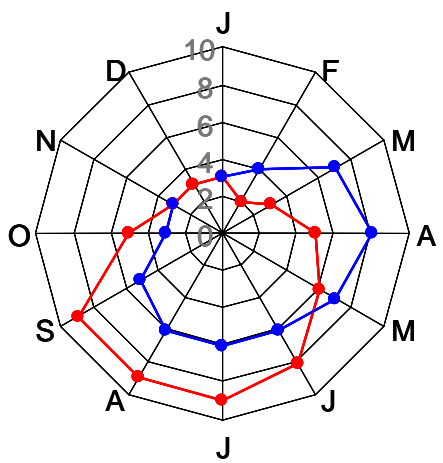

Floração

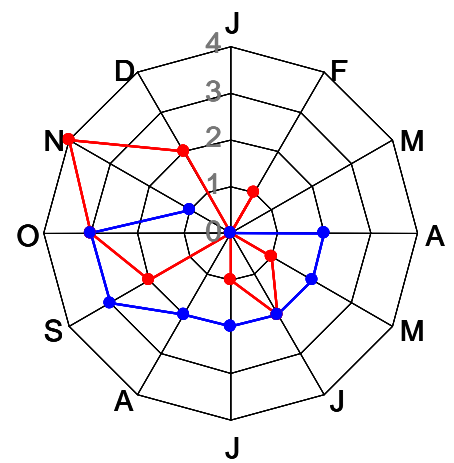

Frutificação

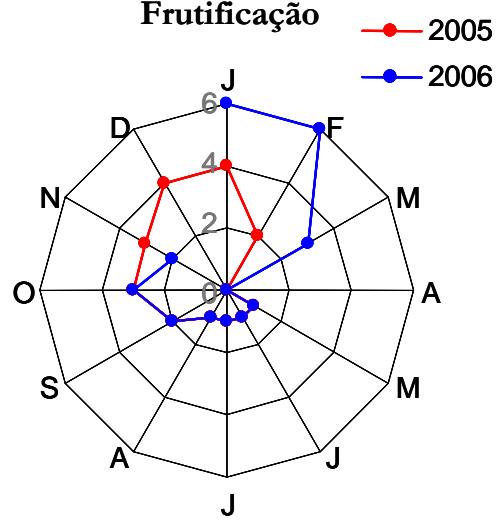

Figura 12. Número de indivíduos $(\mathrm{n}=10)$ apresentando as fenofases avaliadas em cada mês de 2005 (em vermelho) e 2006 (em azul). Partindo do alto dos diagramas, em sentido horário: $\mathrm{J}=$ janeiro; $\mathrm{F}=$ fevereiro; $\mathrm{M}=$ março; $\mathrm{A}=$ abril; $\mathrm{M}=$ maio; $\mathrm{J}=$ junho; $\mathrm{J}=$ julho; $\mathrm{A}=$ agosto; $\mathrm{S}=$ setembro; $\mathrm{O}=$ outubro; $\mathrm{N}=$ novembro; $\mathrm{D}=$ dezembro.
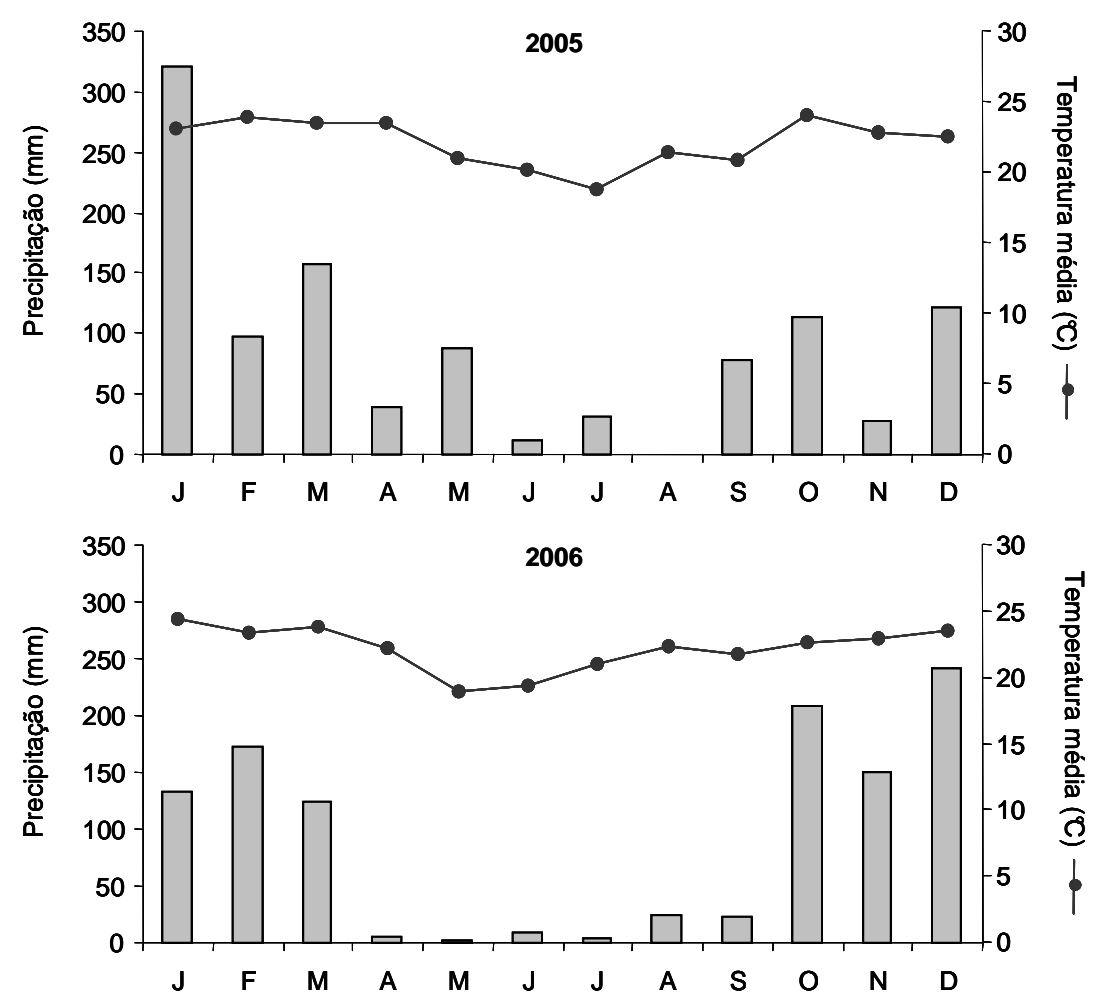

Figura 13. Precipitação mensal $(\mathrm{mm})$ e temperatura do ar média $\left({ }^{\circ} \mathrm{C}\right)$ nos anos de 2005 e 2006 no Cerrado Pé-de-Gigante, Santa Rita do Passa Quatro, SP. Gráficos construídos a partir dos dados cedidos pelo Laboratório de Clima e Biosfera (IAG/USP); posto meteorológico localizado nas coordenadas $47^{\circ} 37^{\prime} 45^{\prime \prime} \mathrm{W}$ e $21^{\circ} 37^{\prime} 00^{\prime \prime} \mathrm{S}$. 
O pico de intensidade de frutificação de $S$. petraea, isto é, o máximo valor médio de frutos por indivíduo (considerando os dez indivíduos amostrados), ocorreu em dezembro de 2005, quando se encontrou uma média de 8,10 \pm 12,20 frutos por indivíduo (Figura 14). Nota-se novo incremento no número médio de frutos encontrados por indivíduo a partir de agosto de 2006, atingindo o valor de 4,20 \pm 10,30 em novembro. Os desvios são muito grandes porque poucas plantas possuíam muitos frutos - as medianas são quase todas iguais a zero, exceto para os meses de janeiro e fevereiro de 2006, em que a mediana chegou a 1,50 frutos por indivíduo.

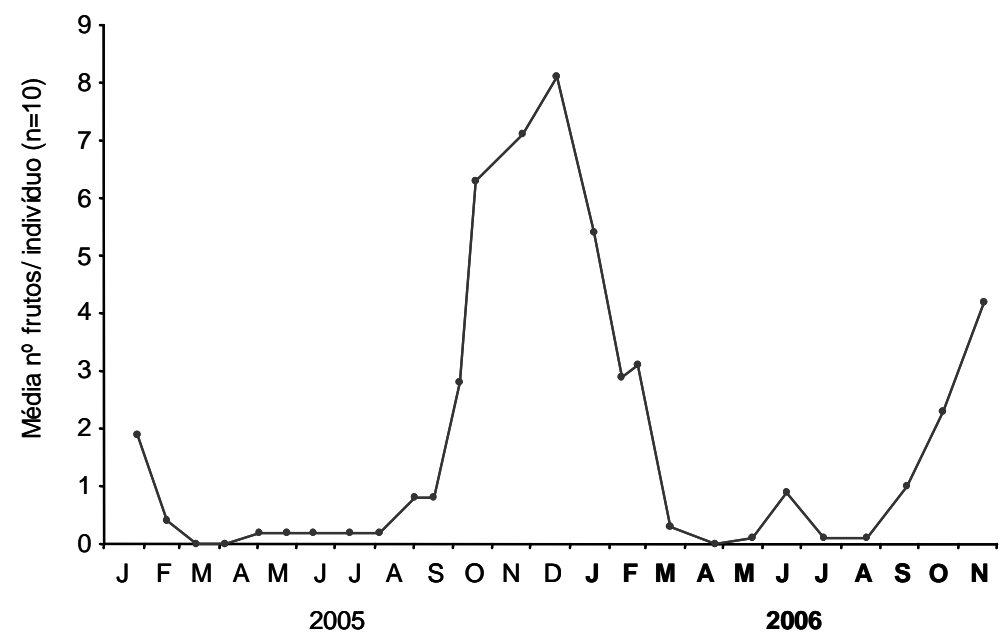

Figura 14. Média do número de frutos por indivíduo de Syagrus petraea $(\mathrm{n}=10)$, entre janeiro de 2005 e novembro de 2006.

Considerando somente os indivíduos em frutificação, entre janeiro de 2005 e novembro de 2006 ( $\mathrm{n}=10$ indivíduos), o maior número médio de frutos por indivíduo nesta fenofase ocorreu em novembro de 2005, quando se encontrou uma média de 23,67 \pm 12,50 frutos por planta (Figura 15). No mesmo mês, em 2006, observa-se um novo pico, com 21,00 $\pm 15,56$ frutos em média por indivíduo em frutificação. 


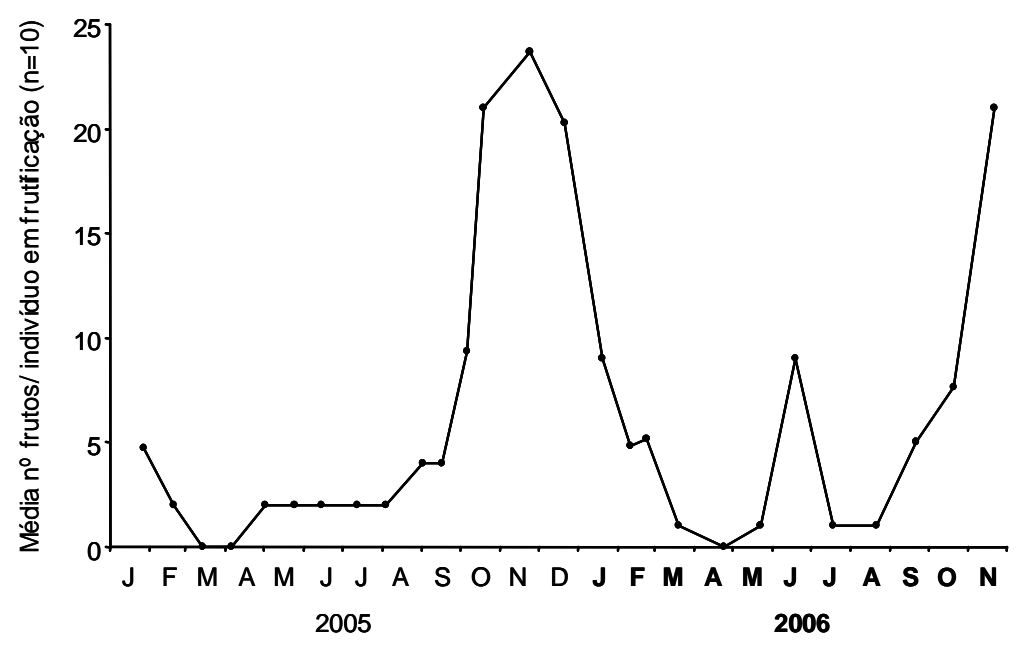

Figura 15. Média do número de frutos por indivíduo de Syagrus petraea em frutificação, entre janeiro de 2005 e novembro de 2006.

Conforme descrito na seção "Material \& Métodos", foram coletados alguns frutos para as análises morfométricas. Como estes frutos foram coletados de outros indivíduos que não aqueles designados ao acompanhamento fenológico, foi possível aumentar o número amostral para estimar a média de frutos encontrados por indivíduo, tomando por base a coleta realizada em janeiro de 2006, período de pico de atividade da fenofase de frutificação de Syagrus petraea (Figura 10). Em 19 de janeiro de 2006, foram encontrados 23 indivíduos em frutificação, incluindo aqueles do acompanhamento fenológico e os que forneceram frutos para as medidas morfométricas, com uma média de 6,13 \pm 5,93 frutos por indivíduo; o máximo valor encontrado foi 21, e o mínimo foi um fruto.

Considerando este valor médio de 6,13 frutos por indivíduo de $S$. petraea em janeiro e a densidade média de 0,024 indivíduo por $\mathrm{m}^{2}$, encontra-se uma disponibilidade média de 0,1471 frutos por $\mathrm{m}^{2}$ (ou 1.471 frutos por ha) no pico de atividade de frutificação. 


\section{B) REDUNDÂNCIA TEMPORAL}

Batalha (1997) registrou 499 espécies de angiospermas no Cerrado Pé-de-Gigante. Deste total, 301 espécies ocorreram na fitofisionomia de cerrado sensu stricto (segundo a classificação adotada pelo autor), além de Attalea geraensis e Syagrus petraea (anexo I).

De acordo com os dados fenológicos disponíveis no trabalho supra-citado, nota-se que a frutificação na comunidade considerada foi bastante regular durante o período de estudo. Não há um pico de frutificação bem definido, mas nota-se um decréscimo da atividade de frutificação em agosto. Comportamento semelhante foi constatado para a floração (Figura 16).

O autor não encontrou nenhum indivíduo de Attalea geraensis com frutos durante todo o período de estudo, ao passo que Syagrus petraea foi registrada com frutos em dezembro, padrão semelhante ao encontrado no presente trabalho.

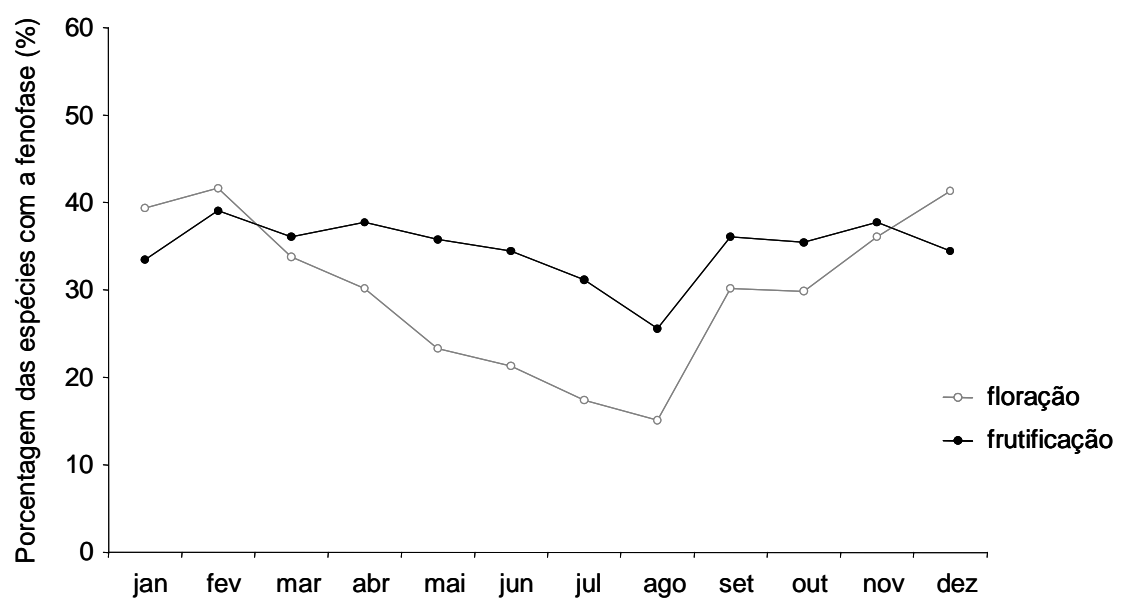

Figura 16. Porcentagem do número de angiospermas ( $\mathrm{n}=301$ espécies - as duas espécies de palmeiras foram retiradas) encontradas em cerrado sensu stricto, no Cerrado Pé-de-Gigante, apresentando as fenofases de floração e frutificação entre setembro de 1995 e fevereiro de 1997 (dados de Batalha 1997).

Dentre as 301 espécies de angiospermas encontradas no cerrado sensu stricto do Cerrado Pé-de-Gigante, 99 espécies, além de A. geraensis e S. petraea, têm frutos carnosos. Considerando somente estas espécies com frutos carnosos, há uma sazonalidade bem marcada na disponibilidade deste recurso (Figura 17). Nota-se uma maior produção de frutos carnosos nos meses mais úmidos - entre novembro e fevereiro - do que na estação seca. 


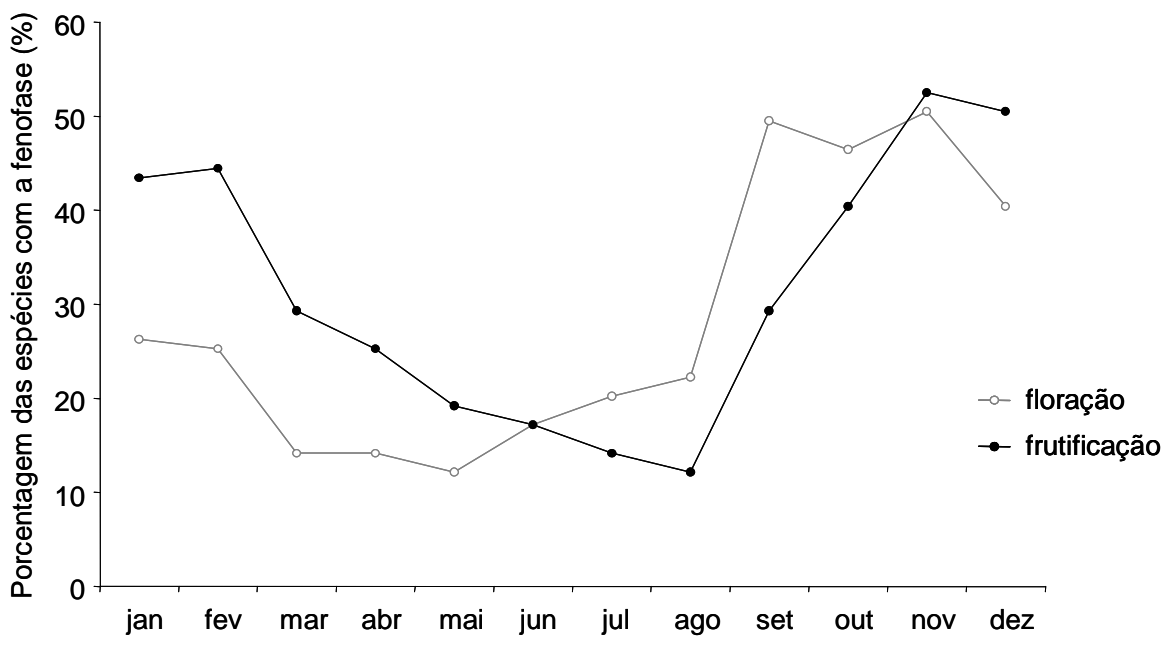

Figura 17. Porcentagem do número de angiospermas com frutos carnosos ( $\mathrm{n}=99$ espécies - as duas espécies de palmeiras foram retiradas) encontradas em cerrado sensu stricto, no Cerrado Pé-deGigante, apresentando as fenofases de floração e frutificação entre setembro de 1995 e fevereiro de 1997 (dados de Batalha 1997).

No trabalho desenvolvido no Cerrado de Emas (Pirassununga, SP), Batalha et al. (1997) estudaram as variações fenológicas de 358 espécies, entre abril de 1994 e abril de 1995. Deste total, foram selecionadas as angiospermas comuns ao cerrado sensu stricto do Cerrado Pé-de-Gigante, o que resultou em um total de 191 espécies consideradas (anexo II). Nota-se que $A$. geraensis e $S$. petraea não foram encontradas no Cerrado de Emas, no entanto, a análise das demais espécies permitiu uma melhor caracterização do comportamento fenológico das plantas nos cerrados paulistas, possibilitando considerações e comparações com os dados fenológicos coletados neste trabalho.

A frutificação da comunidade no Cerrado de Emas, considerando as 191 espécies selecionadas, apresentou certa variação durante o ano, havendo um período de maior atividade de frutificação entre outubro e junho, especialmente entre março e maio, e um período de menor atividade entre julho e setembro. Padrão semelhante também foi encontrado para a floração (Figura 18). 


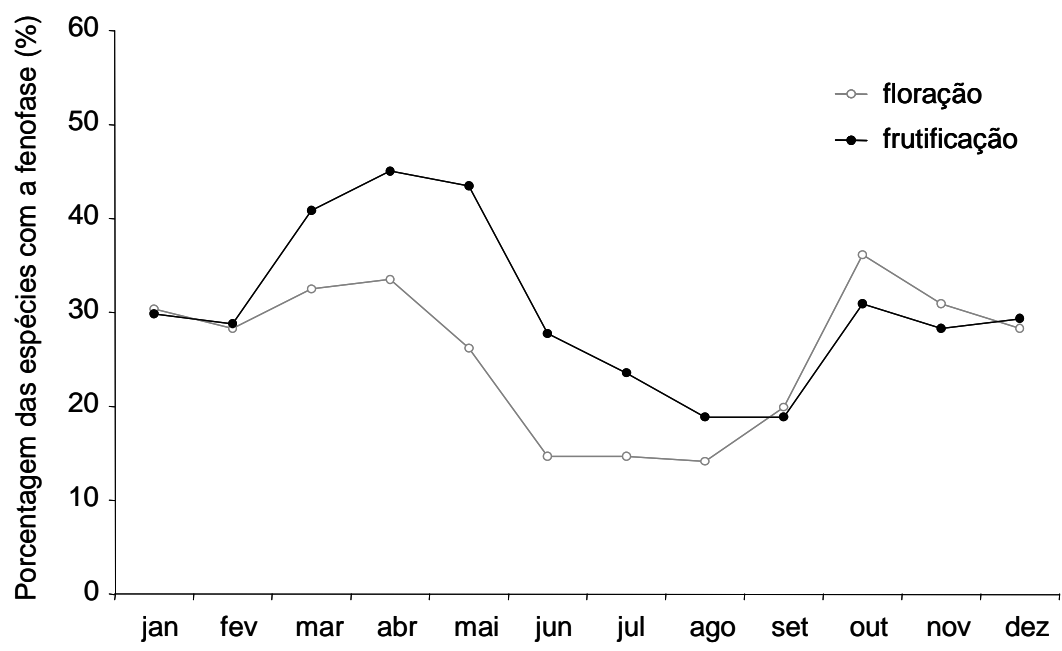

Figura 18. Porcentagem do número de angiospermas ( $n=191$ espécies) encontradas no Cerrado de Emas (em comum com o cerrado sensu stricto no Cerrado Pé-de-Gigante) apresentando as fenofases de floração e frutificação entre abril de 1994 e abril de 1995 (dados de Batalha et al. 1997).

Dentre as 191 espécies de angiospermas encontradas em comum entre o Cerrado de Emas e a fisionomia de cerrado sensu stricto do Cerrado Pé-de-Gigante, 71 espécies possuem síndrome de dispersão zoocórica, com frutos carnosos. Novamente, observa-se um período de maior atividade de frutificação entre outubro e abril, e um período de menor atividade entre os meses de maio e setembro (Figura 19).

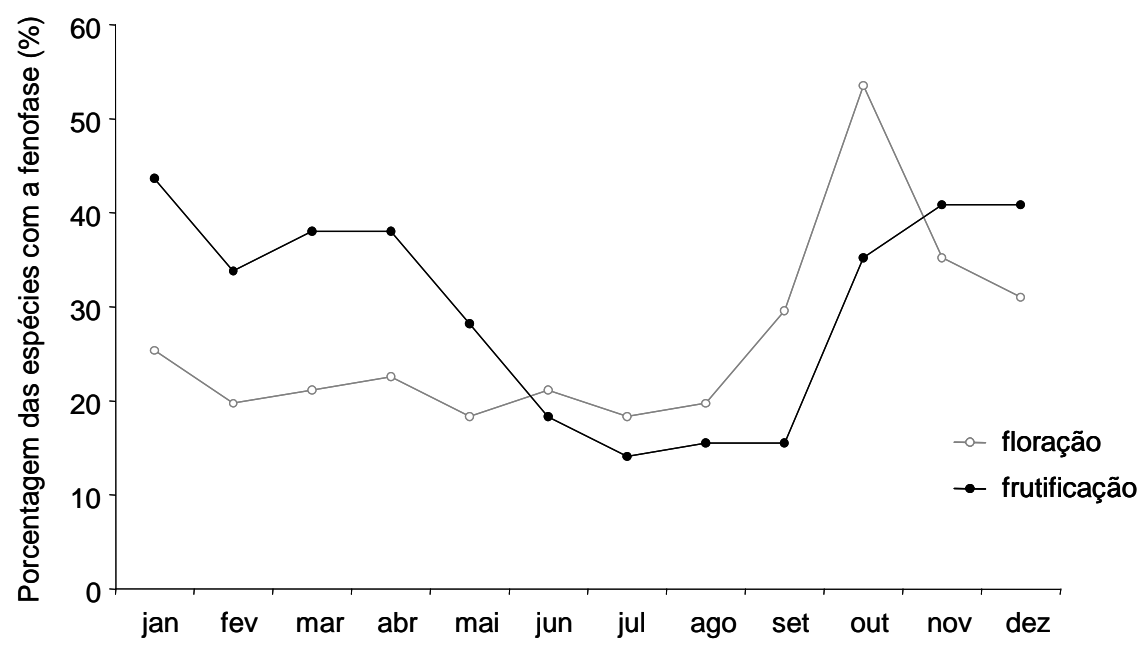

Figura 19. Porcentagem do número de angiospermas com frutos carnosos ( $\mathrm{n}=71$ espécies) encontradas no Cerrado de Emas (em comum com o cerrado sensu stricto no Cerrado Pé-deGigante) apresentando as fenofases de floração e frutificação entre abril de 1994 e abril de 1995 (dados de Batalha et al. 1997).

Qualquer comparação entre as fenologias reprodutivas da comunidade do Cerrado Pé-de-Gigante e do Cerrado de Emas com a disponibilidade de frutos de A. geraensis identificada no presente trabalho fica prejudicada, já que somente um fruto foi produzido durante todo o acompanhamento fenológico. Este único fruto foi produzido em abril de 2006 e permaneceu na planta até o final do acompanhamento, em novembro (Figura 20). 


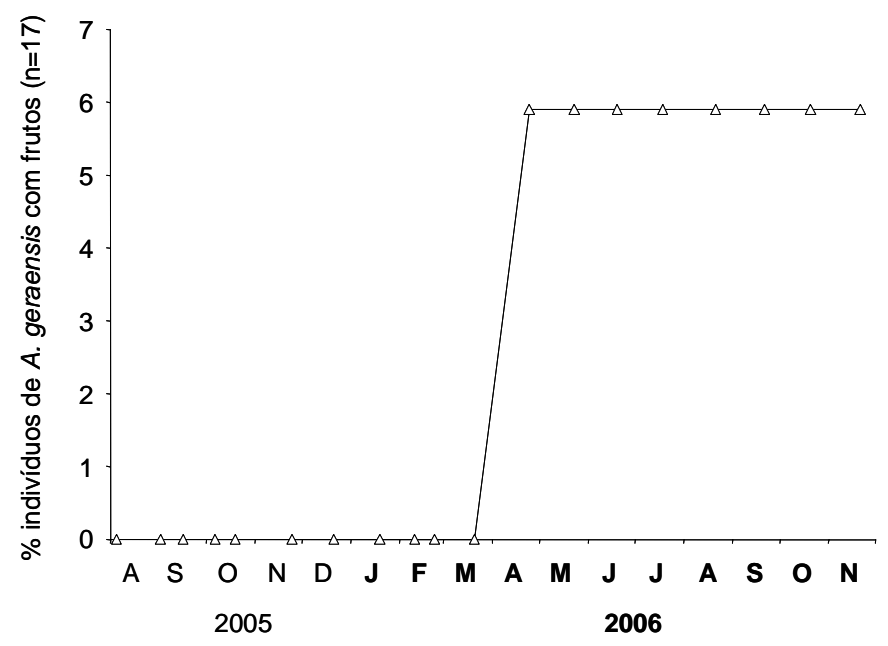

Figura 20: Porcentagem do número de indivíduos de Attalea geraensis $(\mathrm{n}=17)$ na fenofase de frutificação, entre agosto de 2005 e novembro de 2006.

Ambas as comunidades consideradas - cerrado sensu stricto do Cerrado Pé-deGigante e do Cerrado de Emas - apresentaram uma grande proporção das espécies com frutos carnosos frutificando entre outubro e fevereiro, intervalo que corresponde ao período de maior atividade de frutificação de Syagrus petraea (Figura 21).

Considerando o recurso "fruto", independentemente de seu caráter seco ou carnoso, a comunidade encontrada no cerrado sensu stricto do Cerrado Pé-de-Gigante é bastante regular, com cerca de 30\% das espécies frutificando durante todo o ano. Já no Cerrado de Emas, há diminuição na disponibilidade deste recurso entre junho e setembro, quando $S$. petraea também reduz sua atividade de frutificação.

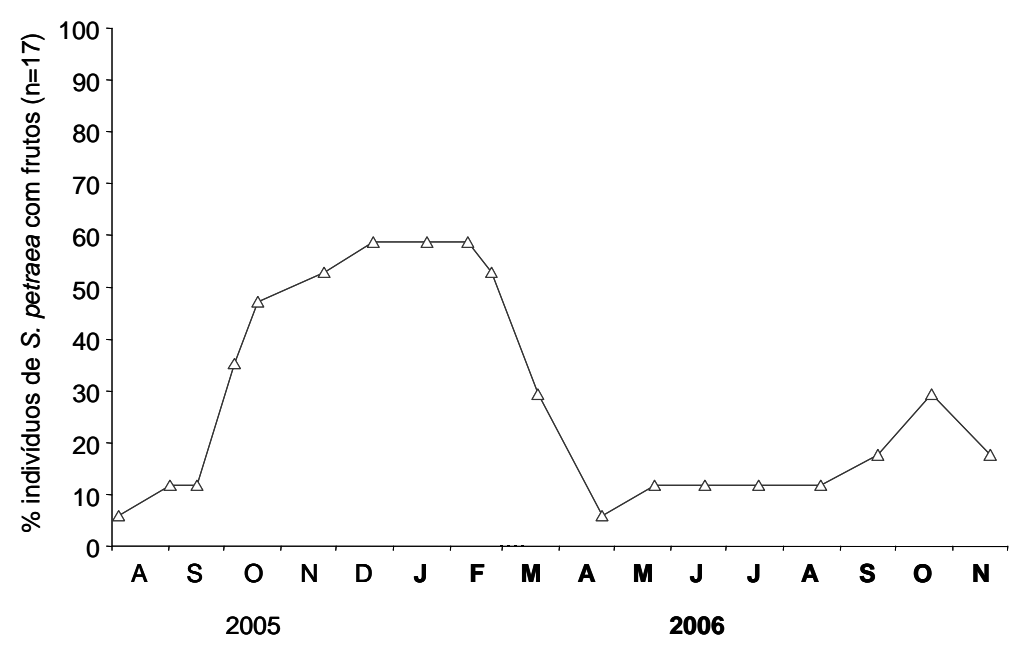

Figura 21: Porcentagem do número de indivíduos de Syagrus petraea $(\mathrm{n}=17)$ na fenofase de frutificação, entre agosto de 2005 e novembro de 2006. 


\section{C) MORFOMETRIA E CONTEÚdo NUTRICIONAL}

Os frutos maduros de Syagrus petraea têm, em média, 21,35 mm de comprimento e 15,35 mm de maior diâmetro (Tabela 3). Nota-se um coeficiente de variação de 14,64 \% e 17,83\%, respectivamente para as medidas de comprimento e diâmetro, valores relativamente baixos quando se considera o fato de que os frutos são provenientes de indivíduos diferentes e não foram cultivados ou realizados tratos culturais.

Tabela 3. Medidas morfométricas (comprimento e diâmetro), massa (fresca e seca) e porcentagem de água (relativa à massa fresca) de 54 frutos coletados entre 16 indivíduos de Syagrus petraea. Os asteriscos $(*)$ indicam os frutos destinados à análise de composição nutricional. CV = coeficiente de variação, expresso em porcentagem, e definido como a razão entre o desvio padrão e a média (Zar 1996).

\begin{tabular}{|c|c|c|c|c|c|}
\hline $\begin{array}{c}\text { Indivíduo } \\
\text { (fruto) }\end{array}$ & $\begin{array}{c}\text { Comprimento } \\
\text { (mm) }\end{array}$ & $\begin{array}{c}\text { Diâmetro } \\
\text { (mm) }\end{array}$ & $\begin{array}{c}\text { Massa fresca } \\
\text { (g) }\end{array}$ & $\begin{array}{c}\text { Massa seca } \\
\text { (g) }\end{array}$ & \% água \\
\hline 1 (a) & 18,35 & 16,15 & 2,822 & 1,501 & 46,80 \\
\hline 1 (b) & 18,85 & 17,30 & 3,333 & 1,488 & 55,35 \\
\hline 1 (c) & 18,70 & 16,10 & 2,676 & 1,412 & 47,23 \\
\hline 1 (d) & 18,00 & 15,80 & 2,259 & 1,166 & 48,38 \\
\hline 2 (a) & 20,95 & 17,30 & 3,628 & 1,867 & 48,53 \\
\hline 2 (b) & 20,50 & 17,30 & 3,283 & 1,620 & 50,66 \\
\hline 2 (c) & 20,55 & 17,45 & 3,531 & 1,755 & 50,30 \\
\hline $3(\mathrm{a})^{*}$ & 20,40 & 11,70 & 2,927 & 1,575 & 46,18 \\
\hline 3 (b)* & 21,35 & 11,10 & 3,211 & 1,684 & 47,55 \\
\hline 3 (c)* & 21,00 & 11,30 & 3,273 & 1,746 & 46,65 \\
\hline 4 (a) & 19,15 & 13,50 & 1,980 & 1,004 & 49,31 \\
\hline 4 (b) & 19,15 & 13,90 & 2,124 & 1,027 & 51,66 \\
\hline 4 (c) & 18,05 & 12,35 & 1,502 & 0,699 & 53,48 \\
\hline $4(\mathrm{~d})$ & 16,15 & 11,85 & 1,321 & 0,690 & 47,81 \\
\hline $4(\mathrm{e})$ & 19,30 & 12,30 & 1,647 & 0,778 & 52,78 \\
\hline $4(\mathrm{f})$ & 12,95 & 9,90 & 0,748 & 0,372 & 50,31 \\
\hline $5(\mathrm{a})^{*}$ & 24,20 & 13,75 & 2,547 & 1,446 & 43,22 \\
\hline 5 (b)* & 22,75 & 13,80 & 2,553 & 1,365 & 46,53 \\
\hline 5 (c)* & 23,25 & 13,75 & 2,493 & 1,380 & 44,66 \\
\hline $5(\mathrm{~d}) *$ & 23,25 & 13,30 & 2,331 & 1,361 & 41,61 \\
\hline $6(\mathrm{a}) *$ & 22,45 & 17,45 & 3,705 & 1,994 & 46,17 \\
\hline $6(\mathrm{~b})^{*}$ & 22,00 & 16,80 & 3,407 & 1,809 & 46,91 \\
\hline $7(\mathrm{a}) *$ & 21,90 & 12,40 & 3,454 & 1,610 & 53,40 \\
\hline 7 (b)* & 21,30 & 18,85 & 4,068 & 1,790 & 55,99 \\
\hline $8(a)^{*}$ & 20,95 & 18,70 & 3,751 & 1,512 & 59,71 \\
\hline $8(\mathrm{~b})^{*}$ & 20,60 & 16,75 & 2,812 & 1,318 & 53,12 \\
\hline $8(\mathrm{c})^{*}$ & 21,25 & 16,55 & 3,837 & 1,705 & 55,55 \\
\hline 9 (a) & 24,20 & 23,15 & 7,506 & 2,764 & 63,18 \\
\hline 9 (b) & 22,25 & 19,55 & 5,463 & 2,072 & 62,08 \\
\hline 9 (c) & 23,30 & 20,70 & 5,626 & 2,160 & 61,61 \\
\hline $10(\mathrm{a})^{*}$ & 25,85 & 18,60 & 5,162 & 2,505 & 51,48 \\
\hline $10(\mathrm{~b})^{*}$ & 26,45 & 16,55 & 4,056 & 1,960 & 51,69 \\
\hline $10(\mathrm{c})^{*}$ & 28,20 & 17,80 & 5,362 & 2,608 & 51,35 \\
\hline $10(\mathrm{~d})^{*}$ & 27,15 & 17,45 & 4,582 & 2,256 & 50,78 \\
\hline $10(\mathrm{e})^{*}$ & 27,30 & 17,70 & 4,344 & 1,960 & 54,89 \\
\hline $10(\mathrm{f})^{*}$ & 24,70 & 17,20 & 4,195 & 1,976 & 52,89 \\
\hline $11(\mathrm{a})^{*}$ & 18,20 & 14,65 & 2,269 & 1,184 & 47,85 \\
\hline
\end{tabular}


Tabela 3 - Continuação

\begin{tabular}{|c|c|c|c|c|c|}
\hline $\begin{array}{c}\text { Indivíduo } \\
\text { (fruto) }\end{array}$ & $\begin{array}{c}\text { Comprimento } \\
(\mathrm{mm})\end{array}$ & $\begin{array}{l}\text { Diâmetro } \\
(\mathrm{mm})\end{array}$ & $\begin{array}{c}\text { Massa fresca } \\
(\mathrm{g})\end{array}$ & $\begin{array}{c}\text { Massa seca } \\
\text { (g) }\end{array}$ & \% água \\
\hline $11(\mathrm{~b})^{*}$ & 18,00 & 15,70 & 2,624 & 1,427 & 45,63 \\
\hline $11(\mathrm{c})^{*}$ & 18,25 & 13,30 & 2,028 & 1,107 & 45,42 \\
\hline $12(\mathrm{a}) *$ & 23,80 & 15,90 & 3,066 & 1,638 & 46,58 \\
\hline $12(\mathrm{~b}) *$ & 25,00 & 15,40 & 3,254 & 1,677 & 48,48 \\
\hline $12(\mathrm{c})^{*}$ & 24,75 & 15,20 & 3,085 & 1,573 & 49,02 \\
\hline $13(\mathrm{a}) *$ & 19,45 & 17,65 & 3,615 & 1,709 & 52,74 \\
\hline $13(\mathrm{~b}) *$ & 19,80 & 18,80 & 4,393 & 2,091 & 52,41 \\
\hline $14(\mathrm{a}) *$ & 17,50 & 14,30 & 2,005 & 0,936 & 53,34 \\
\hline $14(\mathrm{~b}) *$ & 17,60 & 15,00 & 2,252 & 1,025 & 54,50 \\
\hline $14(\mathrm{c})^{*}$ & 17,65 & 13,20 & 1,783 & 0,770 & 56,83 \\
\hline 15 (a) & 22,50 & 13,20 & 1,999 & 0,646 & 67,69 \\
\hline 15 (b) & 23,70 & 13,80 & 2,476 & 1,421 & 42,62 \\
\hline 15 (c) & 22,10 & 14,00 & 2,603 & 1,474 & 43,36 \\
\hline 15 (d) & 24,30 & 14,00 & 2,507 & 1,442 & 42,48 \\
\hline 16 (a) & 22,20 & 11,10 & 2,935 & 1,233 & 58,00 \\
\hline 16 (b) & 24,35 & 16,40 & 3,402 & 1,500 & 55,93 \\
\hline $16(\mathrm{c})$ & 17,20 & 11,35 & 1,185 & 0,547 & 53,83 \\
\hline $\begin{array}{l}\text { Média } \pm \text { desvio } \\
\text { padrão }\end{array}$ & $21,35 \pm 3,13$ & $15,35 \pm 2,74$ & $3,130 \pm 1,240$ & $\begin{array}{c}1,506 \pm \\
0,512\end{array}$ & $51,05 \pm 5,57$ \\
\hline $\mathrm{CV}(\%)$ & 14,64 & 17,83 & 39,627 & 33,982 & 10,91 \\
\hline
\end{tabular}

Os valores de massa fresca e massa seca variaram um pouco mais entre os frutos, o coeficiente de variação ficou entre $30 \%$ e $40 \%$. Já a porcentagem de água presente no material fresco (média de $51 \%$ ) permaneceu mais constante entre os diferentes frutos coletados $(\mathrm{CV}=10,91 \%)$.

Os frutos destinados às análises de composição nutricional constituem uma amostragem mais homogênea (Tabela 4), em que os coeficientes de variação são um pouco mais baixos, e os frutos ligeiramente maiores em média, quando comparada à amostragem total de 54 frutos.

Tabela 4. Medidas morfométricas, massas fresca e seca e porcentagem de água (relativa à massa fresca) dos 31 frutos de Syagrus petraea destinados à análise de composição nutricional. CV = coeficiente de variação, expresso em porcentagem, e definido como a razão entre o desvio padrão e a média (Zar 1996).

\begin{tabular}{cccccc}
\hline & $\begin{array}{c}\text { Comprimento } \\
(\mathbf{m m})\end{array}$ & $\begin{array}{c}\text { Diâmetro } \\
(\mathbf{m m})\end{array}$ & $\begin{array}{c}\text { Massa fresca } \\
(\mathbf{g})\end{array}$ & $\begin{array}{c}\text { Massa seca } \\
(\mathbf{g})\end{array}$ & \% água \\
\hline $\begin{array}{c}\text { Média } \pm \text { desvio } \\
\text { padrão }\end{array}$ & $22,14 \pm 3,08$ & $15,50 \pm 2,31$ & $3,305 \pm 0,928$ & $1,635 \pm 0,422$ & $50,10 \pm 4,42$ \\
\hline CV $(\%)$ & 13,93 & 14,92 & 28,072 & 25,805 & 8,82 \\
\hline
\end{tabular}

O endosperma dos frutos contém mais lipídios do que a "polpa" (teste de Wilcoxon: $Z=-2,803, n=10, p=0,005)$, sendo que esta fração corresponde a cerca de $55 \%$ da massa seca de endosperma e a apenas 10\% da massa seca de "polpa" (Tabela 5). 
O endosperma também é mais rico que a "polpa" em proteínas solúveis totais $(\mathrm{Z}=$ $-2,803, \mathrm{n}=10, \mathrm{p}=0,005)$, sendo que, em média, 2,5\% da massa seca de endosperma corresponde às proteínas solúveis, fração que constitui apenas $0,26 \%$ da matéria seca de "polpa”, em média (Tabela 5).

A “polpa” dos frutos possui mais açúcares solúveis que o endosperma $(Z=-2,497$, $\mathrm{n}=10, \mathrm{p}=0,013)$, correspondendo a aproximadamente $22 \%$ do material seco no caso da "polpa" e a pouco mais de 11\% no caso do endosperma, em média (Tabela 5).

A massa de resíduos após as extrações foi significativamente maior no caso da "polpa", que é bastante fibrosa, do que no caso do endosperma $(Z=-2,803, n=10, p=$ 0,005), indicando que este último é majoritariamente constituído por lipídios, açúcares e proteínas solúveis. 
Tabela 5. Composição nutricional dos frutos maduros de Syagrus petraea ( $\mathrm{n}=31$ frutos, provenientes de 10 indivíduos). Valores expressos em mg.g-1 de massa seca de polpa ou endosperma.

\begin{tabular}{|c|c|c|c|c|c|c|c|c|c|c|}
\hline \multirow[t]{2}{*}{ Indivíduo } & \multicolumn{2}{|c|}{$\begin{array}{c}\text { Lipídios } \\
\left(\mathrm{mg} \cdot \mathrm{g}^{-1} \text { de massa seca) }\right.\end{array}$} & \multicolumn{2}{|c|}{$\begin{array}{c}\text { Açúcares } \\
\left(\mathrm{mg} \cdot \mathrm{g}^{-1} \text { de massa seca) }\right.\end{array}$} & \multicolumn{2}{|c|}{$\begin{array}{c}\text { Proteínas } \\
\left(\mathrm{mg} \cdot \mathrm{g}^{-1} \text { de massa seca }\right)\end{array}$} & \multicolumn{2}{|c|}{$\begin{array}{c}\text { Resíduos } \\
\left(\mathrm{mg} \cdot \mathrm{g}^{-1} \text { de massa seca) }\right. \\
\end{array}$} & \multicolumn{2}{|c|}{$\begin{array}{c}\text { Soma } \\
\left(\mathrm{mg} \cdot \mathrm{g}^{-1} \text { de massa seca) }\right.\end{array}$} \\
\hline & polpa & endosperma & polpa & endosperma & polpa & endosperma & polpa & endosperma & polpa & endosperma \\
\hline 3 & 87,5 & 318,5 & 124,5 & 87,1 & 1,5 & 24,8 & 719,6 & 432,18 & 933,1 & 862,6 \\
\hline 5 & 53,8 & 571,7 & 122,5 & 147,3 & 4,1 & 6,6 & 700,9 & 291,22 & 881,3 & 1016,8 \\
\hline 6 & 40,9 & 636,9 & 182,5 & 77,2 & 1,7 & 29,1 & 663,0 & 204,68 & 888,1 & 947,9 \\
\hline 7 & 180,0 & 595,4 & 405,6 & 119,1 & 2,7 & 35,2 & 472,3 & 214,34 & 1060,6 & 964,0 \\
\hline 8 & 125,9 & 488,3 & 380,1 & 112,3 & 2,5 & 26,2 & 581,1 & 318,82 & 1089,6 & 945,6 \\
\hline 10 & 76,0 & 507,5 & 177,5 & 156,3 & 1,6 & 18,1 & 693,0 & 272,85 & 948,1 & 954,8 \\
\hline 11 & 36,9 & 546,3 & 84,0 & 82,3 & 1,1 & 30,8 & 535,2 & 274,35 & 657,2 & 933,8 \\
\hline 12 & 79,9 & 630,5 & 177,2 & 136,3 & 4,3 & 21,4 & 641,5 & 191,35 & 902,9 & 979,6 \\
\hline 13 & 124,9 & 651,3 & 347,4 & 97,6 & 3,9 & 23,1 & 493,8 & 193,39 & 970,0 & 965,4 \\
\hline 14 & 150,7 & 538,5 & 216,9 & 144,6 & 2,2 & 36,1 & 554,6 & 282,87 & 924,4 & 1002,1 \\
\hline $\begin{array}{l}\text { Média } \pm \\
\text { desv. pad. }\end{array}$ & $\begin{array}{c}95,7 \pm \\
48,1\end{array}$ & $\begin{array}{c}548,5 \pm \\
97,8\end{array}$ & $\begin{array}{c}221,8 \pm \\
114,7\end{array}$ & $\begin{array}{c}116,0 \pm \\
29,2\end{array}$ & $\begin{array}{c}2,6 \pm \\
1,2\end{array}$ & $\begin{array}{c}25,2 \pm \\
8,7\end{array}$ & $\begin{array}{c}605,5 \pm \\
89,9\end{array}$ & $\begin{array}{c}267,6 \pm \\
73,6\end{array}$ & $\begin{array}{c}925,5 \pm \\
117,2\end{array}$ & $\begin{array}{c}957,2 \pm \\
42,0\end{array}$ \\
\hline
\end{tabular}




\section{D) VERTEBRADOS CONSUMIDORES DOS FRUTOS DE ATTALEA GERAENSIS E SYAGRUS PETRAEA}

As câmeras fotográficas automáticas registraram alguns roedores, marsupiais, tamanduá-bandeira, duas espécies de lagarto e três de aves (Tabela 6; anexo III). No entanto, nem todos os visitantes consumiram os frutos. No caso de $A$. geraensis, o único fruto produzido não foi consumido. Portanto, os únicos consumidores identificados referem-se aos frutos de S. petraea e foram os seguintes: Cyanocorax chrysops (Aves: Corvidae), Didelphis albiventris (Marsupialia: Didelphidae), Micoureus paraguayanus (Marsupialia: Didelphidae) e Cerradomys subflavus (Rodentia: Muridae).

Tabela 6. Animais registrados pelas armadilhas fotográficas durante todo o período de exposição (14/junho/2005 a 21/novembro/2006). A categoria "visitante" refere-se aos animais que foram fotografados, mas não consumiram os frutos; "consumidor" refere-se aos animais registrados que consumiram os frutos de $S$. petraea; o traço (-) significa ausência de informação.

\begin{tabular}{|c|c|c|c|c|c|}
\hline Classe & Ordem & Família & Nome científico & $\begin{array}{l}\text { Nome } \\
\text { popular }\end{array}$ & Categoria \\
\hline Reptilia & Squamata & Teiidae & Tupinambis merianae & Teiú & visitante \\
\hline Reptilia & Squamata & Teiidae & Ameiva ameiva & Calango-verde & visitante \\
\hline Aves & Passeriformes & Corvidae & Cyanocorax chrysops & $\begin{array}{c}\text { Gralha do } \\
\text { cerrado }\end{array}$ & consumidor \\
\hline Aves & Gruiformes & Cariamidae & Cariama cristata & Seriema & visitante \\
\hline Aves & Tinamiformes & Tinamidae & Crypturellus sp. & - & visitante \\
\hline Mammalia & Rodentia & não identificado & não identificado & $\begin{array}{c}\text { não } \\
\text { identificado }\end{array}$ & consumidor \\
\hline Mammalia & Rodentia & Muridae & Cerradomys subflavus & Rato-do-Mato & consumidor \\
\hline Mammalia & Rodentia & Muridae & Bolomys lasiurus & Rato-do-Mato & visitante \\
\hline Mammalia & Marsupialia & Didelphidae & Gracilinanus agilis & Cuíca & visitante \\
\hline Mammalia & Marsupialia & Didelphidae & Gracilinanus microtarsus & Cuíca & visitante \\
\hline Mammalia & Marsupialia & Didelphidae & Cryptonanus sp. & - & visitante \\
\hline Mammalia & Marsupialia & Didelphidae & Didelphis albiventris & Gambá & consumidor \\
\hline Mammalia & Marsupialia & Didelphidae & Micoureus paraguayanus & Cuíca & consumidor \\
\hline Mammalia & Xenarthra & Myrmecophagidae & Myrmecophaga tridactyla & $\begin{array}{c}\text { Tamanduá- } \\
\text { bandeira }\end{array}$ & visitante \\
\hline
\end{tabular}

Dentre as 45 plantas monitoradas, oito não foram acompanhadas até o consumo de seus frutos. Duas delas por problemas com as câmeras e impossibilidade de substituí-las e as demais, pelo encerramento das atividades de campo antes de possíveis eventos de remoção ou consumo de partes dos frutos (Tabela 7).

Durante todo o período de exposição das câmeras, foram detectados 40 eventos de consumo, dos quais somente 14 tiveram seus agentes identificados: cinco foram feitos por Didelphis albiventris, outros cinco foram feitos pela gralha-do-cerrado (Cyanocorax chrysops), três foram realizados por Cerradomys subflavus e um único evento de remoção foi feito por 
Micoureus paraguayanus (Tabela 7). Devido a problemas com o equipamento, não foi possível registrar a maioria dos consumidores.

Tabela 7. Períodos de exposição das câmeras fotográficas automáticas, números de frutos consumidos no período e agentes consumidores registrados e identificados.

\begin{tabular}{|c|c|c|c|c|c|}
\hline $\begin{array}{c}\text { Indivíduo } \\
\text { monitorado }\end{array}$ & Período & $\begin{array}{c}\mathrm{N}^{\circ} \mathrm{de} \\
\text { dias }\end{array}$ & $\begin{array}{c}\mathrm{N}^{\circ} \text { de frutos } \\
\text { inicial }\end{array}$ & $\begin{array}{l}\mathrm{N}^{\circ} \text { de frutos } \\
\text { consumidos }\end{array}$ & Agente \\
\hline 1 & $14 / 6 / 05$ a $4 / 8 / 05$ & 51 & 4 & 4 & não registrado \\
\hline 2 & $14 / 6 / 05$ a $19 / 10 / 05$ & 127 & 2 & 2 & D. albiventris \\
\hline 3 & $14 / 6 / 05$ a $16 / 9 / 05$ & 94 & 1 & 0 & defeito \\
\hline 4 & $15 / 6 / 05$ a $1 / 9 / 05$ & 78 & 1 & 1 & não registrado \\
\hline 5 & $15 / 6 / 05$ a $15 / 9 / 05$ & 92 & 2 & 2 & D. albiventris \\
\hline 6 & $15 / 6 / 05$ a $6 / 10 / 05$ & 113 & 9 & 9 & D. albiventris \\
\hline 7 & $1 / 9 / 05$ a $24 / 11 / 05$ & 84 & 11 & 11 & não registrado \\
\hline 8 & $2 / 9 / 05$ a $21 / 12 / 05$ & 110 & 4 & 4 & não registrado \\
\hline 9 & $2 / 9 / 05$ a $21 / 12 / 05$ & 110 & 3 & 3 & não registrado \\
\hline 10 & $15 / 9 / 05$ a $21 / 12 / 05$ & 97 & 11 & 11 & não registrado \\
\hline 11 & $15 / 9 / 05$ a $19 / 1 / 06$ & 126 & 9 & 9 & não registrado \\
\hline 12 & $16 / 9 / 05$ a $23 / 2 / 06$ & 160 & 17 & 15 & não registrado \\
\hline 13 & $6 / 10 / 05$ a $19 / 1 / 06$ & 105 & 8 & 8 & não registrado \\
\hline 14 & $21 / 12 / 05$ a $19 / 1 / 06$ & 29 & 3 & 0 & defeito \\
\hline 15 & $19 / 10 / 05$ a $19 / 1 / 06$ & 92 & 5 & 5 & não registrado \\
\hline 16 & $21 / 12 / 05$ a $19 / 1 / 06$ & 29 & 3 & 2 & não registrado \\
\hline 17 & $21 / 12 / 05$ a $20 / 3 / 06$ & 89 & 3 & 3 & não registrado \\
\hline 18 & $21 / 12 / 05$ a $23 / 2 / 06$ & 64 & 17 & 14 & C. chrysops \\
\hline 19 & 19/1/06 a 10/2/06 & 22 & 6 & 6 & C. chrysops \\
\hline 20 & $19 / 1 / 06$ a $23 / 2 / 06$ & 35 & 13 & 13 & não registrado \\
\hline 21 & $19 / 1 / 06$ a 10/2/06 & 22 & 19 & 19 & não registrado \\
\hline 22 & $19 / 1 / 06$ a $23 / 2 / 06$ & 35 & 10 & 10 & não registrado \\
\hline 23 & $19 / 1 / 06$ a $23 / 2 / 06$ & 35 & 6 & 6 & não registrado \\
\hline 24 & $19 / 1 / 06$ a 10/2/06 & 22 & 5 & 5 & não registrado \\
\hline 25 & $19 / 1 / 06$ a $23 / 2 / 06$ & 35 & 5 & 2 & não registrado \\
\hline 26 & $10 / 2 / 06$ a $24 / 4 / 06$ & 73 & 7 & 7 & não registrado \\
\hline 27 & $10 / 2 / 06$ a $24 / 4 / 06$ & 73 & 14 & 14 & não registrado \\
\hline 28 & $10 / 2 / 06$ a $24 / 4 / 06$ & 73 & 12 & 12 & não registrado \\
\hline 29 & $10 / 2 / 06$ a $23 / 5 / 06$ & 102 & 3 & 3 & C. subflavus \\
\hline 30 & $10 / 2 / 06$ a $23 / 2 / 06$ & 13 & 6 & 1 & não registrado \\
\hline 31 & $20 / 3 / 06$ a $24 / 4 / 06$ & 35 & 4 & 4 & não registrado \\
\hline 32 & $20 / 3 / 06$ a $21 / 9 / 06$ & 185 & 32 & 32 & D. albiventris, C. chrysops \\
\hline 33 & $20 / 3 / 06$ a $19 / 6 / 06$ & 91 & 26 & 26 & não registrado \\
\hline 34 & $20 / 3 / 06$ a $23 / 5 / 06$ & 64 & 4 & 4 & C. chrysops \\
\hline 35 & $24 / 4 / 06$ a $21 / 9 / 06$ & 150 & 6 & 5 & não registrado \\
\hline 36 & $23 / 5 / 06$ a $21 / 8 / 06$ & 90 & 6 & 6 & não registrado \\
\hline 37 & $23 / 5 / 06$ a 19/6/06 & 27 & 5 & 5 & $\begin{array}{c}\text { C. subflavus, D. albiventris, } \\
\text { M. paraguayanus }\end{array}$ \\
\hline 38 & $23 / 5 / 06$ a $21 / 8 / 06$ & 90 & 11 & 11 & $\begin{array}{l}\text { C. subflavus e não } \\
\text { identificado }\end{array}$ \\
\hline 39 & $23 / 5 / 06$ a $21 / 8 / 06$ & 90 & 4 & 4 & C. chrysops \\
\hline Total & $14 / 6 / 05$ a $21 / 9 / 06$ & - & 317 & 298 & 4 espécies \\
\hline
\end{tabular}


Além de ter sido, juntamente com a gralha-do-cerrado, o principal responsável pela remoção dos frutos de Syagrus petraea, Didelphis albiventris foi o animal com maior freqüência dentre todos os registros fotográficos (Figura 22). Este grande número de registros de $D$. albiventris em relação às demais espécies reforça a idéia de que esta espécie de gambá seja um dos principais consumidores dos frutos da palmeira $S$. petraea, na fitofisionomia estudada.

A gralha-do-cerrado (Cyanocorax chrysops), também responsável por cinco eventos de remoção, foi a espécie com a segunda maior freqüência nos registros, com 15 ocorrências. O roedor Cerradomys subflavus, outro consumidor, foi registrado 9 vezes e Micoureus paraguayanus, outra espécie de marsupial, foi registrado uma única vez, consumindo o fruto de S. petraea (Figura 23 C).

O número de visitas do teiú (Tupinambis merianae) também foi expressivo (Figura 22), sendo um indício de que este lagarto também seja um consumidor dos frutos de $S$. petraea. No entanto, nenhum dos registros de consumo foi atribuído a essa espécie, no presente trabalho.

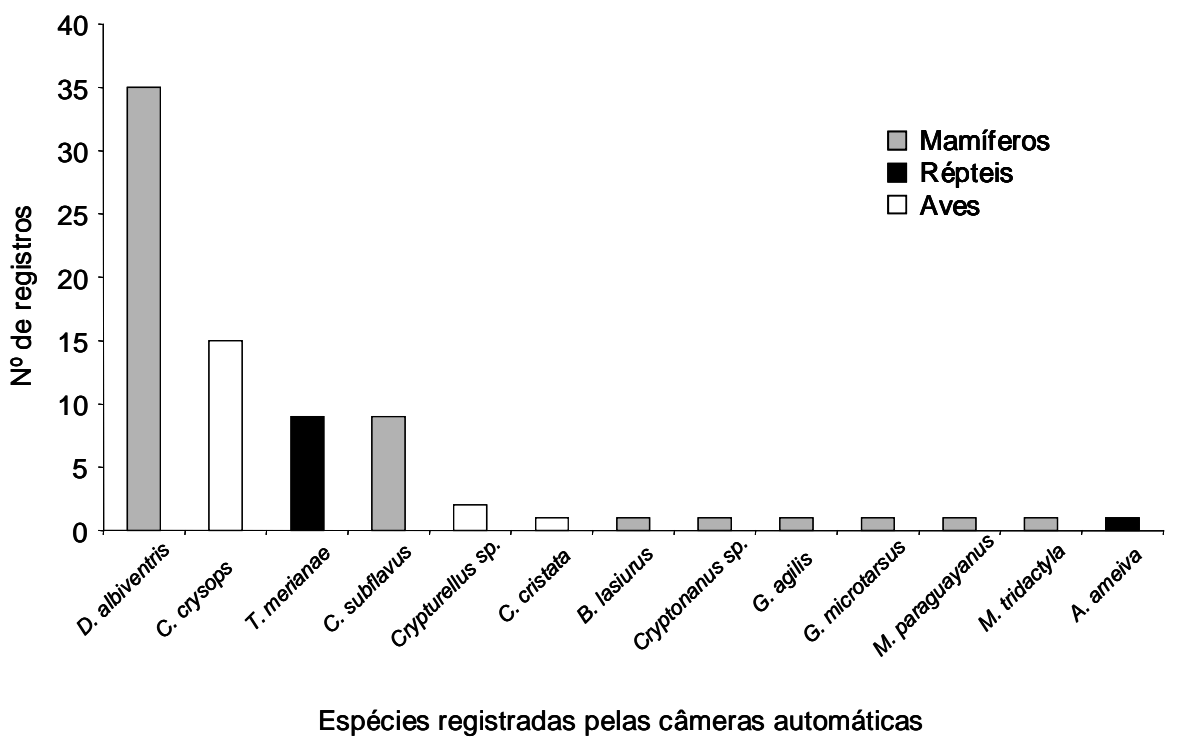

Figura 22. Número de registros correspondente a cada espécie fotografada e identificada (14/junho/2005 a 21/novembro/2006). Os nomes completos, bem como a classificação zoológica de cada espécie, encontram-se na tabela 6 .

Durante todo o período de exposição das câmeras fotográficas, obtiveram-se 103 registros fotográficos de animais, dos quais cerca de $20 \%$ não foram identificados. Na maioria dos casos, estes animais não identificados eram pequenos mamíferos classificados como "visitantes" das palmeiras, mas um dos roedores foi fotografado consumindo os frutos e não pôde ser identificado. 
Os animais considerados "consumidores" - C. chrysops, D. albiventris, M. paraguayanus e C. subflavus- foram todos fotografados manipulando os frutos da palmeira (Figura 23).
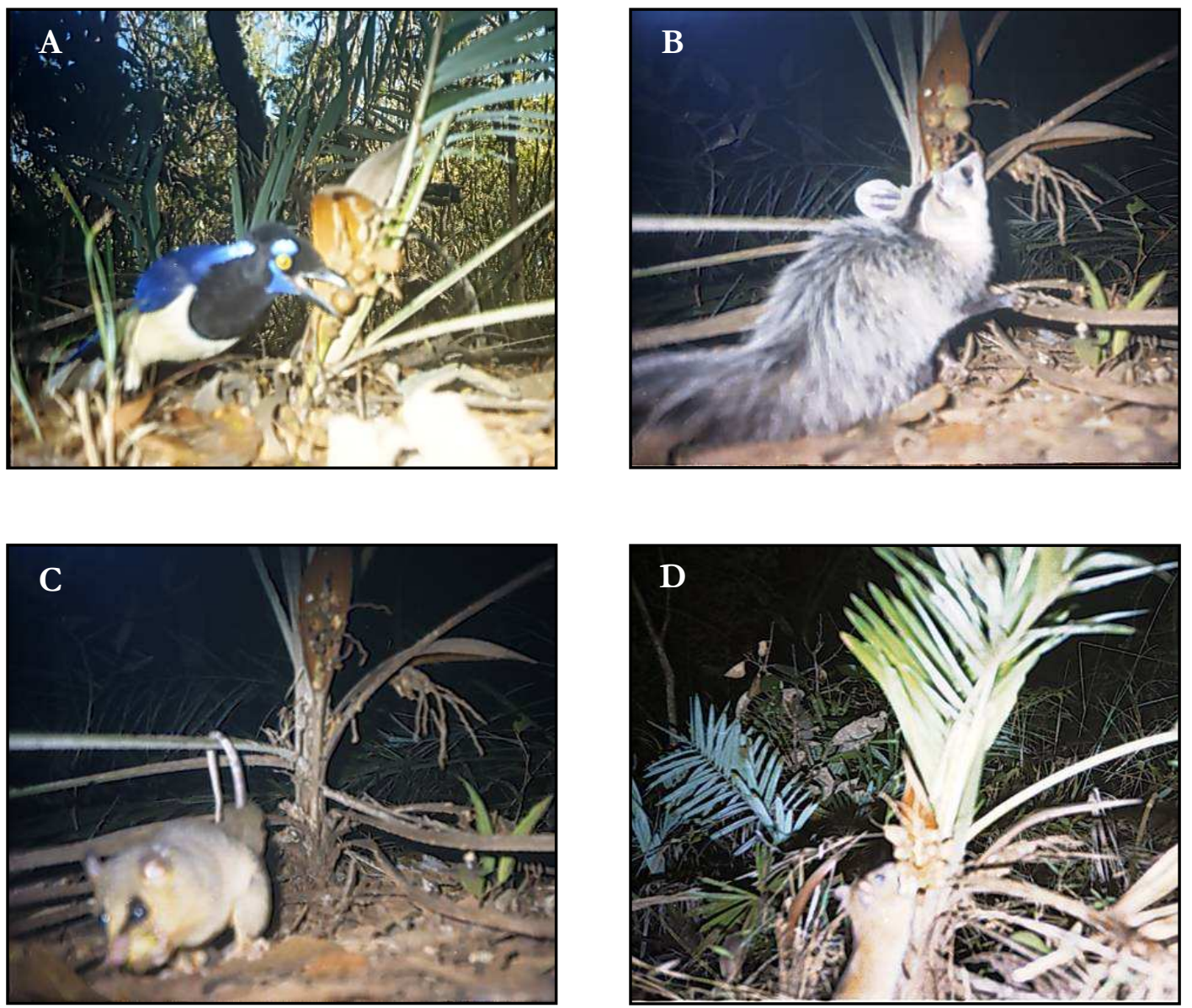

Figura 23. Consumidores dos frutos de Syagrus petraea (Arecaceae). A. Cyanocorax chrysops (Aves: Corvidae). B. Didelphis albiventris (Marsupialia: Didelphidae). C. Micoureus paraguayanus (Marsupialia: Didelphidae). D. Cerradomys subflavus (Rodentia: Muridae).

Durante as verificações das câmeras automáticas em campo, ocasionalmente foram vistos endocarpos limpos de Syagrus petraea no solo, próximos à planta parental, indicando que algum animal consumiu somente a "polpa" e descartou os endocarpos intactos no próprio local (Figura 24). As câmeras não conseguiram registrar o agente em nenhum desses episódios.

Em alguns casos de consumo dos frutos de $S$. petraea por D. albiventris registrados pelas câmeras, encontraram-se, na ocasião das verificações dos equipamentos, alguns frutos ainda na planta parental, mas com a "polpa" totalmente removida (Figura 25), indicando que esta espécie de gambá consome a "polpa" e não o endosperma desses frutos. Em alguns dos registros fotográficos também é possível ver os frutos despolpados ainda nas palmeiras, imediatamente após ter ocorrido o registro de $D$. albiventris como consumidor. 

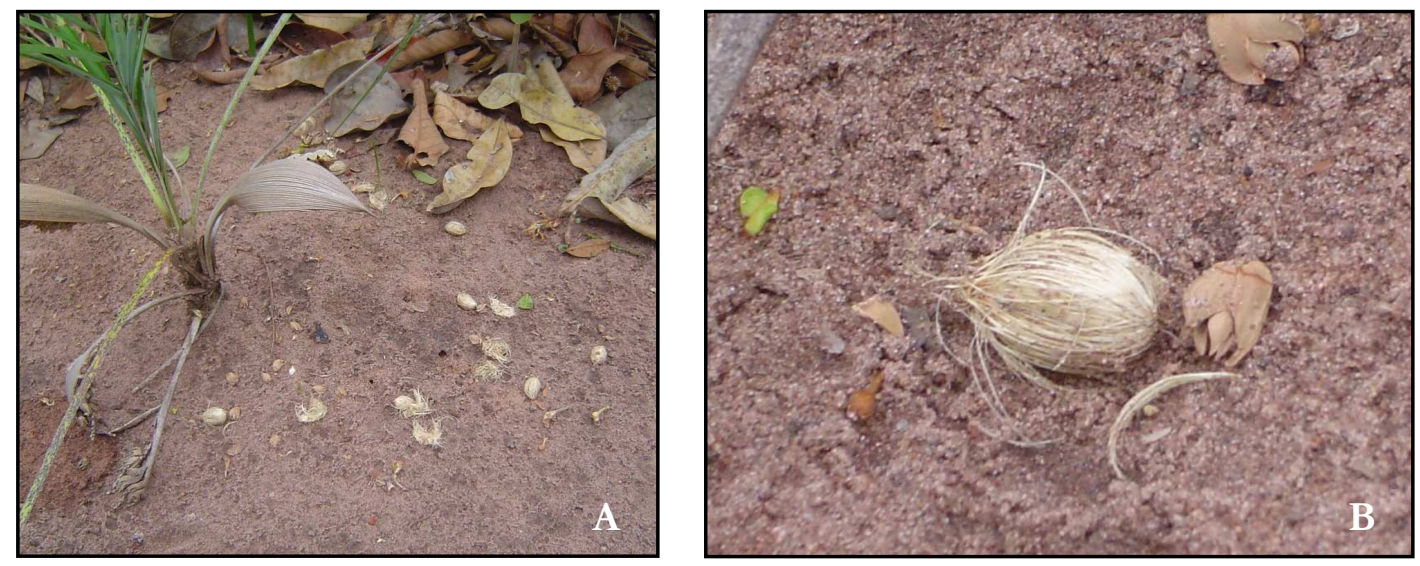

Figura 24. Endocarpos limpos de Syagrus petraea: a "polpa" dos frutos foi removida por um consumidor não identificado. A. Endocarpos limpos de $S$. petraea próximo à planta parental. B. Detalhe de um dos endocarpos (Fotos: Mariana M. Vidal).

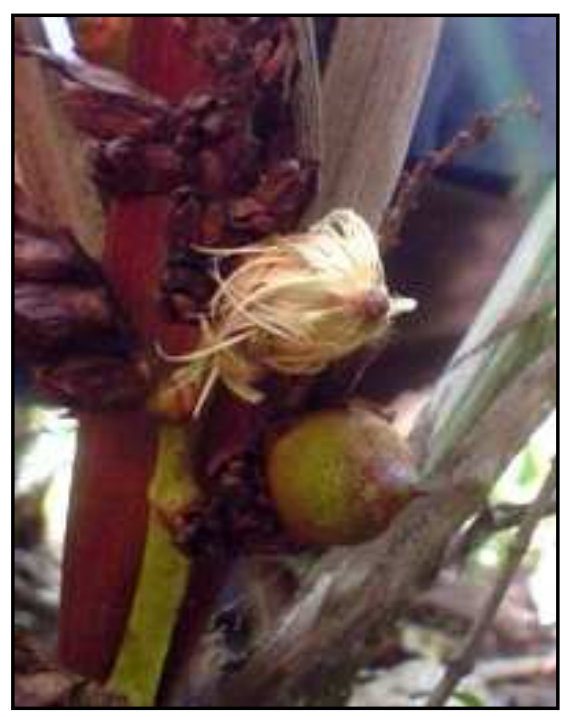

Figura 25. Fruto de Syagrus petraea cuja "polpa" foi removida por D. albiventris (Marsupialia: Didelphidae). O fruto despolpado permaneceu na planta (Foto: Leandro R. Tambosi).

Em uma outra ocasião, foram encontrados próximos à planta parental, endocarpos de Syagrus petraea com marcas de dentes de roedores e sem o endosperma (figura 26). Não foi possível identificar o consumidor através de registros fotográficos, nem se ele consumiu, além do endosperma, a "polpa" dos frutos. 


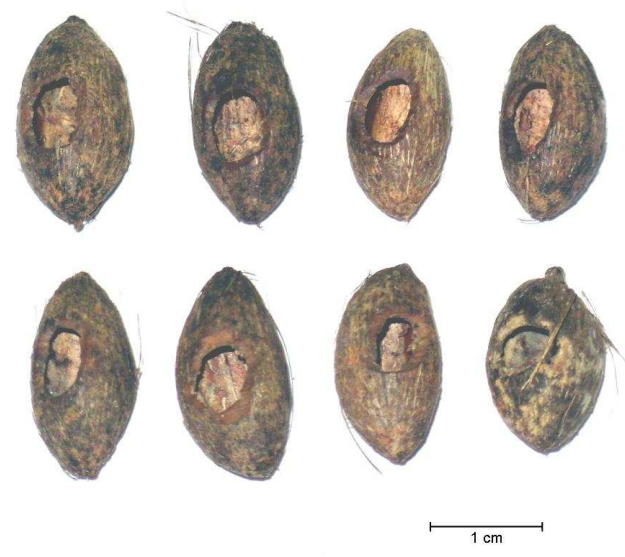

Figura 26. Endocarpos de Syagrus petraea com marcas de dentes de uma espécie de roedor, que rompeu o endocarpo lenhoso e consumiu o endosperma (Foto: Daniela M. Castro). 


\section{DISCUSSÃo}

\section{A) AbundânCia de RECURSo}

Abundância de indivíduos adultos de Attalea geraensis e Syagrus petraea

O presente estudo encontrou densidades médias de 0,006 e 0,024 indivíduo $/ \mathrm{m}^{2}$ para as populações de Attalea geraensis e Syagrus petraea, respectivamente. Como Syagrus petraea pode apresentar caules subterrâneos múltiplos, os valores de densidade de indivíduos desta espécie podem mudar bastante de acordo com o critério escolhido para definição de indivíduo. Neste estudo, foi usada uma distância máxima de $30 \mathrm{~cm}$ entre cada conjunto de folhas emergentes do solo como critério, mas se cada um destes conjuntos fosse considerado um indivíduo, a densidade seria muito mais elevada. Batalha (1997) encontrou 18 indivíduos de Syagrus petraea em $400 \mathrm{~m}^{2}$ de cerrado sensu stricto no Cerrado Péde-Gigante, o que corresponde a 0,045 indivíduo $/ \mathrm{m}^{2}$, valor bastante superior ao encontrado no presente trabalho. Talvez esta diferença possa ser atribuída a diferentes critérios utilizados para a definição de indivíduo.

Em um cerrado sensu stricto em Brotas (SP), Durigan et al. (2002) encontraram uma densidade de 600 indivíduos de $A$. geraensis/ha, isto é, 0,06 indivíduos $/ \mathrm{m}^{2}$, um valor bastante superior ao encontrado aqui. Já no caso de Syagrus petraea, Lima et al (2003) encontraram, em um cerrado sensu stricto no Brasil Central (DF), uma densidade de 172,86 indivíduos de $S$. petraea/ha, ou seja, aproximadamente 0,017 indivíduos $/ \mathrm{m}^{2}$. Este valor é inferior ao encontrado no presente trabalho, apesar dos autores terem considerado cada conjunto de folhas emergentes do solo como um indivíduo. Em Itirapina (SP), foram encontrados 1 indivíduo de $A$. geraensis e 24 indivíduos de $S$. petraea em uma parcela de 0,16 ha (Colpas et al. 2004), o que corresponde a 0,0006 e 0,015 indivíduo $/ \mathrm{m}^{2}$ para A. geraensis e S. petraea, respectivamente.

O padrão de distribuição de A. geraensis em Brotas (Durigan et al. 2002) é aleatório, ao passo que no presente trabalho a espécie parece estar agregada, dada a grande proporção de parcelas sem nenhum indivíduo registrado. O padrão de dispersão de $S$. petraea encontrado por Lima et al. (2003) é agregado, embora a espécie tenha ampla distribuição na área de estudo. Segundo os dados coletados no presente trabalho, aparentemente também há uma distribuição agregada dos indivíduos e, portanto, dos recursos no cerrado denso do Cerrado Pé-de-Gigante. 


\section{Fenologia reprodutiva}

Cerca de cinqüenta indivíduos de $A$. geraensis foram examinados antes da seleção para o acompanhamento fenológico e, como somente dois deles exibiram sinais de eventos reprodutivos, a seleção dos demais espécimes foi feita segundo o porte e a integridade física das folhas. Assim, é possível que nem todos estivessem em idade adulta. Como vários indivíduos foram examinados, uma outra hipótese se mostra mais plausível: a de que o ambiente não seja propício para a reprodução sexuada da espécie. A fisionomia estudada corresponde a um cerrado denso, em que há relativo sombreamento dos estratos inferiores. Eventuais excursões a fisionomias mais abertas do Cerrado Pé-de-Gigante (campo cerrado e campo sujo) possibilitaram a constatação de frutificação em alguns indivíduos de $A$. geraensis, o que pode ser um indício de que a espécie necessite de maior incidência luminosa para florescer e frutificar. Em um trabalho em Itirapina (SP), Roncero-Siles \& Los (2000) encontraram indivíduos de $A$. geraensis de maior porte em campo sujo, quando comparado ao campo cerrado e a uma transição entre cerrado sensu stricto e cerradão. Além disso, as autoras também verificaram um maior percentual de palmeiras não reprodutivas na transição cerrado sensu stricto/cerradão. A maior insolação nas fisionomias abertas pode promover maior desenvolvimento destas palmeiras nessas áreas, ao passo que nas fisionomias mais fechadas, o seu desenvolvimento é mais lento, o que pode ser decorrência de condições ambientais diferentes resultantes, por exemplo, do maior sombreamento (Roncero-Siles \& Los 2000). Uma outra possibilidade que explicaria a baixa atividade reprodutiva de $A$. geraensis em cerrado denso é a propagação vegetativa, comum entre as espécies do cerrado. A ausência de floração por um ou mais anos poderia representar uma estratégia adaptativa, com a economia de reservas (Mantovani 1983).

Vários fatores têm sido citados como potenciais responsáveis pela indução e controle da floração e frutificação, por exemplo, temperatura, precipitação, picos sazonais de irradiação, duração do dia, ritmos endógenos, filogenia e interações com polinizadores e dispersores de sementes (Gottsberger \& Silberbauer-Gottsberger 2006 a , Rathcke \& Lacey 1985). Variações de precipitação na área de estudo podem ter colaborado para a diferença temporal na produção de inflorescências de Syagrus petraea entre os anos de 2005 e 2006, o que acarretou em picos de atividade de floração e frutificação também deslocados no tempo. O ano de 2005 foi atípico, sem estação seca definida e com baixos índices pluviométricos em novembro, dezembro e fevereiro, o que pode ter provocado o atraso na produção das inflorescências fechadas, com conseqüente atraso nas fenofases de floração e frutificação. No entanto, seriam necessários vários anos de acompanhamento para 
estabelecer uma relação entre as variáveis climáticas e o comportamento fenológico das espécies.

Entre os indivíduos de Syagrus petraea, a fenofase com maior sincronia foi a de inflorescências fechadas, já que $90 \%$ dos indivíduos chegaram a apresentar esta fenofase simultaneamente. Já a sincronia da fenofase de floração entre os indivíduos foi relativamente baixa, visto que o pico de atividade foi caracterizado por apenas $40 \%$ dos indivíduos em flor. A sincronia entre os indivíduos acompanhados quanto à fenofase de frutificação também não foi muito elevada, pois a maior parte do período foi caracterizado por cerca de $20 \%$ das plantas frutificando e o pico de atividade ocorreu com $60 \%$ das plantas manifestando a fenofase.

Há uma relação entre a sincronia da floração e a polinização; tal sincronia se daria por uma série de padrões de seleção, como a necessidade de polinização cruzada, necessidade de florescer quando a maior parte dos polinizadores está ativa, ou ainda de florescer e formar frutos na época em que se reduzem ao mínimo as interferências competitivas (Janzen 1980). Sincronia nos níveis de população e indivíduo afeta a densidade floral. Elevada sincronia pode ser vantajosa ou desvantajosa, dependendo de interações dependentes de densidade com outros organismos, já que pode aumentar a atratividade do "display" floral, ou poderia saciar polinizadores ou predadores (Rathcke \& Lacey 1985). Syagrus petraea tem um sistema generalista de polinização por insetos (Gottsberger \& Silberbauer-Gottsberger 2006ª) e seria interessante avaliar, em futuros trabalhos, a sincronia da floração na população e a presença de polinizadores.

O período de amadurecimento dos frutos pode refletir o período com condições favoráveis para o sucesso da dispersão. Elevada sincronia de frutificação tanto no mesmo indivíduo, quanto entre indivíduos diferentes, pode facilitar a dispersão se o aumento na densidade de frutos provocar a atração de mais dispersores. No entanto, a frutificação sincrônica pode ser desvantajosa se causar a permanência dos agentes dispersores na mesma planta por longos períodos e, conseqüentemente, o descarte da maioria das sementes sob a planta parental. Se os predadores diferem dos dispersores de sementes, o grau de sincronia entre indivíduos provavelmente refletirá um balanço entre a atração de dispersores e a saciedade dos predadores (Ratchke \& Lacey 1985).

Não foi possível identificar os períodos de maior atividade dos consumidores de Syagrus petraea, visto que as câmeras fotográficas automáticas não funcionaram da mesma maneira durante todo o período de estudo. Além disso, não foi feita a distinção entre os dispersores e predadores das sementes, pois o método empregado não possibilita que 
detalhes da manipulação dos frutos sejam detectados. Desta maneira, o presente trabalho não permite relacionar o padrão de atividade dos dispersores com o período de frutificação, o que pode ser feito em futuros estudos.

Diferentemente do padrão de floração encontrado no presente trabalho para Syagrus petraea, em que os únicos meses sem flores foram janeiro e março, os dados de Batalha (1997) identificaram um período de floração mais restrito para a espécie, entre março e julho. Em Botucatu (SP), Gottsberger \& Silberbauer-Gottsberger (2006 $)$ encontraram indivíduos de $S$. petraea com flores entre junho e dezembro. Estas diferenças podem ser atribuídas a fatores climáticos ou à metodologia empregada nos diferentes estudos, já que tanto o trabalho de Batalha (1997) quanto o de Gottsberger \& Silberbauer-Gottsberger $\left(2006^{\text {a }}\right.$ ) abordaram a fenologia em nível de comunidade, utilizando métodos distintos do empregado neste estudo.

As outras palmeiras encontradas em cerrado sensu stricto no Cerrado Pé-de-Gigante, Butia paraguayensis, Syagrus flexuosa e Syagrus romanzoffiana, florescem entre setembro e abril, padrão também distinto do encontrado no presente trabalho para Syagrus petraea (Batalha 1997). Tais palmeiras frutificaram entre fevereiro e novembro (Batalha 1997), padrão também diferente do encontrado para $S$. petraea neste trabalho, em que a frutificação ocorreu, apesar das variações, durante praticamente todos os meses do ano, sendo o mês de abril o único sem expressão desta fenofase em 2005 e 2006.

O número de frutos produzidos varia bastante entre espécies e gêneros de palmeiras, sendo que para a tribo Cocoeae encontra-se um valor médio de $405 \pm 792$ frutos produzidos por infrutescência, dados variando de 5 a 3.670 frutos entre 23 espécies diferentes (dados extraídos de Henderson 2002). O número médio de frutos encontrados para Syagrus petraea no pico de atividade de frutificação foi de 6,13 frutos por planta, número relativamente baixo quando se considera tanto a média, como o valor mínimo de frutos produzidos na tribo Cocoeae, à qual pertence o gênero Syagrus.

\section{B) REDUNDÂNCIA TEMPORAL}

A redundância temporal é definida em termos do grau com que a disponibilidade de um determinado recurso vegetal está sincronizada com a disponibilidade de recursos alimentares alternativos usados por um determinado grupo de consumidores (Peres 2000). Como os consumidores dos frutos de Syagrus petraea têm dietas generalistas, conforme discutido mais adiante, a redundância temporal torna-se muito difícil de ser analisada. Desta 
maneira, a discussão restringiu-se à sincronia entre a disponibilidade dos frutos de $S$. petraea e a disponibilidade de outros frutos na comunidade.

Os dados de Batalha (1997) e Batalha et al. (1997) indicam maior atividade de frutificação durante a estação úmida, quando ocorre o pico de atividade de frutificação de Syagrus petraea. De maneira semelhante, Gottsberger \& Silberbauer-Gottsberger $\left(2006^{\mathrm{b}}\right)$ verificaram que a maioria das espécies de dispersão endo e sinzoocórica frutificaram durante a estação quente e chuvosa, entre outubro e março, em um cerrado em Botucatu (SP). Esta maior frutificação durante a estação úmida também foi encontrada por Mantovani \& Martins (1988) em Moji Guaçu (SP), considerando as espécies de dispersão zoocórica.

Durante os meses mais úmidos, é possível observar que a atividade dos animais, ao menos durante o dia, é alta quando comparada com a estação seca, provavelmente por causa da maior umidade e sombreamento, o que torna o ambiente mais ameno do que durante a estação seca, quando as árvores e arbustos parcialmente perdem suas folhas e a insolação é mais intensa (Gottsberger \& Silberbauer-Gottsberger $2006^{\text {b }}$ ).

Gottsberger \& Silberbauer-Gottsberger (1983), em um cerrado em Botucatu (SP), identificaram o período de frutificação de $S$. petraea entre setembro e outubro, ou seja, no início da estação úmida, quando a maioria das espécies endo e sinzoocóricas frutificaram. Weiser \& Godoy (2001), em um trabalho realizado em cerrado sensu stricto no Cerrado Péde-Gigante entre novembro de 1996 e abril de 1998, encontraram indivíduos de S. petraea com frutos no mês de janeiro. Batalha (1997) registrou o período de frutificação desta palmeira em dezembro, também em cerrado sensu stricto no Cerrado Pé-de-Gigante. De maneira semelhante, o presente trabalho identificou a data média da fenofase de frutificação desta espécie em 06 de janeiro. Assim, S. petraea frutifica em período de abundância de recursos aos frugívoros, considerando toda a comunidade de angiospermas ou somente as espécies com frutos carnosos. No entanto, nos meses de maior escassez do recurso "frutos carnosos" nas comunidades, $S$. petraea também diminui sua atividade de frutificação, mas alguns poucos indivíduos ainda apresentam frutos, podendo constituir um recurso alimentar alternativo.

Como, durante todo o acompanhamento fenológico, somente um fruto foi produzido por Attalea geraensis, é difícil esboçar tendências relacionadas à redundância temporal na disponibilidade deste recurso. O único fruto foi produzido em abril de 2006 e permaneceu na planta até o final do acompanhamento, em novembro, o que pode ser um indício de que esta espécie possa frutificar durante o período mais seco, quando há menor 
disponibilidade de frutos carnosos na comunidade, o que a caracterizaria como um recurso importante à fauna nestes períodos de escassez. Batalha (1997) não encontrou nenhum indivíduo de A. geraensis com frutos entre setembro de 1995 e fevereiro de 1997 . Weiser \& Godoy (2001) também não registraram indivíduos desta palmeira com frutos em cerrado sensu stricto no Pé-de-Gigante entre novembro de 1996 e abril de 1998, indicando que a confiabilidade deste recurso é relativamente baixa na fisionomia estudada neste trabalho.

\section{C) MORFOMETRIA E CONTEÚDO NUTRICIONAL}

Os frutos maduros de Syagrus petraea têm, em média, 21,35 mm de comprimento e 15,35 mm de maior diâmetro; Henderson et al. (1995) encontraram um valor de $20 \mathrm{~mm}$ de diâmetro máximo dos frutos maduros desta mesma espécie. Crepaldi et al. (2001) encontraram frutos de tamanhos semelhantes para a espécie Syagrus coronata. Os valores médios de comprimento e diâmetro dos frutos da tribo Cocoeae (considerando sete espécies: Astrocaryum standleyanum, A. vulgare, A. gynacanthum, Attalea maripa, A. butyracea, Bactris guineensis e Elaeis guineensis) são maiores - 36,20 mm e 23,95 mm, respectivamente (Jordano 2005).

Henderson (2002) cita que há indicações de polimorfismo no tamanho dos frutos, mesmo dentro de uma mesma infrutescência, o que pode estar relacionado à posição do fruto no cacho, com frutos proximais maiores do que os distais. No presente trabalho, a variação de tamanho não foi muito grande mesmo entre indivíduos diferentes: comprimento $\mathrm{CV}=14,64 \%$; diâmetro $\mathrm{CV}=17,83 \%$. Esses valores são relativamente baixos quando se considera o fato de que os frutos são provenientes de indivíduos diferentes, sujeitos a distintas condições microclimáticas no campo.

O conteúdo de água nos frutos frescos de Syagrus petraea corresponde a $51 \%$ da massa total, em média, valor bastante próximo ao obtido para as sete espécies da tribo Cocoeae, ou seja, $56 \%$ (Jordano 2005).

A massa de resíduos após as extrações foi maior no caso da "polpa" do que no caso do endosperma de Syagrus petraea. O mesocarpo dos frutos é bastante fibroso, e estas fibras insolúveis contribuem, em grande parte, pela massa residual das extrações, contendo celulose, hemiceluloses, ligninas e proteínas insolúveis como principais componentes. $\mathrm{O}$ endosperma é mais macio e a pouca massa de resíduos indica que é majoritariamente constituído por lipídios, açúcares e proteínas solúveis, compostos de reserva de rápida mobilização para o processo germinativo. 
O endosperma dos frutos de $S$. petraea contém mais lipídios e mais proteínas solúveis que a "polpa". Teores elevados de lipídios no endocarpo de frutos de outras palmeiras do gênero Syagrus são relatados na literatura. Crepaldi et al. (2001) encontraram mais de 49 \% de lipídios no endosperma de Syagrus coronata, esta proporção foi de somente 4,5\% na "polpa" desta espécie. O endosperma de Syagrus romanzoffiana (como Arecastrum romanzoffianum) apresenta cerca de $52 \%$ da massa correspondente a óleos (Balick 1979), ao passo que a "polpa" é pouco gordurosa, contendo apenas 2,5\% de lipídios (Atchley 1984).

Outros gêneros da tribo Cocoeae também apresentam uma proporção elevada de lipídios no endosperma. McSweeney (1995), estudando a palmeira Attalea cohune (como Orbignya cohune), relata que uma porcentagem entre $64,5 \%$ e $71,8 \%$ da massa do endosperma corresponde a óleos. O endosperma da palmeira Astrocaryum jauari possui $35,2 \%$ da massa seca correspondente a lipídios (Borgtoft-Pedersen 1994).

Atchley (1984) fez uma compilação de dados sobre a composição nutricional de "polpas", sementes e partes vegetativas de palmeiras, incluindo dez espécies da tribo Cocoeae, à qual pertence o gênero Syagrus. Reunindo os dados de Atchley (1984) e Jordano (2005), nota-se que o principal componente da "polpa" dos frutos destas palmeiras são os carboidratos, que correspondem a $54 \pm 33 \%$ da massa, em média. As gorduras constituem $29 \pm 27 \%$ da massa da "polpa", e as proteínas, somente $4 \pm 3 \%$.

Quanto ao endosperma destas espécies da tribo Cocoeae, o principal componente são as gorduras $(50,0 \pm 17,2 \%$ da massa do material), seguidas pelos açúcares $(22,3 \pm$ $9,6 \%)$ e proteínas $(10,1 \pm 4,0 \%)$.

Considerando somente os dados disponíveis para o gênero Syagrus, observa-se que a composição dos frutos de $S$. petraea assemelha-se com a composição dos frutos de $S$. coronata, cuja "polpa" contém 4,5\% de lipídios, 3,2 \% de proteínas e 13,2\% de carboidratos e o endosperma possui mais de $49 \%$ de lipídios, 11,5\% de proteínas e 9,7\% de carboidratos (Crepaldi et al. 2001). A "polpa" de S. romanzoffiana possui muito mais carboidratos que $S$. petraea e $S$. coronata, contendo $86,5 \%$ de açúcares, $2,5 \%$ de lipídios e 6\% de proteínas (Atchley 1984).

Com estes dados, é possivel verificar que os frutos de Syagrus petraea seguem o padrão geral de composição nutricional de outras espécies da mesma tribo, ou seja, endospermas ricos em lipídios, e açúcares como componente nutricional majoritário nas "polpas". As proteínas constituem uma fração muito baixa das massas de endosperma e "polpa". No entanto, no caso de Syagrus petraea, a "polpa" parece ser menos nutritiva que a média para a tribo, já que S. petraea possui aproximadamente $22 \%$ de açúcares, $10 \%$ de 
lipídios e 0,26 \% de proteínas na "polpa", valores abaixo da média obtida para Cocoeae por Atchley (1984) e Jordano (2005) - 54 \%, $29 \%$ e $4 \%$ respectivamente.

\section{D) VERTEBRADOS CONSUMIDORES DOS FRUTOS DE SYAGRUS PETRAEA}

Apesar do registro de treze espécies diferentes pelas armadilhas fotográficas, somente quatro foram identificadas como consumidoras dos frutos de Syagrus petraea: Cyanocorax chrysops (Aves: Corvidae), Didelphis albiventris (Marsupialia: Didelphidae), Micoureus paraguayanus (Marsupialia: Didelphidae) e Cerradomys subflavus (Rodentia: Muridae). Nota-se, portanto, que os frutos desta palmeira não constituem um recurso utilizado por um grande número de espécies frugívoras, visto que a diversidade local de possíveis consumidores é relativamente alta (ver Lyra Jorge \& Pivello 2005). Assim, além de estarem disponíveis em sincronia com as demais espécies, os frutos de $S$. petraea não são generalizados, não podendo ser considerados um recurso tipicamente "chave" (Galetti \& Peres 1993, Peres 2000). Também não é possível dizer que os frutos de $S$. petraea consistem em um recursochave para as espécies consumidoras, dada a dieta generalista das quatro espécies identificadas.

Tanto para diásporos grandes quanto para os pequenos, as aves parecem ser responsáveis por uma porção considerável da sua dispersão no cerrado (Gottsberger \& Silberbauer-Gottsberger $2006^{\text {b) }}$. Além dos frutos de Syagrus petraea, a gralha-do-cerrado (Cyanocorax chrysops) consome frutos de outras espécies de palmeiras, tais como Mauritia flexuosa e Syagrus flexuosa (Amaral \& Macedo 2003, Macedo 2002). No entanto, a dieta desta ave é onívora, composta principalmente por insetos e frutos, os quais incluem frutos de pequi (Caryocar brasiliense), Schefflera macrocarpa, Psittacanthus robustus, Pouteria ramiflora e Eugenia calycina (Amaral \& Macedo 2003), além dos frutos das palmeiras citadas. A dieta variada de C. chrysops indica que são aves oportunistas, que fazem uso de qualquer recurso sazonalmente abundante ou disponível. A alta proporção de frutos em sua dieta, associada com a sua movimentação por longas distâncias, sugerem que esta espécie pode ser um importante dispersor de sementes no cerrado (Amaral \& Macedo 2003).

Aproximadamente $2 / 3$ dos mamíferos que vivem ou passam parte do tempo no cerrado se alimentam de frutos e sementes que crescem nesta formação. Esse alimento pode ser a base de sua dieta ou pode representar itens ocasionais ou suplementos da dieta (Gottsberger \& Silberbauer-Gottsberger 2006 ${ }^{\mathrm{b}}$ ). Roedores, apesar de serem capazes de romper o endocarpo lenhoso dos frutos das palmeiras e consumir a semente, normalmente preferem consumir o mesocarpo acessível (Tomlinson 1990). No entanto, foi detectado no 
presente trabalho um evento em que o endosperma dos frutos de Syagrus petraea foi consumido por um roedor, que pode ter sido Cerradomys subflarus, o único roedor aqui identificado como consumidor dos frutos desta palmeira.

A dieta de Cerradomys subflavus (substituindo Oryzomys subflavus, ver Weksler et al. 2006) foi classificada como frugívora/onívora por Mares et al. 1986. Análises estomacais em indivíduos desta espécie de roedor demonstraram uma dieta de vegetação herbácea e frutos (Eisenberg \& Redford 1999). Vieira (2003), estudando a dinâmica de alguns roedores na Estação Ecológica de Itirapina (SP), encontrou fragmentos de sementes, tecidos vegetais de dicotiledôneas e monocotiledôneas e partes de exoesqueletos de artrópodes nas fezes de Cerradomys subflavus. Portanto, nota-se que este roedor utiliza, além de frutos de Syagrus petraea, outros recursos alimentares variados, inclusive de origem animal, o que faz com que possíveis períodos de escassez de frutos desta palmeira não constituam períodos de falta de alimento para esta espécie.

Os frutos de palmeiras podem ser armazenados por roedores para posterior consumo durante períodos de escassez (Forget 1991, Hoch \& Adler 1997, Janzen 1971, Smythe 1989, Voeks 2002). Este comportamento de estocagem é responsável pela dispersão de sementes de várias espécies, já que as sementes escondidas podem escapar do consumo por algum motivo e se encontrar em um local propício para a germinação e estabelecimento (Jansen \& Forget 2001). Seria interessante monitorar os frutos de Syagrus petraea de maneira a analisar o destino da semente. Talvez o roedor registrado pelas armadilhas fotográficas, apesar da dieta generalista, armazene os frutos da palmeira e possa atuar ocasionalmente como dispersor, e não predador, de suas sementes.

Os marsupiais neotropicais são geralmente conhecidos como pequenos mamíferos onívoros. No entanto, estudos recentes evidenciam que alguns marsupiais podem apresentar dietas mais frugívoras, carnívoras ou insetívoras, dependendo da espécie ou grupo e do ambiente em que ocorrem. De qualquer maneira, os invertebrados parecem ser os principais itens alimentares de marsupiais didelfídeos (Casella 2006). Frutos são fontes hídricas e energéticas para marsupiais que os consomem em grandes quantidades, pois contêm água, açúcares e gorduras (Cáceres 2000).

Didelphis albiventris é um marsupial onívoro, sua dieta contém vertebrados, invertebrados e frutos de diversas espécies. Na Argentina, estômagos de D. albiventris contiveram grandes números de invertebrados, pequenas aves, ovos, partes vegetais, inclusive frutos (Eisenberg \& Redford 1999). Fragmentos da polpa de frutos da palmeira Syagrus romanzoffiana foram encontrados nas fezes desta espécie de gambá em fragmentos de 
floresta ombrófila mista no sul do Brasil (Cáceres 2002). De maneira semelhante, observou-se no presente trabalho que este gambá consome a polpa dos frutos de Syagrus petraea, no entanto, é possível que ele também ingira os frutos inteiros, dispersando as sementes. Como o método de armadilhas fotográficas não possibilita a observação de detalhes da manipulação dos frutos pelos frugívoros, não foi possível afirmar se $D$. albiventris ingere os frutos inteiros, podendo atuar como dispersor das sementes, ou se sempre consome a "polpa" dos frutos, descartando os endocarpos no próprio local. No cerrado, D. albiventris pode dispersar muitas Solanaceae e representantes de famílias como Araceae, Cucurbitaceae e também Arecaceae (Gottsberger \& Silberbauer-Gottsberger $\left.2006^{\mathrm{b}}\right)$.

Micoureus paraguayanus, outro marsupial registrado como consumidor dos frutos de S. petraea neste estudo, é arborícola e sua dieta é principalmente insetívora, porém o consumo que faz de frutos é considerado bastante importante, sendo encontradas sementes de Piper spp., Cecropia sp., Ficus sp., Maclura sp. e Ottonia sp. em suas fezes (Cáceres et al. 2002, Casella 2006, Goulart et al. 2006). No entanto, nenhuma semente de palmeira foi encontrada nas fezes deste marsupial em Floresta Atlântica no sul do Brasil (Cáceres et al. 2002).

Quanto aos demais animais registrados pelas armadilhas fotográficas neste estudo, Tupinambis merianae pode ser um consumidor de frutos de $S$. petraea, apesar de não ter sido identificado como tal. O grande número de registros desta espécie, juntamente com as descrições de seus hábitos alimentares, levam à possibilidade de que esse lagarto seja um dos consumidores, talvez responsável por parte dos eventos de remoção cujos agentes não foram identificados. Tupinambis merianae é uma espécie reconhecidamente consumidora de frutos, além de artrópodes e vertebrados, e parece desempenhar um papel como dispersor de sementes (Gottsberger \& Silberbauer-Gottsberger $2006^{\text {b) }}$. Castro \& Galetti (2004) ofereceram frutos de várias espécies, inclusive de palmeiras, a indivíduos de $T$. merianae mantidos em cativeiro. Dentre as palmeiras, foram oferecidos frutos de Archantophoenix cunninghamiana, Elaeis guineensis, Euterpe edulis, Mauritia flexuosa, Syagrus oleracea e Syagrus romanzoffiana e, para algumas espécies, até $65 \%$ dos frutos oferecidos foram consumidos. Deste modo, nota-se que é possível que os teiús sejam consumidores dos frutos de $S$. petraea, apesar de não terem sido designados como tal no presente trabalho.

Dado o grande número de eventos de remoção sem identificação dos agentes, é possível que outros animais consumam os frutos de $S$. petraea. Algumas considerações 
podem ser feitas a respeito da dieta dos demais animais registrados, buscando listar possíveis consumidores.

Dentre as aves, a seriema (Cariama cristata, família Cariamidae) se alimenta de gafanhotos e outros artrópodes, roedores, calangos e outros animais pequenos, inclusive, ocasionalmente, ofídios (Sick 1997). Segundo estas informações, é improvável que esta ave (registrada uma única vez pelas armadilhas fotográficas) utilize os frutos de Syagrus petraea como recurso alimentar.

Tinamídeos se alimentam de bagas, frutas caídas, folhas e sementes duras, e também procuram pequenos artrópodes e moluscos. Freqüentemente $2 / 3$ do conteúdo do papo e do estômago dessas aves são compostos por sementes digeridas; tinamídeos não são dispersores de plantas (Sick 1997). Segundo Schubart et al. (1965), diversas espécies de Crypturellus mostram alimentação variada; existem exemplares exclusivamente herbívoros, outros com alimentação mista e, finalmente, exemplares insetívoros. Prevalece em quase três dúzias de exemplares examinados pelos autores, a matéria vegetal, sendo as sementes de Cyperaceae, Malvaceae, gramíneas, e Euphorbiaceae as mais comuns. A única espécie de Crypturellus encontrada no Cerrado Pé-de-Gigante por Develey et al (2005) foi C. tataupa (Inhambu-chintã), cuja dieta consiste de frutos, folhas, brotos, sementes e alguns pequenos insetos, especialmente durante a estação reprodutiva (Chikilian \& Speroni 1996). Segundo estas informações sobre a dieta de Crypturellus sp., é possível designá-lo como consumidor potencial dos frutos de Syagrus petraea, no entanto, são necessários detalhes sobre a sua morfologia para verificar se é capaz de ingerir os frutos da palmeira. Características morfológicas da ave frugívora, tais como o tamanho corporal e tamanho do bico, são importantes na determinação da habilidade do frugívoro em se alimentar de frutos de dado tamanho (Izhaki 2002). A largura do bico de C. tataupa mede cerca de $13 \mathrm{~mm}$ e a altura do bico é de $7 \mathrm{~mm}$ aproximadamente (Piratelli 1999). Como as dimensões dos frutos maduros de Syagrus petraea $($ comprimento $=21 \mathrm{~mm}$ e diâmetro $=15 \mathrm{~mm}$ ) são maiores que o bico desta ave, ela não é capaz de ingeri-los inteiros, mas talvez remova pequenos pedaços da "polpa".

Entre os répteis, tartarugas, lagartos e iguanídeos podem ter um papel importante como dispersores de sementes, mesmo com frugivoria infreqüente e não obrigatória (Jordano 2000). A dieta do lagarto Ameiva ameiva consiste numa variedade de vertebrados e invertebrados, mas é dominada por gafanhotos, baratas, besouros, aranhas e larvas de insetos (Vitt \& Colli 1994). Em um trabalho feito nos Estados Unidos, indivíduos de $A$. ameiva em cativeiro recusaram comer plantas palatáveis a muitas espécies de lagartos 
onívoras e herbívoras (Cooper et al. 2002). Deste modo, segundo seus hábitos alimentares descritos na literatura, A. ameiva, registrado em uma única ocasião pelas armadilhas fotográficas, não pode ser considerado um consumidor em potencial dos frutos de Syagrus petraea.

Quanto aos mamíferos marsupiais, Martins \& Bonato (2004) encontraram para Gracilinanus microtarsus, em um trabalho em Floresta Atlântica, uma dieta composta majoritariamente por invertebrados e não encontraram nenhum item vegetal. Vieira \& Izar (1999) encontraram sementes de Araceae em amostras fecais de G. microtarsus coletadas também em Floresta Atlântica, e sugeriram que a espécie pode desempenhar um papel importante na dispersão de sementes de epífitas. Estudando a dieta de Gracilinanus agilis em fragmentos de cerradão no Brasil central, Campos et al. (2004) encontraram uma preferência por material animal (artrópodes) e uma pequena proporção (cerca de 6\%) dos itens consumidos era de origem vegetal. Assim, é pouco provável que as duas espécies de Gracilinanus registradas pelas armadilhas fotográficas sejam consumidoras dos frutos de Syagrus petraea.

O tamanduá (Myrmecophaga tridactyla, família Myrmecophagidae) tem uma dieta exclusiva de formigas e cupins (Redford 1985). Não foram encontrados dados a respeito da dieta de Cryptonanus sp, um outro marsupial registrado pelas armadilhas fotográficas.

Além de Cerradomys subflavus, as câmeras fotográficas automáticas registraram uma outra espécie de roedor - Bolomys lasiurus - que se alimenta de sementes, partes vegetativas de dicotiledôneas e monocotiledôneas, e artrópodes. O consumo de artrópodes por este roedor é bastante significativo, sendo a espécie considerada extremamente oportunista quanto à utilização de recursos (Vieira 2003). De acordo com esta descrição da dieta, $B$. lasiurus pode ser um consumidor dos frutos e/ou sementes de Syagrus petraea, apesar de não ter sido registrado como responsável por nenhum dos eventos de remoção.

Todos os animais designados como consumidores, e possíveis consumidores, mencionados possuem dietas generalistas e não dependem exclusivamente dos recursos oferecidos por Syagrus petraea.

Gottsberger \& Silberbauer-Gottsberger (1983) constataram que a dispersão dos frutos de Syagrus petraea é feita por meio de endozoocoria e sinzoocoria. Os grupos animais que dispersam os frutos da palmeira por ingestão são aves, lagartos e mamíferos nãovoadores, estes últimos também transportando os frutos deliberadamente (sinzoocoria), juntamente com morcegos e besouros. Os autores observaram besouros rolando frutos caídos de $S$. petraea para longe da planta-mãe, onde foram enterrados em possíveis locais de 
estabelecimento. A ação destes besouros tem importância para o estabelecimento e germinação das sementes. Muitas espécies de palmeiras com caules subterrâneos parecem germinar somente quando enterradas a $10 \mathrm{~cm}$ de profundidade no solo (Rawitscher \& Rachid 1946 apud Gottsberger \& Silberbauer-Gottsberger 2006 ${ }^{\mathrm{b}}$ ). É possível, então, que parte dos eventos de remoção cujos agentes não foram identificados tenha sido resultado da queda dos frutos e posterior transporte por invertebrados, que não são detectados pelas câmeras fotográficas automáticas.

O lobo-guará (Chrysocyon bracbyurus) é altamente onívoro, consumindo pequenos vertebrados, insetos, folhagens e frutos de diversas espécies, inclusive de Syagrus petraea (Motta-Junior \& Martins 2002). No entanto, nenhum indivíduo de lobo-guará foi fotografado pelas câmeras automáticas no presente estudo, mas há registros de sua presença no Cerrado Pé-de-Gigante (Lyra-Jorge e Pivello 2005).

Em trabalho desenvolvido em Itirapina (SP), Bueno et al. (2004) encontraram frutos de A. geraensis e $S$. petraea nas galerias de Clyomys bishopi (Rodentia: Echimyidae), que os utilizam como itens alimentares. No entanto, este roedor não foi encontrado no levantamento realizado no Cerrado Pé-de-Gigante (Lyra Jorge \& Pivello 2005), nem foi registrado pelas armadilhas fotográficas. 


\section{CONSIDERAÇõES FINAIS}

A caracterização dos frutos de Attalea geraensis como recurso foi prejudicada neste estudo pela baixa atividade reprodutiva desta espécie no período. No entanto, levantou-se a questão do porque desta frutificação tão baixa no cerrado denso, dado que vários indivíduos em fisionomias campestres foram encontrados com frutos durante $\mathrm{O}$ desenvolvimento do trabalho. Os frutos de Syagrus petraea, por outro lado, estiveram disponíveis durante a maior parte do tempo, apesar da sazonalidade bastante acentuada.

A abundância de indivíduos de $S$. petraea em cerrado denso no Cerrado Pé-deGigante é relativamente alta, quando comparada com outras áreas de cerrado, no entanto, o número de frutos disponíveis por indivíduo é baixo. O padrão de distribuição dos indivíduos adultos e, conseqüentemente, do recurso, parece ser agregado. É importante colocar que este padrão de distribuição é muito relativo, dependendo da escala de observação. Assim, em função da área de vida, dos hábitos e de outras características do consumidor, os frutos podem ser "percebidos" como agregados ou dispersos no espaço.

A disponibilidade de um trabalho desenvolvido na mesma área de estudo e que abrangeu a fenologia de toda a comunidade (Batalha 1997) permitiu estudar o aspecto da sincronia de frutificação entre as diferentes espécies e as palmeiras. No entanto, a redundância temporal do recurso estudado - frutos de Syagrus petraea - é difícil de ser avaliada, dado o caráter generalista da dieta dos animais que utilizam tal recurso como item alimentar. Como os consumidores identificados também se alimentam de vários outros itens, inclusive de origem animal, torna-se muito difícil verificar se o dado recurso vegetal está sincronizado com a disponibilidade de recursos alimentares alternativos usados pelo grupo de consumidores. Desta maneira, a discussão sobre a redundância temporal ficou limitada à sincronia entre a disponibilidade dos frutos de $S$. petraea e a disponibilidade de outros frutos na comunidade, considerando-se tanto o recurso "frutos", independentemente da sua qualidade carnosa ou seca, como somente os recursos similares, ou seja, "frutos carnosos".

A identificação dos possíveis consumidores de frutos de $S$. petraea foi feita com o uso de câmeras fotográficas automáticas. A identificação dos animais por fotografias pode ser difícil, principalmente no caso de pequenos mamíferos, que muitas vezes diferem entre si por pequenos detalhes morfológicos, às vezes impossíveis de serem analisados por meio de fotografias desta natureza. O método também não fornece detalhes da manipulação dos frutos pelos frugívoros, não permitindo afirmar se um dado animal fotografado consumiu somente a "polpa" dos frutos, se os ingeriu inteiros, ou ainda se rompeu o endocarpo 
lenhoso e consumiu o endosperma. Uma outra limitação do método é o aspecto técnico, já que muitos equipamentos disparavam em função do calor, o que prejudicou a identificação dos responsáveis por muitos dos eventos de remoção. Por outro lado, as armadilhas fotográficas permitem registrar os animais de hábito noturno, que, neste caso, correspondem à maior parte dos consumidores, o que seria dificultado caso fossem feitas somente observações focais.

As análises da composição nutricional dos frutos de Syagrus petraea mostraram que eles constituem um recurso nutritivo, principalmente o endosperma, que é mais rico que a "polpa", e que contém principalmente lipídios. A "polpa" é composta principalmente por fibras e outros materiais insolúveis, apresentando também considerável fração de carboidratos solúveis.

Os dados obtidos no presente estudo, principalmente aqueles relacionados com Syagrus petraea, incluindo dados de abundância, caracterização do comportamento fenológico, aspectos do conteúdo nutricional dos frutos e identificação dos principais consumidores, são muito importantes para que sejam desenvolvidos futuros trabalhos envolvendo a dispersão e predação das sementes, processos fundamentais na dinâmica da população. 


\section{REFERÊNCIAS BIBLIOGRÁFICAS}

Amaral, M.F. \& Macedo, R.H.F. 2003. Breeding patterns and habitat use in the endemic Curl-crested Jay of central Brazil. Journal of Field Ornithology 74: 331-340.

Atchley, A.A. 1984. Nutritional value of palms. Principes 28: 138-143.

Balick, M.J. 1979. Amazonian oil palms of promise: a survey. Economic Botany 33: 11-28.

Batalha, M.A. 1997. Análise da vegetação da ARIE Cerrado Pé-de-Gigante (Santa Rita do Passa Quatro, SP). Dissertação de Mestrado, Instituto de Biociências, Universidade de São Paulo, São Paulo, 179 pp.

Batalha, M.A., Aragaki, S. \& Mantovani, W. 1997. Florística do Cerrado em Emas (Pirassununga, SP). Boletim de Botânica da Universidade de São Paulo 16: 49-64.

Batalha, M.A. \& Mantovani, W. 2000. Reproductive phenological patterns of cerrado plant species at the Pé-de-Gigante reserve (Santa Rita do Passa Quatro, SP, Brazil): a comparison between the herbaceous and woody floras. Revista Brasileira de Biologia $\mathbf{6 0}$ : 129-145.

Bencke, C.S.C. \& Morellato, L.P.C. 2002. Comparação de dois métodos de avaliação da fenologia de plantas, sua interpretação e representação. Revista Brasileira de Botânica 25: 269-275.

Borgtoft-Pedersen, H. 1994. Mocora palm-fibers: use and management of Astrocaryum standleyanum (Arecaceae) in Ecuador. Economic Botany 48: 310-325.

Bradford, M.M. 1976. A rapid and sensitive method for the quantitation of microgram quantities of protein utilizing the principle of protein-dye binding. Analytical Biochemistry 72: $248-254$.

Bueno, A.A., Lapenta, M.J., Oliveira, F. \& Motta-Júnior, J.C. 2004. Association of the "IUCN vulnerable" spiny rat Clyomys bishopi (Rodentia: Echimyidae) with palm trees and armadillo burrows in southeastern Brazil. Rev. Biol. Trop. 52: 1009-1011.

Cáceres, N.C. 2000. Dieta, adaptações à alimentação e dispersão de sementes por marsupiais do sul do Brasil. Tese de Doutorado, Universidade Federal do Paraná, Paraná.

Cáceres, N.C. 2002. Food habits and seed dispersal by the white-eared opossum, Didelphis albiventris, in Southern Brazil. Studies on Neotropical Fauna and Environment 37: 97-104.

Cáceres, N.C., Ghizoni-Júnior, I.R. \& Graipel, M.E. 2002. Diet of two marsupials, Lutreolina crassicaudata and Micoureus demerarae, in a coastal Atlantic Forest island of Brazil. Mammalia 66: 331-340.

Campos, J.B., Mendonça, A.F., Bocchiglieri, A. \& Henriques, R.P.B. 2004. Dieta de Gracilinanus agilis em fragmentos naturais de cerradão do Brasil Central. In: Livro de resumos do XXV Congresso Brasileiro de Zoologia. Brasília: Sociedade Brasileira de Zoologia. $513 \mathrm{pp}$.

Casella, J. 2006. Dieta e frugivoria por marsupiais didelfideos em uma floresta estacional semidecidual no Parque Nacional do Iguaçu, Paraná, Brasil. Dissertação de Mestrado, Universidade Federal de Mato Grosso do Sul, Mato Grosso do Sul, 50 pp.

Castro, E.R. \& Galetti, M. 2004. Frugivoria e dispersão de sementes pelo lagarto teiú Tupinambis merianae (Reptilia: Teiidae). Papéis Avulsos de Zoologia 44: 91-97. 
Chikilian, M. \& Speroni, N.B. de. 1996. Comparative study of the digestive system of three species of Tinamou. I. Crypturellus tataupa, Nothoprocta cinerascens, e Nothura maculosa (Aves: Tinamidae). Journal of Morphology 228: 77-88.

Colpas, F.T., Garcia, E., Cianciaruso, M.V., Gimenez, V.M.M \& Pereira, Z.F. 2004. Distribuição de abundância das espécies na comunidade arbustivo-arbórea de um fragmento de cerrado sensu stricto na Estação Experimental e Ecológica de Itirapina, SP. In: Santos, F.A.M., Martins, F.R. \& Tamashiro, J.Y. (orgs.). Relatórios de projetos desenvolvidos na disciplina NE211 - Ecologia de Campo II do Programa de Pós-Graduação em Ecologia, IB, UNICAMP. <http://www.ib.unicamp.br/profs/fsantos/ecocampo/ne211/2004/relat2a.pdf>. [Acesso em 20/04/2006].

Cooper, W.E.Jr., Caldwell, J.P., Vitt, L.J., Pérez-Mellado, V. \& Baird, T.A. 2002. Foodchemical discrimination and correlated evolution between plant diet and plant-chemical discrimination in lacetiform lizards. Canadian Journal of Zoology 80: 655-663.

Crepaldi, I.C., Almeida-Muradian, L.B., Rios, M.D.G., Penteado, M.V.C. \& Salatino, A. 2001. Composição nutricional do fruto de licuri (Syagrus coronata (Martius) Beccari). Revista Brasileira de Botânica 24: 155-159.

Develey, P.F., Cavana, D.D. \& Pivello, V.R. 2005. Aves. In: Pivello, V.R. \& Varanda, E.M. (eds.). O Cerrado Pé-de-Gigante: ecologia e conservaşão - Parque Estadual de Vassununga. Secretaria do Meio Ambiente do Estado de São Paulo, São Paulo, pp. 121-134.

Dubois, M., Gilles, K.A., Hamilton, J.K., Rebers, P.A. \& Smith, F. 1956. Colorimetric method for determination of sugars and related substances. Analytical Chemistry 28: 350356.

Durigan, G., Nishikawa, D.L.L., Rocha, E., Silveira, E.R., Pulitano, F.M., Regalado, L.B., Carvalhaes, M.A., Paranaguá, P.A. \& Ranieri, V.E.L. 2002. Caracterização de dois estratos da vegetação em uma área de cerrado no município de Brotas, SP, Brasil. Acta Botanica Brasilica 16: 251-262.

d'Eça-Neves, F.F. \& Morellato, L.P.C. 2004. Métodos de amostragem e avaliação utilizados em estudos fenológicos de florestas tropicais. Acta Botanica Brasilica 18: 99-108.

Eisenberg, J.F. \& Redford, K.H. 1999. Mammals of the Neotropics Volume 3. University of Chicago Press, Chicago.

Filgueiras, T.S. 2002. Herbaceous plant communities. In: Oliveira, P. S. \& Marquis, R. J. The Cerrados of Brazil. Ecology and natural history of a neotropical savanna. Columbia University Press, New York, pp. 121-139.

Forget, P.-M. 1991. Scatterhoarding of Astrocaryum paramaca by Proechimys in French Guiana: comparison with Myoprocta exilis. Tropical ecology 32: 155-167.

Freitas, G.K. de. 1999. Invasão biológica pelo capim-gordura (Melinis minutiflora Beauv.) em um fragmento de cerrado (ARIE Cerrado Pé-de-Gigante, Santa Rita do Passa Quatro, SP). Dissertação de Mestrado, Instituto de Biociências, Universidade de São Paulo, São Paulo, 157 pp.

Galetti, M. \& Aleixo, A. 1998. Effects of palm heart harvesting on avian frugivores in the Atlantic rain forest of Brazil. Journal of Applied Ecology 35: 286-293.

Galetti, M. \& Peres, C.A. 1993. 'Plantas-chave' em florestas tropicais. Ciência Hoje 16: 57-58.

Galetti, M., Pizo, M.A. \& Morellato, L.P.C. 2003. Fenologia, frugivoria e dispersão de sementes. In: Cullen Jr., L., Rudran, R. \& Valladares-Pádua, C. (orgs.). Métodos de estudos 
em Biologia da Conservação \& Manejo da Vida Silvestre. Editora da Universidade Federal do Paraná, Curitiba, pp. 395-422.

Gottsberger, G. \& Silberbauer-Gottsberger, I. 1983. Dispersal and distribution in the cerrado vegetation of Brazil. Sonderbd. Naturwiss. Ver. Hamburg. 7: 315-352.

Gottsberger, G. \& Silberbauer-Gottsberger, I. $2006^{\text {a }}$. Life in the Cerrado: a South American Tropical Seasonal Ecosystem. Volume I. Origin, Structure, Dynamics and Plant Use. Ulm: Reta Verlag, Germany.

Gottsberger, G. \& Silberbauer-Gottsberger, I. $2006^{\text {b. }}$. Life in the Cerrado: a South American Tropical Seasonal Ecosystem. Volume II. Pollination and seed dispersal. Ulm: Reta Verlag, Germany.

Goulart, F.V.B., Souza, F.L., Pavese, H.B. \& Graipel, M.E. 2006. Estrutura populacional e uso do estrato vertical por Micoureus paraguayanus (Didelphimorphia, Didelphidae) em fragmentos de Floresta Atlântica de planície no sul do Brasil. Biotemas 19: 45-53.

Henderson, A., Galeano, G. \& Bernal, R. 1995. Field guide to the palms of the Americas. Princeton University Press, Princeton, New Jersey.

Henderson, A. 2002. Evolution and ecology of palms. The New York Botanical Garden Press, New York.

Hoch, G.A. \& Adler, G.H. 1997. Removal of black palm (Astrocaryum standleyanum) seeds by spiny rats (Proechimys semispinosus). Journal of Tropical Ecology 13: 51-58.

Izhaki, I. 2002. The role of fruit traits in determining fruit removal in East Mediterranean Ecosystems. In: Levey, D.J., Silva, W.R. \& Galetti, M. (eds). Seed Dispersal and Frugivory: Ecology, Evolution and Conservation. CAB International, pp. 161-175.

Jansen, P.A. \& Forget, P.-M. 2001. Scatterhoarding rodents and tree regeneration. In: Bongers, F., Charles-Dominique, P., Forget, P.-M. \& Théry, M. (eds.). Nouragues. Dynamics and plant-animal interactions in a neotropical rainforest. Kluwer Academic Publishers, Dordrecht, pp. 275-288.

Janzen, D.H. 1971. The fate of Scheelea rostrata fruits beneath the parent tree; predispersal attack by bruchids. Principes 15: 89-101.

Janzen, D.H. 1980. Ecologia Vegetal nos Trópicos. Coleção Temas de Biologia, volume 7. EPU: Editora da Universidade de São Paulo.

Johnson, D. 1988. Worldwide endangerment of useful palms. Advances in Economic Botany 6: 268-273.

Johnson, D. and the IUCN/SSC Palm Specialist Group. 1996. Palms: their conservation and sustained utilization. Status survey and Conservation Action Plan. IUCN, Gland, Switzerland and Cambridge, UK.

Jordano, P. 2000. Fruits and frugivory. In: Fenner, M. (ed.). Seeds: the ecology of regeneration in plant communities. CAB International Publishing, Wallingford, UK, pp. 125-166.

Jordano, P. 2005. The FRUBASE page. Disponível em: http://ebd10.ebd.csic.es/mywork/frubase/frubase.html. Acesso em 09/05/2006.

Kiew, R. \& Davison, G.W.H. 1991. Relationship between wild palms and other plants and animals. In: Johnson, D. (ed.). Palms for human needs in Asia. A.A. Balkema Publishers, Netherlands, pp. 237-243.

Köppen, W. 1948. Climatologia. Fondo de Cultura Económica, México. 
Korman, V. \& Pivello, V.R. 2005. Impactos pelo uso inadequado das terras e legislação ambiental. In: Pivello, V.R. \& Varanda, E.M. (eds.). O Cerrado Pé-de-Gigante: ecologia e conservação - Parque Estadual de V assununga. Secretaria do Meio Ambiente do Estado de São Paulo, São Paulo, pp. 273-282.

Lima, E.S., Felfili, J.M., Marimon, B.S. \& Scariot, A. 2003. Diversidade, estrutura e distribuição espacial de palmeiras em um cerrado sensu stricto no Brasil Central - DF. Revista Brasileira de Botânica 26: 361-370.

Lorenzi, H. Souza, H.M., Medeiros-Costa, J.T., Cerqueira, L.S.C. \& von Behr, N. 1996. Palmeiras no Brasil: nativas e exóticas. Editora Plantarum, Nova Odessa, SP.

Lyra Jorge, M.C. \& Pivello, V.R. 2005. Mamíferos. In: Pivello, V.R. \& Varanda, E.M. (eds.). O Cerrado Pé-de-Gigante: ecologia e conservação - Parque Estadual de Vassununga. Secretaria do Meio Ambiente do Estado de São Paulo, São Paulo, pp. 135-148.

Macedo, R.H.F. 2002. The avifauna: ecology, biogeography, and behavior. In: Oliveira, P.S. \& Marquis, R.J. The Cerrados of Brazil. Ecology and natural history of a neotropical savanna. Columbia University Press, New York, pp. 242-265.

Mantovani, W. 1983. Composição e similaridade florística, fenologia e espectro biológico do Cerrado na Reserva Biológica de Moji Guaçu, Estado de São Paulo. Dissertação de Mestrado, Instituto de Biologia, Universidade Estadual de Campinas, Campinas, 147 pp.

Mantovani, W. \& Martins, F.R. 1988. Variações fenológicas das espécies do cerrado da Reserva Biológica de Moji Guaçu, Estado de São Paulo. Revista Brasileira de Botânica 11: 101-112.

Mares, M.A., Ernest, K.A. \& Gettinger, D.D. 1986. Small mammal community structure and composition in the cerrado province of Central Brazil. Journal of Tropical Ecology 2 : 289-300.

Martins, E.G. \& Bonato, V. 2004. On the diet of Gracilinanus microtarsus (Marsupialia, Didelphidae) in an Atlantic Rainforest fragment in southeastern Brazil. Mammalian Biology 69: 58-60.

McSweeney, K. 1995. The cohune palm (Orbignya cobune, Arecaceae) in Belize: a survey of uses. Economic Botany 49: 162-171.

Medeiros-Costa, J.T. \& Panizza, S. 1983. Palms of the Cerrado Vegetation Formation of São Paulo State, Brazil. Principes 27: 118-125.

Melo, J.T., Silva, J.A., Torres, R.A.A., Silveira, C.E.S. \& Caldas, L.S. 1998. Coleta, propagação e desenvolvimento inicial de espécies do cerrado. In: Sano, S.M. \& Almeida, S.P. (eds.). Cerrado: ambiente e flora. EMBRAPA-CPAC, Planaltina, DF, pp. 195-243.

Mesquita Júnior, H.N. de. 1998. Análise temporal com sensor orbital de unidades fisionômicas de cerrado na Gleba Pé-de-Gigante (Parque Estadual de Vassununga - SP). Dissertação de Mestrado, Instituto de Biociências, Universidade de São Paulo, São Paulo, 118 pp.

Morellato, L.P.C., Leitão Filho, H.F., Rodrigues, R.R. \& Joly, C.A. 1990. Estratégias fenológicas de espécies arbóreas em floresta de altitude na Serra do Japi, Jundiaí, São Paulo. Revista Brasileira de Biologia 50: 149-162.

Morellato, L.P.C., Talora, D.C., Takahasi, A., Bencke, C.C., Romera, E.C. \& Zipparro, V.B. 2000. Phenology of Atlantic Rain Forest Trees: a Comparative Study. Biotropica 32: 811823. 
Motta-Junior, J.C. \& Martins, K. 2002. The frugivorous diet of the maned wolf, Chrysocyon brachyurus, in Brazil: ecology and conservation. In: Levey, D.J., Silva, W.R. \& Galetti, M. (eds). Seed Dispersal and Frugivory: Ecology, Evolution and Conservation. CAB International, pp. 291-303.

Myers, N., Mittermeier, R.A., Mittermeier, C.G., Fonseca, G.A.B. \& Kent, J. 2000. Biodiversity hotspots for conservation priorities. Nature 403: 853-858.

Oliveira, P.S. \& Marquis, R.J. 2002. The Cerrados of Brazil. Ecology and natural history of a neotropical savanna. Columbia University Press, New York.

Peres, C.A. 2000. Identifying keystone plant resources in tropical forests: the case of gums from Parkia pods. Journal of Tropical Ecology 16: 287-317.

Piratelli, A.J. 1999. Comunidades de aves de sub-bosque na região leste de Mato Grosso do Sul. Tese de Doutorado, Instituto de Biologia, Universidade Estadual Paulista, Rio Claro, 206 pp.

Pires Neto, A.G., Rocha, H.R., Cooper, M. \& Shida, C. N. 2005. Fisiografia da região. In: Pivello, V.R. \& Varanda, E.M. (eds.). O Cerrado Pé-de-Gigante: ecologia e conservaşão - Parque Estadual de Vassununga. Secretaria do Meio Ambiente do Estado de São Paulo, São Paulo, pp. 15-28.

Pivello, V.R., Bittencourt, M.D., Mantovani, W., Mesquita Júnior, H.N. de, Batalha, M.A. \& Shida, C.N. 1998. Proposta de zoneamento ecológico para a reserva de cerrado Pé-deGigante (Santa Rita do Passa Quatro, SP). Brazilian Journal of Ecology 2: 108-118.

Pivello, V.R., Bittencourt, M.D., Mesquita Júnior, H.N. de \& Batalha, M.A. 1999. Banco de dados em SIG para ecologia aplicada: exemplo do Cerrado Pé-de-Gigante, SP. Caderno de Informações Georreferenciadas - $C I G, \quad 1(3), \quad$ artigo 4. (http://www.cpa.unicamp.br/revista/cigv1n3a4.html).

Pivello, V.R. \& Korman, V. 2005. Conservação e manejo da biodiversidade. In: Pivello, V.R. \& Varanda, E.M. (eds.). O Cerrado Pé-de-Gigante: ecologia e conservação - Parque Estadual de Vassununga. Secretaria do Meio Ambiente do Estado de São Paulo, São Paulo, pp. 297-310.

Putz, F.E. 1986. Studies in Palm Ecology: an Introduction. Principes 30: 91.

Rathcke, B. \& Lacey, E.P. 1985. Phenological patterns of terrestrial plants. Annual Review of Ecology and Systematics 16: 179-214.

Redford, K.H. 1985. Feeding and food preference in captive and wild giant anteaters (Myrmecophaga tridactyla). Journal of Zoology 205: 559-572.

Ribeiro, J.F. \& Walter, B.M.T. 1998. Fitofisionomias do Bioma Cerrado. In: Sano, S.M. \& Almeida, S.P. (eds.). Cerrado: ambiente e flora. EMBRAPA-CPAC, Planaltina, DF, pp. 89166.

Roncero-Siles, M.F. \& Los, M.M. 2000. Attalea geraensis em diferentes fisionomias de cerrado: distribuição e estrutura da população. In: Martins, M., Mantovani, W. \& Metzger, J.P. (orgs.). Livro da Disciplina Ecologia de Campo 2000. Programa de Pós Graduação em Ecologia, Instituto de Biociências, Universidade de São Paulo, pp. 153165.

Ruggiero, P.G.C., Batalha, M.A., Pivello, V.R. \& Meirelles, S.T. 2002. Soil-vegetation relationships in cerrado (Brazilian savanna) and semideciduous Forest, Southeastern Brazil. Plant Ecology 160: 1-16.

Schubart, O., Aguirre, A.C. \& Sick, H. 1965. Contribuição para o conhecimento da alimentação das aves brasileiras. Arquivos de Zoologia 12: 95-249. 
Shida, C.N. 2005. Evolução do uso das terras na região. In: Pivello, V.R. \& Varanda, E.M. (eds.). O Cerrado Pé-de-Gigante: ecologia e conservação - Parque Estadual de Vassununga. Secretaria do Meio Ambiente do Estado de São Paulo, São Paulo, pp. 29-42.

Sick, H. 1997. Ornitologia Brasileira. Editora Nova Fronteira, Rio de Janeiro.

Smythe, N. 1989. Seed survival in the palm Astrocaryum standleyanum: evidence for dependence upon its seed dispersers. Biotropica 21: 50-56.

Terborgh, J. 1986. Keystone plant resources in the tropical forest. In: Soulé, M.E. (ed.). Conservation biology: the science of scarcity and diversity. Sinauer Associates, Inc. Publishers, Sunderland, Massachusetts, pp. 330-344.

Tomlinson, P.B. 1990. The structural biology of palms. Oxford University Press, Oxford, UK.

Uhl, N. \& Dransfield, J. 1987. Genera Palmarum. A classification of palms based on the work of Harold E. Moore, Jr. Allen Press, Inc., Lawrence, Kansas.

Vieira, E.M. \& Izar, P. 1999. Interaction between aroids and arboreal mammals in the Brazilian Atlantic rainforest. Plant Ecology 145: 75-82.

Vieira, M.V. 2003. Seasonal niche dynamics in coexisting rodents of the Brazilian Cerrado. Studies on Neotropical Fauna and Environment 38: 7-15.

Vitt, L.J. \& Colli, G.R. 1994. Geographical ecology of a Neotropical lizard: Ameiva ameiva (Teiidae) in Brazil. Canadian Journal of Zoology 72: 1986-2008.

Voeks, R.A. 2002. Reproductive ecology of the piassava palm (Attalea funifera) of Bahia, Brazil. Journal of Tropical Ecology 18: 121-136.

Weiser, V.L. \& Godoy, S.A.P. 2001. Florística em um hectare de cerrado stricto sensu na ARIE - Cerrado Pé-de-Gigante, Santa Rita do Passa Quatro, SP. Acta Botanica Brasilica 15: 201-212.

Weksler, M., Percequillo, A.R. \& Voss, R.S. 2006. Ten new genera of Oryzomyine rodents (Cricetidae: Sigmodontinae). American Museum Novitates 3537: 1-29.

Zar, J.H. 1996. Biostatistical Analysis. Prentice-Hall International, $3^{\text {a }}$ ed. 
ANEXo I. Lista das angiospermas presentes em fisionomia de cerrado sensu stricto, no Cerrado Péde-Gigante (Santa Rita do Passa Quatro, SP). Dados extraídos de Batalha (1997). Síndrome de dispersão: ane $=$ anemocórica; aut $=$ autocórica; $z$ zoo $=$ zoocórica. Forma de vida: cam $=$ caméfita; cam-fan = caméfita ou fanerófita; epi $=$ epífita; fan = fanerófita; geo = geófita; hem $=$ hemicriptófita; lia $=$ liana; par $=$ parasita vascular; $\mathrm{spv}=$ semi-parasita vascular; ter $=$ terófita. Período de frutificação: 1 = janeiro; 2 = fevereiro; ...; 11 = novembro; $12=$ dezembro. $O$ hífen $(-)$ representa continuidade entre meses, enquanto a vírgula (,) significa interrupção.

\begin{tabular}{|c|c|c|c|c|}
\hline Família & Espécie & $\begin{array}{c}\text { Síndrome de } \\
\text { dispersão }\end{array}$ & $\begin{array}{l}\text { Forma } \\
\text { de vida }\end{array}$ & $\begin{array}{l}\text { Período de } \\
\text { frutificação }\end{array}$ \\
\hline \multirow[t]{2}{*}{ Acanthaceae } & Hygrophila brasiliensis & aut & hem & 6 \\
\hline & Ruellia geminiflora & aut & hem & 4 \\
\hline \multirow[t]{2}{*}{ Amaranthaceae } & Alternanthera brasiliana & aut & hem & $2-5$ \\
\hline & Gomphrena virgata & aut & hem & $3-11$ \\
\hline Amaryllidaceae & Alstroemeria pulchella & aut & hem & $3-4$ \\
\hline \multirow[t]{2}{*}{ Anacardiaceae } & Anacardium bumile & zOO & cam-fan & $9-10$ \\
\hline & Tapirira guianensis & zOO & fan & - \\
\hline \multirow[t]{5}{*}{ Annonaceae } & Annona coriacea & zOO & cam-fan & $9-12$ \\
\hline & Annona crassiflora & zoo & fan & $11-12$ \\
\hline & Annona dióica & zOO & cam & 1 \\
\hline & Duguetia furfuracea & zoo & fan & $1-12$ \\
\hline & Xylopia aromatica & zoo & fan & $1-12$ \\
\hline \multirow[t]{9}{*}{ Apocynaceae } & Aspidosperma tomentosum & ane & fan & - \\
\hline & Forsteronia glabrescens & ane & lia & $12-9$ \\
\hline & Hancornia speciosa & zOO & fan & $9-11$ \\
\hline & Himatanthus obovata & ane & fan & - \\
\hline & Mandevilla vellutina & ane & fan & 1 \\
\hline & Odontadenia lútea & ane & hem & $5-10$ \\
\hline & Oxypetalum appendiculatum & ane & lia & 9 \\
\hline & Rhodocalyx rotundifolius & ane & lia & - \\
\hline & Temnadenia violácea & ane & hem & $10-5$ \\
\hline Araliaceae & Didymopanax vinosum & $\mathrm{ZOO}$ & fan & $2-11$ \\
\hline \multirow[t]{5}{*}{ Arecaceae } & Attalea geraensis & $\mathrm{zOO}$ & geo & - \\
\hline & Butia paraguayensis & zoo & fan & - \\
\hline & Syagrus flexuosa & zoo & cam-fan & $9-11$ \\
\hline & Syagrus petraea & zoo & cam & 12 \\
\hline & Syagrus romanzoffiana & zoo & fan & $2-11$ \\
\hline \multirow[t]{2}{*}{ Asclepiadaceae } & Astephanus carassensis & ane & lia & - \\
\hline & Ditassa acerosa & ane & hem & - \\
\hline \multirow[t]{15}{*}{ Asteraceae } & Aspilia reflexa & aut & hem & $11-1$ \\
\hline & Baccharis dracunculifolia & ane & cam & $1-7$ \\
\hline & Baccharis humilis & ane & cam & $11-6$ \\
\hline & Baccharis rufescens & ane & cam & 9 \\
\hline & Bidens gardneri & zoo & ter & $12-8$ \\
\hline & Chaptalia integerrima & ane & ter & $3-4$ \\
\hline & Conyza canadensis & ane & ter & $12-3$ \\
\hline & Dasyphyllum sprengelianum & ane & cam & $6-11$ \\
\hline & Elephantopus mollis & ane & hem & 6-9 \\
\hline & Emilia coccínea & ane & ter & $11-3$ \\
\hline & Eremanthus sphaerocephalus & ane & hem & $7-10$ \\
\hline & Eupatorium chlorolepsis & ane & hem & - \\
\hline & Eupatorium maximiliani & ane & cam & $1-12$ \\
\hline & Eupatorium squalidum & ane & ter & $4-10$ \\
\hline & Gochnatia barrosii & ane & cam & $9-10$ \\
\hline
\end{tabular}




\begin{tabular}{|c|c|c|c|c|}
\hline Família & Espécie & $\begin{array}{c}\text { Síndrome de } \\
\text { dispersão }\end{array}$ & $\begin{array}{l}\text { Forma } \\
\text { de vida }\end{array}$ & $\begin{array}{l}\text { Período de } \\
\text { frutificação }\end{array}$ \\
\hline \multirow[t]{18}{*}{ Asteraceae } & Gochnatia pulchra & ane & cam & $6-11$ \\
\hline & Kanimia oblongifolia & ane & cam & $9-2$ \\
\hline & Mikania cordifolia & ane & lia & $2-10$ \\
\hline & Orthopappus angustifolius & ane & hem & $2-10$ \\
\hline & Piptocarpha rotundifolia & ane & fan & $1-12$ \\
\hline & Porophyllum angustissimum & ane & ter & $6-9$ \\
\hline & Trichogonia salviifolia & ane & hem & $12-8$ \\
\hline & Vernonia bardanoides & ane & hem & $2-10$ \\
\hline & Vernonia cephalotes & ane & hem & - \\
\hline & Vernonia ferruginea & ane & cam & - \\
\hline & Vernonia holosericea & ane & cam & 9 \\
\hline & Vernonia lappoides & ane & hem & $3-4$ \\
\hline & Vernonia obtusata & ane & cam & $6-7$ \\
\hline & Vernonia onopordioides & ane & hem & $3-6$ \\
\hline & Vernonia polyanthes & ane & cam & $10-7$ \\
\hline & Vernonia rubriramea & ane & cam & $6-10$ \\
\hline & Vernonia scabra & ane & cam & $7-9$ \\
\hline & Viguiera discolor & aut & hem & $2-5$ \\
\hline \multirow[t]{14}{*}{ Bignoniaceae } & Anemopaegma arvense & ane & hem & 10 \\
\hline & Arrabidaea brachypoda & ane & cam & 4 \\
\hline & Arrabidaea craterophora & ane & lia & 4-11 \\
\hline & Arrabidaea florida & ane & lia & $7-9$ \\
\hline & Cremastus pulcher & ane & lia & - \\
\hline & Cybistax antisyphillitica & ane & fan & - \\
\hline & Distictella mansoana & ane & lia & $11-9$ \\
\hline & Jacaranda caroba & ane & cam-fan & $7-1$ \\
\hline & Jacaranda decurrens & ane & cam & - \\
\hline & Jacaranda rufa & ane & cam & - \\
\hline & Memora peregrina & ane & cam & $9-3$ \\
\hline & Pyrostegia venusta & ane & lia & $7-12$ \\
\hline & Tabebuia áurea & ane & fan & - \\
\hline & Tabebuia ochracea & ane & fan & - \\
\hline Bixaceae & Cochlospermum regium & ane & cam & $9-11$ \\
\hline Bombacaceae & Eriotheca gracilipes & ane & fan & $9-12$ \\
\hline \multirow[t]{5}{*}{ Bromeliaceae } & Aechmea bromeliifolia & aut & epi & 11 \\
\hline & Ananas ananassoides & $\mathrm{zOO}$ & hem & $9-5$ \\
\hline & Bromelia balansae & $\mathrm{zOO}$ & hem & $9-7$ \\
\hline & Dickia tuberosa & aut & hem & 11 \\
\hline & Tillandsia geminiflora & aut & epi & $4-5,9$ \\
\hline Burseraceae & Protium beptaphyllum & $\mathrm{ZOO}$ & fan & $8-2$ \\
\hline Caryocaraceae & Caryocar brasiliense & $\mathrm{ZOO}$ & cam-fan & $11-2$ \\
\hline Caryophyllaceae & Polycarpaea corymbosa & aut & hem & $3-6$ \\
\hline Celastraceae & Austroplenckia populnea & ane & fan & - \\
\hline \multirow[t]{3}{*}{ Chrysobalanaceae } & Conepia grandiflora & $\mathrm{zOO}$ & fan & $10-2$ \\
\hline & Licania humilis & zOO & cam-fan & $10-12$ \\
\hline & Parinari excelsa & zOO & cam & $9-12$ \\
\hline \multirow[t]{3}{*}{ Clusiaceae } & Kielmeyera coriacea & ane & fan & - \\
\hline & Kielmeyera rubriflora & ane & fan & - \\
\hline & Kielmeyera variabilis & ane & fan & $5-11$ \\
\hline
\end{tabular}




\begin{tabular}{|c|c|c|c|c|}
\hline Família & Espécie & $\begin{array}{c}\text { Síndrome de } \\
\text { dispersão }\end{array}$ & $\begin{array}{l}\text { Forma } \\
\text { de vida }\end{array}$ & $\begin{array}{l}\text { Período de } \\
\text { frutificação }\end{array}$ \\
\hline Commelinaceae & Commelina erecta & aut & ter & $9-6$ \\
\hline \multirow[t]{2}{*}{ Connaraceae } & Connarus suberosus & $\mathrm{zOO}$ & fan & - \\
\hline & Rourea induta & $\mathrm{zOO}$ & fan & $11-4$ \\
\hline \multirow[t]{2}{*}{ Convolvulaceae } & Ipomoea procurrens & aut & lia & - \\
\hline & Jacquemontia tamnifolia & aut & lia & $8-3$ \\
\hline Cucurbitaceae & Cayaponia espelina & $\mathrm{ZOO}$ & lia & $12-2$ \\
\hline \multirow[t]{6}{*}{ Cyperaceae } & Bulbostylis birtella & aut & hem & $2-7$ \\
\hline & Bulbostylis sphaerocephala & aut & hem & $2-6$ \\
\hline & Cyperus cayennensis & aut & hem & $1-5$ \\
\hline & Cyperus diffusus & aut & hem & $3-10$ \\
\hline & Rhynchospora exaltata & aut & hem & $10-7$ \\
\hline & Scleria comosa & aut & hem & $12-8$ \\
\hline \multirow[t]{2}{*}{ Dilleniaceae } & Davilla elliptica & aut & fan & $12-6$ \\
\hline & Davilla rugosa & aut & lia & 4,11 \\
\hline Ebenaceae & Diospyros hispida & $\mathrm{zOO}$ & fan & $11-2$ \\
\hline \multirow{4}{*}{ Erythroxylaceae } & Erythroxylum campestre & zoO & fan & $10-2$ \\
\hline & Erythroxylum cuneifolium & zoO & fan & $10-11$ \\
\hline & Erythroxylum suberosum & $\mathrm{zOO}$ & fan & $10-2$ \\
\hline & Erythroxylum tortuosum & zOO & fan & - \\
\hline \multirow[t]{6}{*}{ Euphorbiaceae } & Croton eriocladus & aut & ter & $12-7$ \\
\hline & Croton sclerocalyx & aut & hem & $1-6$ \\
\hline & Manihot caerulescens & aut & hem & $12-4$ \\
\hline & Manihot tripartita & aut & hem & 11 \\
\hline & Phyllanthus orbiculatus & aut & ter & $11-6$ \\
\hline & Sebastiania serrulata & aut & ter & $1-5$ \\
\hline \multirow[t]{10}{*}{ Fabaceae - Caesalpinioideae } & Baubinia rufa & aut & fan & $1-12$ \\
\hline & Chamaechrista debilis & aut & cam & $1-12$ \\
\hline & Chamaechrista desvauxii & aut & cam & $2-7$ \\
\hline & Chamaechrista flexuosa & aut & cam & $2-9$ \\
\hline & Copaifera langsdorfii & $\mathrm{zOO}$ & fan & $9-6$ \\
\hline & Dyptichandra aurantiaca & ane & fan & $1-11$ \\
\hline & Hymenaea stigonocarpa & zOO & fan & $7-10$ \\
\hline & Sclerolobium paniculatum & ane & fan & - \\
\hline & Senna rugosa & aut & fan & $4-11$ \\
\hline & Senna sylvestris & aut & fan & 9 \\
\hline \multirow[t]{15}{*}{ Fabaceae - Faboideae } & Acosmium subelegans & ane & fan & - \\
\hline & Aeschynomene marginata & zOO & hem & $1-12$ \\
\hline & Andira anthelmia & zOO & fan & 2 \\
\hline & Andira laurifolia & $\mathrm{zOO}$ & cam & 12 \\
\hline & Bowdichia virgilioides & ane & fan & - \\
\hline & Crotalaria vitellina & aut & hem & $2-4$ \\
\hline & Dalbergia miscolobium & ane & fan & $5-10$ \\
\hline & Deguelia nitidula & aut & lia & $6-8$ \\
\hline & Enterolobium gummiferum & aut & fan & - \\
\hline & Eriosema crinitum & aut & hem & - \\
\hline & Galactia grewiiffolia & aut & hem & $9-4$ \\
\hline & Indigofera suffruticosa & aut & hem & $5-7$ \\
\hline & Machaerium acutifolium & ane & fan & $8-6$ \\
\hline & Macroptilium gracile & aut & lia & 6 \\
\hline & Periandra mediterranea & aut & hem & $5-6$ \\
\hline
\end{tabular}




\begin{tabular}{|c|c|c|c|c|}
\hline Família & Espécie & $\begin{array}{c}\text { Síndrome de } \\
\text { dispersão }\end{array}$ & $\begin{array}{l}\text { Forma } \\
\text { de vida }\end{array}$ & $\begin{array}{l}\text { Período de } \\
\text { frutificação }\end{array}$ \\
\hline \multirow[t]{6}{*}{ Fabaceae - Faboideae } & Pterodon pubescens & ane & fan & $1-12$ \\
\hline & Rhynchosia melanocarpa & zOO & lia & $1-3$ \\
\hline & Stylosanthes gracilis & aut & hem & $11-8$ \\
\hline & Stylosanthes guianensis & aut & ter & 5 \\
\hline & Vatairea macrocarpa & ane & fan & - \\
\hline & Zornia latifolia & zOO & hem & $11-4$ \\
\hline \multirow{9}{*}{ Fabaceae - Mimosoideae } & Anadenanthera falcata & ZOO & fan & $1-12$ \\
\hline & Anadenanthera peregrina & zoO & fan & 4,12 \\
\hline & Dimorphandra mollis & zOO & fan & $1-9$ \\
\hline & Mimosa gracilis & ane & cam & - \\
\hline & Mimosa pigra & zOO & cam & - \\
\hline & Mimosa xanthocentra & ane & cam & $1-7$ \\
\hline & Plathymenia reticulata & ane & fan & 12 \\
\hline & Stryphnodendron adstringens & zOO & fan & - \\
\hline & Stryphnodendron polyphyllum & aut & fan & $6-12$ \\
\hline \multirow[t]{2}{*}{ Flacourtiaceae } & Casearia grandiflora & $\mathrm{zOO}$ & fan & $9-2$ \\
\hline & Casearia sylvestris & zOO & fan & $9-10$ \\
\hline \multirow[t]{2}{*}{ Hippocrateaceae } & Peritassa campestris & zOO & fan & 11 \\
\hline & Tontelea micrantha & $\mathrm{zOO}$ & fan & 一 \\
\hline \multirow[t]{6}{*}{ Lamiaceae } & Hyptis cana & aut & hem & 9 \\
\hline & Hyptis eriophylla & aut & ter & $6-9$ \\
\hline & Hyptis mutabilis & aut & ter & 5 \\
\hline & Hyptis reticulata & aut & hem & $1-12$ \\
\hline & Hyptis rugosa & aut & hem & $3-10$ \\
\hline & Peltodon tomentosus & aut & hem & $2-9$ \\
\hline \multirow[t]{3}{*}{ Lauraceae } & Cassytha americana & zOO & par & 8 \\
\hline & Ocotea corymbosa & zOO & fan & $3-4$ \\
\hline & Ocotea pulchella & zOO & fan & $2-7$ \\
\hline Loganiaceae & Strychnos bicolor & ZOO & lia & $11-5$ \\
\hline Loranthaceae & Psittacanthus robustus & ZOO & spv & 10 \\
\hline \multirow[t]{2}{*}{ Lythraceae } & Cuphea carthaginensis & aut & cam & $1-3$ \\
\hline & Lafoensia pacari & aut & fan & - \\
\hline \multirow[t]{13}{*}{ Malpighiaceae } & Banisteriopsis campestris & ane & lia & $2-10$ \\
\hline & Banisteriopsis laevifolia & ane & lia & $5-9$ \\
\hline & Banisteriopsis pubipetala & ane & lia & $9-1$ \\
\hline & Banisteriopsis stellaris & ane & lia & $2-7$ \\
\hline & Banisteriopsis variabilis & ane & lia & $9-11$ \\
\hline & Byrsonima coccolobifolia & zOO & fan & $12-2$ \\
\hline & Byrsonima crassa & zoO & fan & 2 \\
\hline & Byrsonima intermedia & zoO & fan & $10-6$ \\
\hline & Byrsonima verbascifolia & zoO & fan & 11 \\
\hline & Heteropteris byrsonimifolia & ane & fan & $9-4$ \\
\hline & Heteropteris umbellata & ane & lia & $11-2$ \\
\hline & Mascagnia cordifolia & ane & lia & $10-11$ \\
\hline & Peixotoa tomentosa & ane & lia & 7 \\
\hline \multirow[t]{2}{*}{ Malvaceae } & Pavonia hexaphylla & aut & cam & $2-5$ \\
\hline & Sida linifolia & aut & ter & $3-5$ \\
\hline \multirow[t]{3}{*}{ Melastomataceae } & Leandra lacunosa & ane & fan & $11-7$ \\
\hline & Miconia albicans & zOO & cam-fan & $6-1$ \\
\hline & Miconia fallax & zOO & cam & $9-2$ \\
\hline
\end{tabular}




\begin{tabular}{|c|c|c|c|c|}
\hline Família & Espécie & $\begin{array}{c}\text { Síndrome de } \\
\text { dispersão }\end{array}$ & $\begin{array}{l}\text { Forma } \\
\text { de vida }\end{array}$ & $\begin{array}{l}\text { Período de } \\
\text { frutificação }\end{array}$ \\
\hline \multirow[t]{4}{*}{ Melastomataceae } & Miconia ligustroides & ZOO & fan & $1-7$ \\
\hline & Miconia rubiginosa & zOO & fan & $9-6$ \\
\hline & Miconia stenostachya & zOO & cam-fan & 11 \\
\hline & Tibouchina stenocarpa & ane & fan & $5-10$ \\
\hline Menispermaceae & Cissampelos ovalifolia & aut & hem & 2 \\
\hline Monimiaceae & Siparuna guianensis & ZOO & fan & - \\
\hline \multirow[t]{2}{*}{ Moraceae } & Brosimum gaudichaudii & $\mathrm{zOO}$ & fan & $9-11$ \\
\hline & Ficus citrifolia & zOO & fan & 12 \\
\hline Myristicaceae & Virola sebifera & $\mathrm{zOO}$ & fan & $5-11$ \\
\hline \multirow[t]{15}{*}{ Myrtaceae } & Campomanesia pubescens & $\mathrm{zOO}$ & fan & $10-2$ \\
\hline & Eugenia aurata & zoO & fan & 3 \\
\hline & Eugenia bimarginata & zOO & fan & $9-12$ \\
\hline & Eugenia hiemalis & zOO & fan & - \\
\hline & Eugenia langsdorfii & zoO & fan & 11 \\
\hline & Eugenia livida & zOO & fan & 12 \\
\hline & Eugenia punicifolia & zOO & fan & $2-4$ \\
\hline & Myrcia bella & zOO & fan & $9-2$ \\
\hline & Myrcia guianensis & $\mathrm{zOO}$ & fan & - \\
\hline & Myrcia lasiantha & zOO & fan & $9-6$ \\
\hline & Myrcia lingua & $\mathrm{zOO}$ & fan & $12-4$ \\
\hline & Myrcia tomentosa & zOO & fan & $11-12$ \\
\hline & Myrcia uberavensis & zOO & fan & $10-1$ \\
\hline & Psidium australe & zOO & cam & $11-1$ \\
\hline & Psidium cinereum & zOO & cam & $10-4$ \\
\hline \multirow[t]{2}{*}{ Nyctaginaceae } & Guapira noxia & ZOO & fan & $10-11$ \\
\hline & Neea theifera & zOO & fan & $11-1$ \\
\hline Ochnaceae & Ouratea spectabilis & $\mathrm{zOO}$ & fan & $10-1$ \\
\hline Orchidaceae & Galeandra montana & ane & geo & 4 \\
\hline Oxalidaceae & Oxalis physocallyx & aut & cam & $12-5$ \\
\hline \multirow[t]{21}{*}{ Poaceae } & Andropogon leucostachys & aut & hem & $12-7$ \\
\hline & Aristida jubata & ane & hem & $5-9$ \\
\hline & Axonopus barbigerus & zOO & hem & $4-5,9-10$ \\
\hline & Axonopus marginatus & $\mathrm{zOO}$ & hem & $4-5$ \\
\hline & Brachiaria decumbens & zOO & hem & $1-8$ \\
\hline & Chloris barbata & zOO & hem & 5 \\
\hline & Digitaria insularis & ane & hem & - \\
\hline & Echinolaena inflexa & zOO & hem & $4-11$ \\
\hline & Eragrostis airoides & zOO & hem & $2-4$ \\
\hline & Eragrostis articulata & zOO & ter & 4 \\
\hline & Eragrostis maypurensis & zOO & ter & 4 \\
\hline & Gymnopogon foliosus & ane & hem & $5-9$ \\
\hline & Ichnanthus sericeus & zOO & hem & $1-12$ \\
\hline & Loudetiopsis chrysothrix & zoO & hem & $4-11$ \\
\hline & Melinis minutiflora & ane & hem & $6-11$ \\
\hline & Panicum cayennense & zoO & ter & $3-6$ \\
\hline & Panicum maximum & zOO & hem & $5-7$ \\
\hline & Panicum olyroides & zoO & hem & $3-11$ \\
\hline & Panicum parvifolium & zOO & hem & $3-10$ \\
\hline & Panicum procurrens & zoO & hem & - \\
\hline & Panicum repens & zOO & hem & 6 \\
\hline
\end{tabular}




\begin{tabular}{|c|c|c|c|c|}
\hline Família & Espécie & $\begin{array}{c}\text { Síndrome de } \\
\text { dispersão }\end{array}$ & $\begin{array}{l}\text { Forma } \\
\text { de vida }\end{array}$ & $\begin{array}{l}\text { Período de } \\
\text { frutificação }\end{array}$ \\
\hline \multirow[t]{4}{*}{ Poaceae } & Rbynchelitrum repens & ane & ter & $5-2$ \\
\hline & Schyzachirium condensatum & ane & hem & $3-10$ \\
\hline & Setaria geniculata & $\mathrm{zOO}$ & ter & 5 \\
\hline & Tristachya leiostachya & $\mathrm{zOO}$ & hem & $5-7$ \\
\hline \multirow[t]{2}{*}{ Polygalaceae } & Bredemeyera floribunda & $\mathrm{zOO}$ & fan & $5-10$ \\
\hline & Securidaca tomentosa & ane & lia & $10-12$ \\
\hline \multirow[t]{3}{*}{ Portulacaceae } & Portulaca hirsutissima & aut & hem & $12-2$ \\
\hline & Portulaca mucronata & aut & hem & - \\
\hline & Tallinum paniculatum & aut & hem & $11-4$ \\
\hline Proteaceae & Roupala montana & ane & fan & - \\
\hline Rhamnaceae & Crumenaria polygaloides & ane & hem & 9 \\
\hline Rosaceae & Prunus sellowii & $\mathrm{ZOO}$ & fan & - \\
\hline \multirow[t]{13}{*}{ Rubiaceae } & Alibertia macrophylla & $\mathrm{zOO}$ & fan & $11-12$ \\
\hline & Alibertia sessilis & zOO & cam & $10-12$ \\
\hline & Borreria verticilata & aut & hem & $2-4$ \\
\hline & Borreria warmingii & aut & hem & $1-2$ \\
\hline & Coccoypselum lanceolatum & $\mathrm{zOO}$ & hem & $3-4$ \\
\hline & Declieuxia fruticosa & zOO & hem & $12-7$ \\
\hline & Diodia schumanii & aut & ter & $2-5$ \\
\hline & Diodia teres & aut & ter & $6-7$ \\
\hline & Palicourea coriacea & $\mathrm{zOO}$ & cam & $11-4$ \\
\hline & Palicourea rigida & $\mathrm{zOO}$ & cam-fan & $1-6$ \\
\hline & Psychotria deflexa & zOO & cam & - \\
\hline & Psychotria tricholoba & zoO & cam & $4-5$ \\
\hline & Tocoyena formosa & $\mathrm{zOO}$ & fan & $2-7$ \\
\hline \multirow[t]{8}{*}{ Sapindaceae } & Magonia pubescens & ane & fan & $1-3$ \\
\hline & Matayba elaeagnoides & $\mathrm{zOO}$ & fan & - \\
\hline & Paullinia elegans & ane & lia & - \\
\hline & Serjania erecta & ane & cam & $11-2$ \\
\hline & Serjania lethalis & ane & lia & $9-10$ \\
\hline & Serjania reticulata & ane & lia & $5-10$ \\
\hline & Talisia angustifolia & $\mathrm{zOO}$ & cam & 1 \\
\hline & Toulicia tomentosa & ane & cam & $5-10$ \\
\hline \multirow[t]{4}{*}{ Sapotaceae } & Pouteria ramiflora & $\mathrm{zOO}$ & fan & $12-2$ \\
\hline & Pouteria subcaerulea & zOO & cam & $12-2$ \\
\hline & Pouteria torta & zOO & fan & $9-3$ \\
\hline & Pradosia brevipes & zOO & hem & - \\
\hline Smilacaceae & Smilax cissoides & $\mathrm{zOO}$ & lia & $11-2$ \\
\hline \multirow[t]{3}{*}{ Solanaceae } & Solanum erianthum & $\mathrm{zOO}$ & cam & 12 \\
\hline & Solanum lycocarpum & zOO & cam & $1-2$ \\
\hline & Solanum palinacanthum & zOO & ter & $8-3$ \\
\hline \multirow[t]{3}{*}{ Sterculiaceae } & Byttneria sagittifolia & aut & hem & $2-5$ \\
\hline & $W$ altheria americana & aut & hem & $1-10$ \\
\hline & $W$ altheria communis & aut & hem & $2-4$ \\
\hline Styracaceae & Styrax ferrugineus & $\mathrm{zOO}$ & fan & $7-9$ \\
\hline Tiliaceae & Luehea divaricata & aut & fan & $11-12$ \\
\hline \multirow[t]{4}{*}{ Verbenaceae } & Aegiphila Ihotrkiana & $\mathrm{zOO}$ & fan & - \\
\hline & Lantana camara & $\mathrm{zOO}$ & cam & $12-3$ \\
\hline & Lantana fucata & $\mathrm{zOO}$ & cam & 11 \\
\hline & Lippia lasiocalycina & aut & cam & $11-3$ \\
\hline
\end{tabular}




\begin{tabular}{llccc}
\hline Família & \multicolumn{1}{c}{ Espécie } & $\begin{array}{c}\text { Síndrome de } \\
\text { dispersão }\end{array}$ & $\begin{array}{c}\text { Forma } \\
\text { de vida }\end{array}$ & $\begin{array}{c}\text { Período de } \\
\text { frutificação }\end{array}$ \\
\hline Verbenaceae & Lippia lupulina & aut & hem & $9-11$ \\
& Lippia salviifolia & aut & cam & $5-9$ \\
\hline Vitaceae & Cissus erosa & zoo & lia & $2-4,9$ \\
& Cissus inundata & zoo & lia & $11-12$ \\
\hline Vochysiaceae & Qualea dichotoma & ane & fan & 10 \\
& Qualea grandiflora & ane & fan & $5-12$ \\
& Qualea multiflora & ane & fan & - \\
& Qualea parviflora & ane & fan & $9-4$ \\
& Vochysia cinamommea & ane & fan & $2-12$ \\
& Vochysia tucanorum & ane & fan & 4 \\
\hline
\end{tabular}


ANEXo II. Espécies listadas no anexo I e também presentes no Cerrado de Emas (Pirassununga, SP). Dados extraídos de Batalha et al. 1997. Formas de vida: cam = caméfita; cam-fan = caméfita ou fanerófita; epi $=$ epífita; fan $=$ fanerófita; geo $=$ geófita; hem $=$ hemicriptófita; lia $=$ liana; ter $=$ terófita. Períodos de frutificação: $1=$ janeiro; 2 = fevereiro; ...; $11=$ novembro; $12=$ dezembro. $\mathrm{O}$ hífen (-) representa continuidade entre meses, enquanto a vírgula (,) significa interrupção.

\begin{tabular}{|c|c|c|c|c|}
\hline Família & Espécie & $\begin{array}{c}\text { Síndrome } \\
\text { de } \\
\text { dispersão }\end{array}$ & $\begin{array}{c}\text { Forma de } \\
\text { vida }\end{array}$ & $\begin{array}{l}\text { Período de } \\
\text { frutificação }\end{array}$ \\
\hline Acanthaceae & Ruellia geminiflora & aut & hem & $5,10-12$ \\
\hline Amaranthaceae & Gomphrena virgata & aut & hem & 7 \\
\hline \multirow[t]{2}{*}{ Anacardiaceae } & Anacardium bumile & $\mathrm{ZOO}$ & cam-fan & - \\
\hline & Tapirira guianensis & zOO & fan & 5 \\
\hline \multirow[t]{4}{*}{ Annonaceae } & Annona coriacea & zOO & cam & - \\
\hline & Annona dioica & zOO & cam & - \\
\hline & Duguetia furfuracea & zOO & fan & 7 \\
\hline & Xylopia aromatica & zOO & fan & $4-10$ \\
\hline \multirow[t]{6}{*}{ Apocynaceae } & Aspidosperma tomentosum & ane & fan & $1-12$ \\
\hline & Hancornia speciosa & zOO & fan & - \\
\hline & Mandevilla vellutina & ane & hem & - \\
\hline & Odontadenia lutea & ane & lia & $3-10$ \\
\hline & Rhodocaly $x$ rotundifolius & ane & hem & 1 \\
\hline & Temnadenia violacea & ane & lia & 3 \\
\hline Araliaceae & Didymopanax vinosum & ZOO & fan & $4-8$ \\
\hline \multirow[t]{2}{*}{ Arecaceae } & Butia paraguayensis & ZOO & fan & $12-3$ \\
\hline & Syagrus flexuosa & $\mathrm{zOO}$ & fan & 11 \\
\hline \multirow[t]{21}{*}{ Asteraceae } & Aspilia reflexa & aut & hem & $10-4$ \\
\hline & Baccharis dracunculifolia & ane & cam & 3 \\
\hline & Baccharis rufescens & ane & cam & 2,7 \\
\hline & Bidens gardneri & zOO & ter & $2-10$ \\
\hline & Chaptalia integerrima & ane & ter & $4-1$ \\
\hline & Elephantopus mollis & ane & hem & 3 \\
\hline & Emilia coccinea & ane & ter & $11-5$ \\
\hline & Eremanthus sphaerocephalus & ane & hem & 9 \\
\hline & Eupatorium chlorolepsis & ane & hem & $3-5$ \\
\hline & Eupatorium maximiliani & ane & cam & $4-5$ \\
\hline & Eupatorium squalidum & ane & ter & $3-11$ \\
\hline & Gochnatia barrosii & ane & cam & $7-10$ \\
\hline & Gochnatia pulchra & ane & cam & $5-9$ \\
\hline & Kanimia oblongifolia & ane & cam & $10-12$ \\
\hline & Mikania cordifolia & ane & lia & $5-10$ \\
\hline & Orthopappus angustifolius & ane & hem & $3-5$ \\
\hline & Piptocarpha rotundifolia & ane & fan & $10-5$ \\
\hline & Vernonia bardanoides & ane & hem & $3-10$ \\
\hline & Vernonia ferruginea & ane & cam & 10 \\
\hline & Vernonia rubriramea & ane & cam & $4-10$ \\
\hline & Viguiera discolor & aut & hem & 2 \\
\hline \multirow[t]{7}{*}{ Bignoniaceae } & Anemopaegma arvense & ane & hem & 4,12 \\
\hline & Arrabidaea brachypoda & ane & cam & $11-7$ \\
\hline & Cybistax antisyphillitica & ane & fan & 3 \\
\hline & Distictella mansoana & ane & lia & $6-10$ \\
\hline & Jacaranda caroba & ane & cam-fan & 1 \\
\hline & Jacaranda decurrens & ane & cam & - \\
\hline & Jacaranda rufa & ane & cam & 一 \\
\hline
\end{tabular}




\begin{tabular}{|c|c|c|c|c|}
\hline Família & Espécie & $\begin{array}{c}\text { Síndrome } \\
\text { de } \\
\text { dispersão }\end{array}$ & $\begin{array}{c}\text { Forma de } \\
\text { vida }\end{array}$ & $\begin{array}{l}\text { Período de } \\
\text { frutificação }\end{array}$ \\
\hline \multirow[t]{3}{*}{ Bignoniaceae } & Pyrostegia venusta & ane & lia & - \\
\hline & Tabebuia aurea & ane & fan & - \\
\hline & Tabebuia ochracea & ane & fan & - \\
\hline Bixaceae & Cochlospermum regium & ane & cam & 10 \\
\hline Bombacaceae & Eriotheca gracilipes & ane & fan & - \\
\hline \multirow[t]{4}{*}{ Bromeliaceae } & Aechmea bromeliifolia & aut & epi & 4 \\
\hline & Ananas ananassoides & zOO & hem & $3-4$ \\
\hline & Dickia tuberosa & aut & hem & $10-4$ \\
\hline & Tillandsia geminiflora & aut & epi & - \\
\hline Burseraceae & Protium heptaphyllum & $\mathrm{zOO}$ & fan & $6-8$ \\
\hline Caryocaraceae & Caryocar brasiliense & $\mathrm{ZOO}$ & cam-fan & $10-5$ \\
\hline Caryophyllaceae & Polycarpaea corymbosa & aut & hem & $4-6$ \\
\hline Celastraceae & Austroplenckia populnea & ane & fan & - \\
\hline Clusiaceae & Kielmeyera coriacea & ane & fan & $4-9$ \\
\hline \multirow[t]{2}{*}{ Connaraceae } & Connarus suberosus & $\mathrm{ZOO}$ & fan & $12-1$ \\
\hline & Rourea induta & $\mathrm{zOO}$ & fan & $10-5$ \\
\hline Convolvulaceae & Ipomoea procurrens & aut & lia & 5 \\
\hline Cucurbitaceae & Cayaponia espelina & $\mathrm{ZOO}$ & lia & $11-2$ \\
\hline \multirow[t]{5}{*}{ Cyperaceae } & Bulbostylis hirtella & aut & hem & $3-7$ \\
\hline & Bulbostylis sphaerocephala & aut & hem & 5 \\
\hline & Cyperus cayennensis & aut & hem & $12-4$ \\
\hline & Cyperus diffusus & aut & hem & $1-6$ \\
\hline & Rhynchospora exaltata & aut & hem & $5-11$ \\
\hline \multirow[t]{2}{*}{ Dilleniaceae } & Davilla elliptica & aut & fan & $4-12$ \\
\hline & Davilla rugosa & aut & lia & 4-11 \\
\hline \multirow[t]{4}{*}{ Erythroxylaceae } & Erythroxylum campestre & $\mathrm{ZOO}$ & fan & $12-6$ \\
\hline & Erythroxylum cuneifolium & zoo & fan & $10-2$ \\
\hline & Erythroxylum suberosum & zOO & fan & $10-5$ \\
\hline & Erythroxylum tortuosum & $\mathrm{zOO}$ & fan & - \\
\hline \multirow[t]{3}{*}{ Euphorbiaceae } & Croton sclerocalyx & aut & hem & $1-4$ \\
\hline & Manihot tripartita & aut & hem & $10-3$ \\
\hline & Phyllanthus orbiculatus & aut & ter & 4 \\
\hline \multirow[t]{6}{*}{ Fabaceae - Caesalpinioideae } & Baubinia rufa & aut & fan & $2-10$ \\
\hline & Chamaechrista flexuosa & aut & cam & $2-6$ \\
\hline & Copaifera langsdorfii & zOO & fan & $3-11$ \\
\hline & Hymenaea stigonocarpa & zOO & fan & 9 \\
\hline & Senna rugosa & aut & fan & $4-9$ \\
\hline & Senna sylvestris & aut & fan & $1-10$ \\
\hline \multirow[t]{10}{*}{ Fabaceae - Faboideae } & Acosmium subelegans & ane & fan & 11 \\
\hline & Aeschynomene marginata & zOO & hem & $10-5$ \\
\hline & Andira laurifolia & zoo & cam & - \\
\hline & Bowdichia virgilioides & ane & fan & - \\
\hline & Crotalaria vitellina & aut & hem & $3-5$ \\
\hline & Dalbergia miscolobium & ane & fan & $5-8$ \\
\hline & Eriosema crinitum & aut & hem & - \\
\hline & Machaerium acutifolium & ane & fan & $7-5$ \\
\hline & Rhynchosia melanocarpa & zOO & lia & $4-11$ \\
\hline & Stylosanthes guianensis & aut & ter & $12-7$ \\
\hline
\end{tabular}




\begin{tabular}{|c|c|c|c|c|}
\hline Família & Espécie & $\begin{array}{c}\text { Síndrome } \\
\text { de } \\
\text { dispersão }\end{array}$ & $\begin{array}{c}\text { Forma de } \\
\text { vida }\end{array}$ & $\begin{array}{l}\text { Período de } \\
\text { frutificação }\end{array}$ \\
\hline \multirow[t]{6}{*}{$\overline{\text { Fabaceae - Mimosoideae }}$} & Anadenanthera falcata & zOO & fan & $3-4,7$ \\
\hline & Dimorphandra mollis & zOO & fan & $9-5$ \\
\hline & Mimosa gracilis & ane & cam & 5 \\
\hline & Mimosa xanthocentra & ane & cam & $3-4$ \\
\hline & Stryphnodendron adstringens & zOO & fan & $9-6$ \\
\hline & Stryphnodendron polyphyllum & aut & fan & 5 \\
\hline Flacourtiaceae & Casearia sylvestris & $\mathrm{ZOO}$ & fan & 10 \\
\hline Hippocrateaceae & Peritassa campestris & ZOO & fan & 6 \\
\hline \multirow[t]{2}{*}{ Lamiaceae } & Hyptis eriophylla & aut & ter & $2-6$ \\
\hline & Peltodon tomentosus & aut & hem & $12-5$ \\
\hline \multirow[t]{2}{*}{ Lauraceae } & Ocotea corymbosa & $\mathrm{ZOO}$ & fan & - \\
\hline & Ocotea pulchella & $\mathrm{zOO}$ & fan & - \\
\hline \multirow[t]{2}{*}{ Lythraceae } & Cuphea carthaginensis & aut & cam & 3 \\
\hline & Lafoensia pacari & aut & fan & 5 \\
\hline \multirow[t]{10}{*}{ Malpighiaceae } & Banisteriopsis campestris & ane & lia & $3-5$ \\
\hline & Banisteriopsis laevifolia & ane & lia & 2,9 \\
\hline & Banisteriopsis stellaris & ane & lia & $4-5$ \\
\hline & Banisteriopsis variabilis & ane & lia & $4-10$ \\
\hline & Byrsonima coccolobifolia & $\mathrm{zOO}$ & fan & $9-5$ \\
\hline & Byrsonima intermedia & zOO & fan & $12-8$ \\
\hline & Byrsonima verbascifolia & zOO & fan & $11-12$ \\
\hline & Heteropteris byrsonimifolia & ane & fan & $10-11$ \\
\hline & Heteropteris umbellata & ane & lia & $11-12$ \\
\hline & Mascagnia cordifolia & ane & lia & $10-12$ \\
\hline Malvaceae & Sida linifolia & aut & ter & $4-5$ \\
\hline \multirow[t]{6}{*}{ Melastomataceae } & Leandra lacunosa & ane & fan & - \\
\hline & Miconia albicans & $\mathrm{ZOO}$ & cam & $9-1$ \\
\hline & Miconia ligustroides & zOO & fan & 3 \\
\hline & Miconia rubiginosa & zOO & fan & $4-6$ \\
\hline & Miconia stenostachya & zOO & cam & $8-1$ \\
\hline & Tibouchina stenocarpa & ane & fan & $5-7$ \\
\hline Menispermaceae & Cissampelos ovalifolia & aut & hem & \\
\hline Monimiaceae & Siparuna guianensis & $\mathrm{ZOO}$ & fan & $11-8$ \\
\hline \multirow[t]{2}{*}{ Moraceae } & Brosimum gaudichaudii & $\mathrm{ZOO}$ & fan & $10-11$ \\
\hline & Ficus citrifolia & $\mathrm{zOO}$ & fan & 5 \\
\hline Myristicaceae & Virola sebifera & ZOO & fan & - \\
\hline \multirow[t]{12}{*}{ Myrtaceae } & Campomanesia pubescens & $\mathrm{ZOO}$ & fan & $10-4$ \\
\hline & Eugenia aurata & zOO & fan & 3 \\
\hline & Eugenia bimarginata & zOO & fan & - \\
\hline & Eugenia hiemalis & zOO & fan & - \\
\hline & Eugenia livida & zOO & fan & $8-11$ \\
\hline & Eugenia punicifolia & zOO & fan & 4 \\
\hline & Myrcia bella & zOO & fan & $10-11$ \\
\hline & Myrcia lasiantha & zOO & cam & - \\
\hline & Myrcia lingua & zOO & fan & $10-3$ \\
\hline & Myrcia tomentosa & zOO & fan & $10-1$ \\
\hline & Psidium australe & zOO & cam & $10-3$ \\
\hline & Psidium cinereum & zOO & cam & $11-3$ \\
\hline
\end{tabular}




\begin{tabular}{|c|c|c|c|c|}
\hline Família & Espécie & $\begin{array}{c}\text { Síndrome } \\
\text { de } \\
\text { dispersão }\end{array}$ & $\begin{array}{c}\text { Forma de } \\
\text { vida }\end{array}$ & $\begin{array}{l}\text { Período de } \\
\text { frutificação }\end{array}$ \\
\hline \multirow[t]{2}{*}{ Nyctaginaceae } & Guapira noxia & $\mathrm{ZOO}$ & fan & 10 \\
\hline & Neea theifera & $\mathrm{ZOO}$ & fan & $11-2$ \\
\hline Ochnaceae & Ouratea spectabilis & $\mathrm{ZOO}$ & fan & 12 \\
\hline Orchidaceae & Galeandra montana & ane & geo & - \\
\hline Oxalidaceae & Oxalis physocallyx & aut & cam & $3-5$ \\
\hline \multirow[t]{13}{*}{ Poaceae } & Aristida jubata & ane & hem & $3-9$ \\
\hline & Axonopus barbigerus & zOO & hem & $3-6$ \\
\hline & Brachiaria decumbens & zOO & hem & $3-7$ \\
\hline & Digitaria insularis & ane & hem & 12 \\
\hline & Echinolaena inflexa & zOO & hem & $2-7$ \\
\hline & Eragrostis articulata & $\mathrm{zOO}$ & ter & 4 \\
\hline & Gymnopogon foliosus & ane & hem & 6 \\
\hline & Loudetiopsis chrysothrix & zOO & hem & $3-6$ \\
\hline & Melinis minutiflora & ane & hem & $5-7$ \\
\hline & Panicum olyroides & $\mathrm{zOO}$ & hem & 5 \\
\hline & Panicum parvifolium & $\mathrm{zOO}$ & hem & $4-5$ \\
\hline & Rbynchelitrum repens & ane & ter & 5 \\
\hline & Setaria geniculata & $\mathrm{ZOO}$ & ter & $3-5$ \\
\hline Proteaceae & Roupala montana & ane & fan & - \\
\hline Rhamnaceae & Crumenaria polygaloides & ane & hem & $10-12$ \\
\hline \multirow[t]{9}{*}{ Rubiaceae } & Alibertia macrophylla & $\mathrm{ZOO}$ & fan & $10-1$ \\
\hline & Alibertia sessilis & zOO & cam & $10-1$ \\
\hline & Coccoypselum lanceolatum & $\mathrm{zOO}$ & hem & $3-4$ \\
\hline & Declieuxia fruticosa & $\mathrm{zOO}$ & hem & 4 \\
\hline & Diodia schumanii & aut & ter & $4-8$ \\
\hline & Diodia teres & aut & ter & $3-4$ \\
\hline & Palicourea rigida & $\mathrm{zOO}$ & cam-fan & $12-4$ \\
\hline & Psychotria tricholoba & $\mathrm{zOO}$ & cam & $11,3-4$ \\
\hline & Tocoyena formosa & $\mathrm{zOO}$ & fan & $1-10$ \\
\hline \multirow[t]{3}{*}{ Sapindaceae } & Serjania erecta & ane & cam & $1-12$ \\
\hline & Serjania letalis & ane & lia & 10 \\
\hline & Serjania reticulata & ane & lia & - \\
\hline \multirow[t]{2}{*}{ Sapotaceae } & Pouteria torta & $\mathrm{ZOO}$ & fan & - \\
\hline & Pradosia brevipes & $\mathrm{zOO}$ & hem & $1-2$ \\
\hline \multirow[t]{2}{*}{ Solanaceae } & Solanum lycocarpum & $\mathrm{ZOO}$ & cam & $11-5$ \\
\hline & Solanum palinacanthum & $\mathrm{zOO}$ & ter & $1-12$ \\
\hline \multirow[t]{3}{*}{ Sterculiaceae } & Byttneria sagittifolia & aut & hem & $1-6$ \\
\hline & Waltheria americana & aut & hem & 3 \\
\hline & Waltheria communis & aut & hrm & $12-2$ \\
\hline \multirow[t]{6}{*}{ Verbenaceae } & Aegiphila lhotzkiana & $\mathrm{ZOO}$ & cam-fan & $10-4$ \\
\hline & Lantana camara & $\mathrm{zOO}$ & cam & $1-4$ \\
\hline & Lantana fucata & $\mathrm{zOO}$ & cam & $3-5$ \\
\hline & Lippia lasiocalycina & aut & cam & 3,6 \\
\hline & Lippia lupulina & aut & hem & $1-5,10$ \\
\hline & Lippia salvïfolia & aut & cam & 5 \\
\hline \multirow[t]{2}{*}{$\overline{\text { Vitaceae }}$} & Cissus erosa & $\mathrm{zOO}$ & lia & 1 \\
\hline & Cissus inundata & $\mathrm{ZOO}$ & lia & $12-5$ \\
\hline \multirow[t]{3}{*}{ Vochysiaceae } & Qualea grandiflora & ane & fan & $11-6$ \\
\hline & Qualea parviflora & ane & fan & - \\
\hline & Vochysia tucanorum & ane & fan & $10-7$ \\
\hline
\end{tabular}


ANEXo III. Animais registrados pelas armadilhas fotográficas durante todo o período de exposição (14/junho/2005 a 21/novembro/2006). Fotografias: Mariana Morais Vidal.

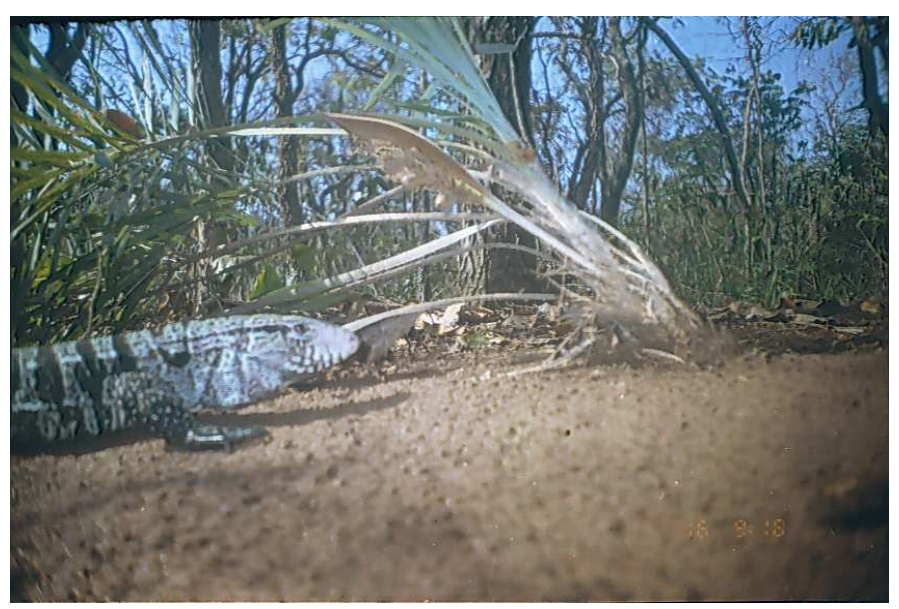

Tupinambis merianae (Reptilia: Teiidae)

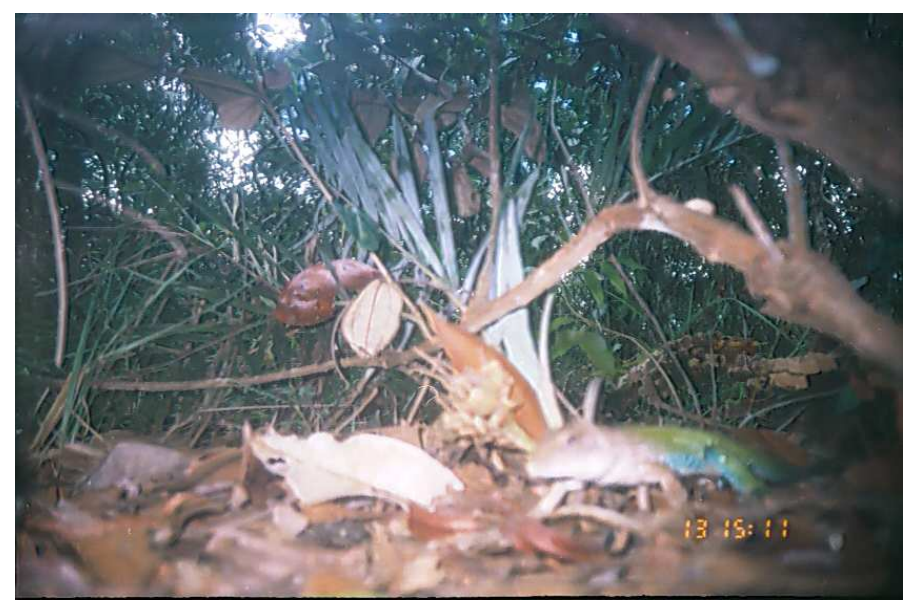

Ameiva ameiva (Reptilia: Teiidae)

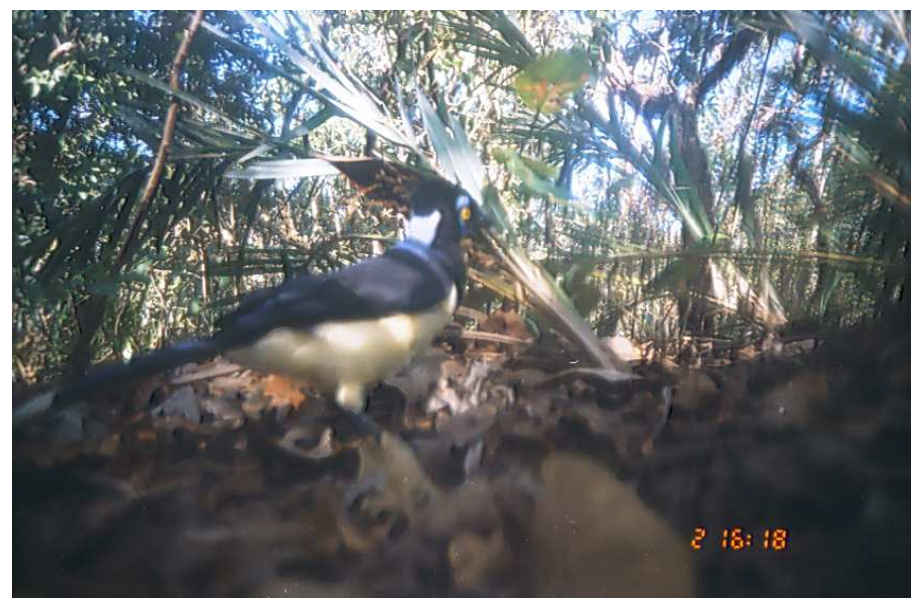

Cyanocorax chrysops (Aves: Corvidae) 


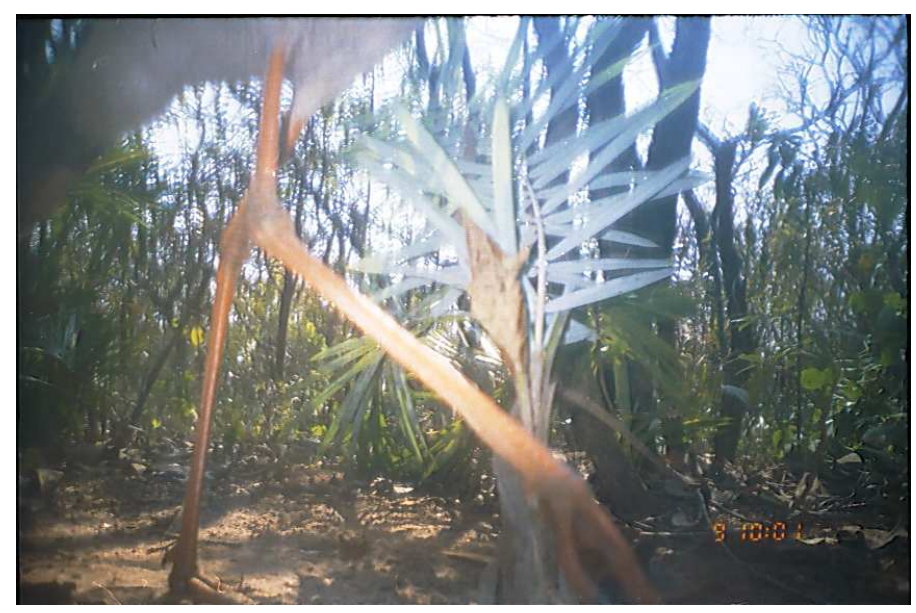

Cariama cristata (Aves: Cariamidae)

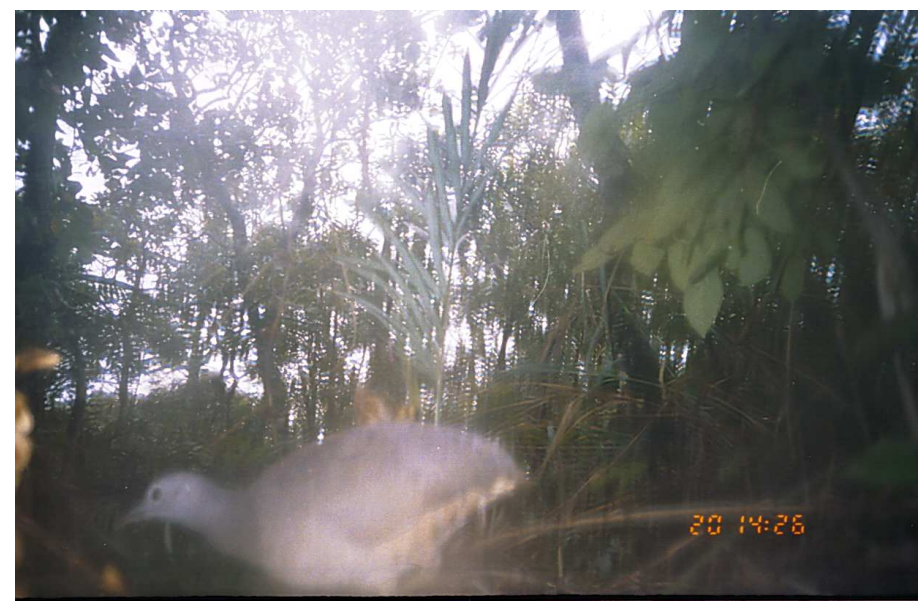

Crypturellus sp. (Aves: Tinamidae)

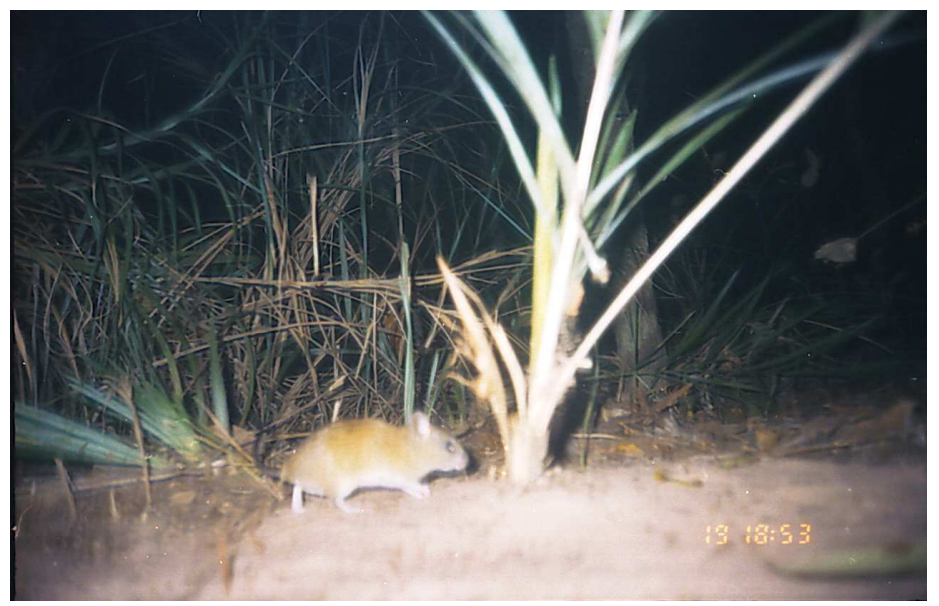

Cerradomys subflavus (Rodentia: Muridae) 


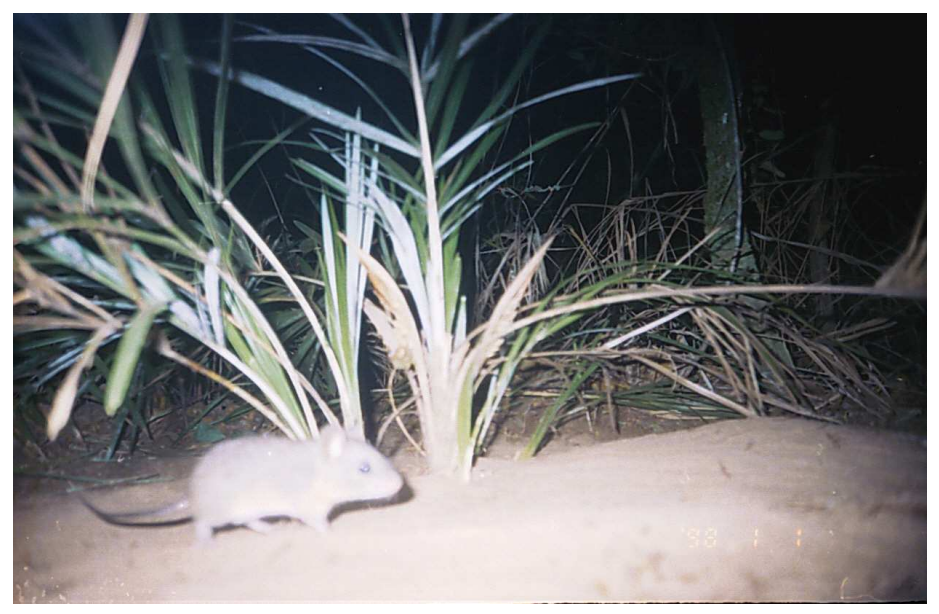

Bolomys lasiurus (Rodentia: Muridae)

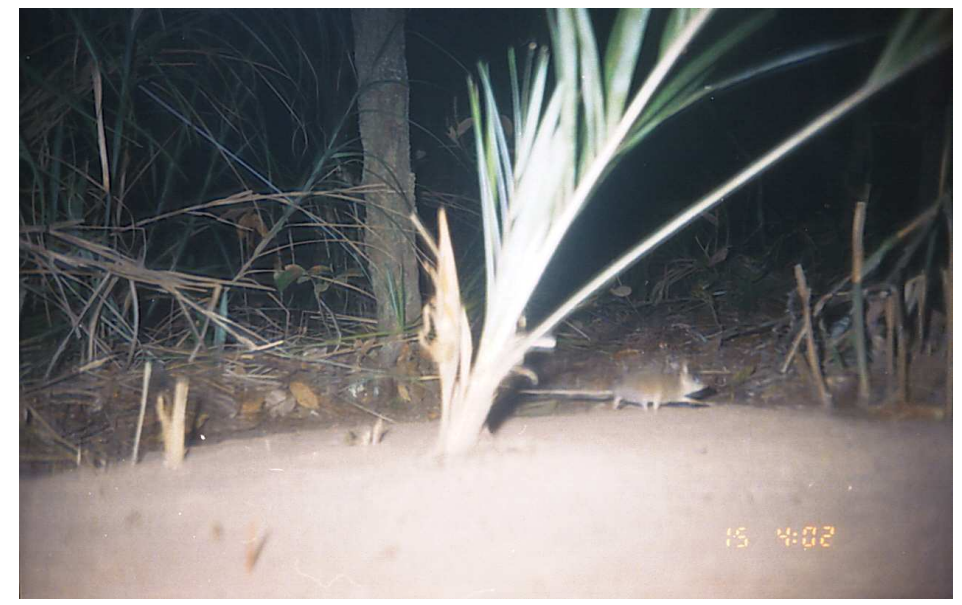

Gracilinanus microtarsus (Marsupialia: Didelphidae)

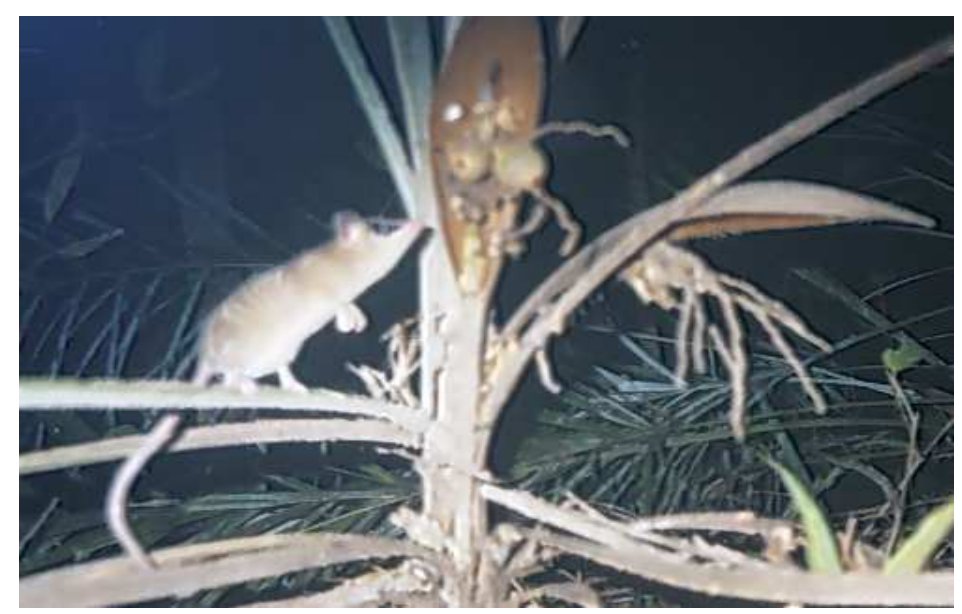

Gracilinanus agilis (Marsupialia: Didelphidae) 


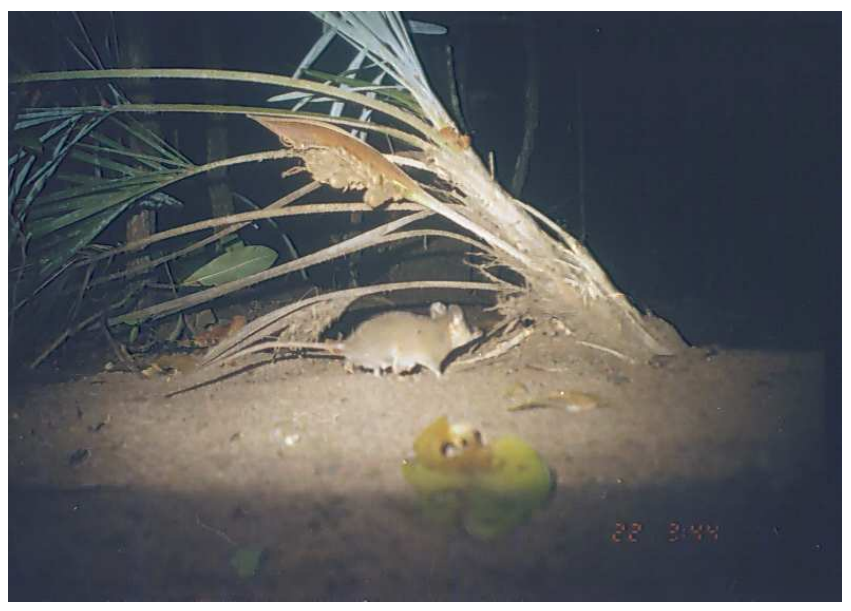

Cryptonanus sp. (Marsupialia: Didelphidae)

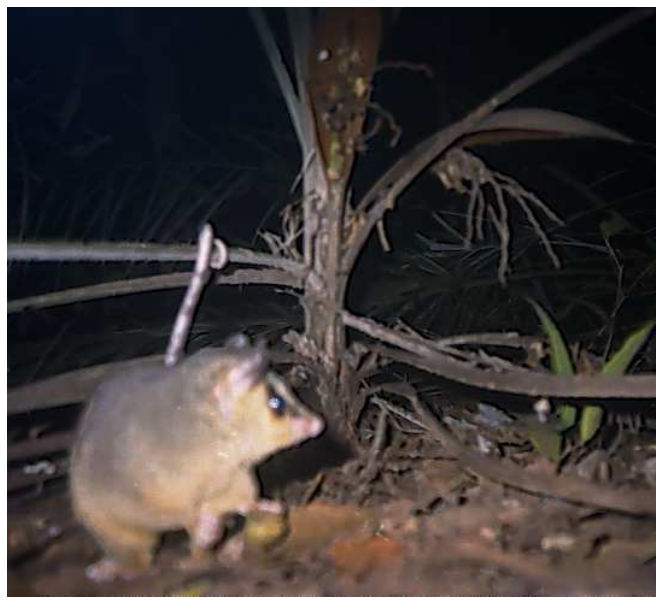

Micoureus paraguayanus (Marsupialia: Didelphidae)

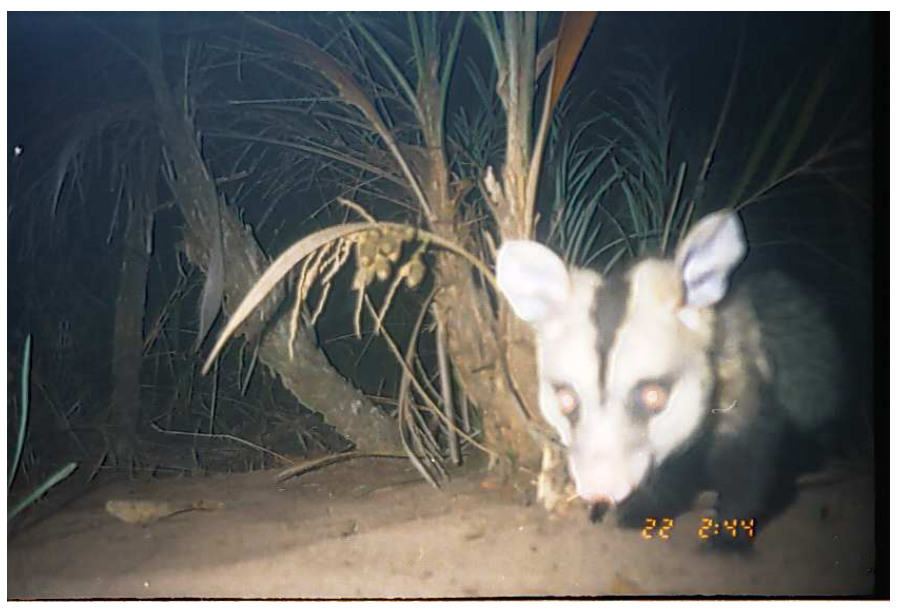

Didelphis albiventris (Marsupialia: Didelphidae) 


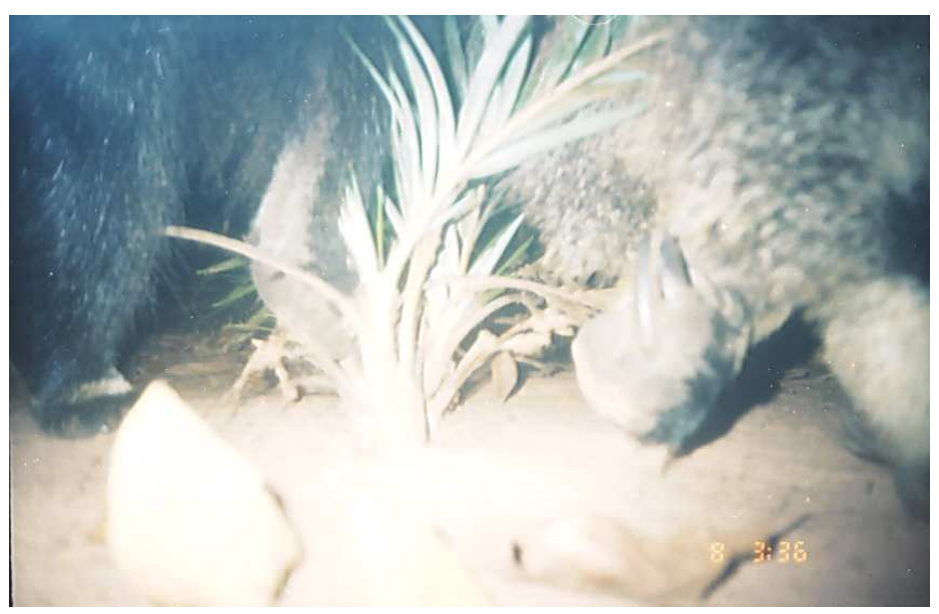

Myrmecophaga tridactyla (Xenarthra: Myrmecophagidae) 